\title{
Can Films Impact Sexism in STEM? Examining this Possibility with the Popular Documentary "Picture a Scientist"
}

\author{
Evava S. Pietri \\ University of Colorado Boulder \\ Arispa Weigold \\ Indiana University-Purdue University Indianapolis \\ Lisa M. P. Munoz \\ SciComm Services, Inc. \\ Corinne A. Moss-Racusin \\ Skidmore College
}

Correspondence concerning this manuscript should be addressed to Evava S. Pietri, Department of Psychology and Neuroscience, University of Colorado, Boulder, Muenzinger D244, 345 UCB, Boulder, CO, 80309. E-mail: evava.pietri@colorado.edu

The authors thank Sharon Shattuck, Ian Cheney, Manette Pottle, Amy Brand, and the "Picture a Scientist" film team, Sarah Goodwin and the Wonder Collaborative/Science Communication Lab team; ro*co films, and the more than 1,300 institutions who screened "Picture a Scientist" and helped recruit participants for these studies. 


\begin{abstract}
High-impact interventions are necessary to reduce persistent gender disparities and sexism in STEM. "Picture a Scientist," a popular documentary featuring stories and research about bias and discrimination in STEM, reached a large international audience. And yet, the extent to which this type of high-quality media can impact gender bias remains unclear. In a unique collaboration between film creators and researchers, the current large-scale field studies explored whether "Picture a Scientist" functioned as an online intervention targeting gender bias in STEM. Exploratory Study 1 found that viewers who were more engaged with the film were also more inspired to continue learning about the issues highlighted in the documentary and combating bias and unfair treatment. Employing a quasi-experimental design, preregistered Study 2 demonstrated that compared to those who had not watched the film (but intended to), participants who had viewed the film indicated higher awareness of gender bias and stronger intentions to address this bias through personal actions and new policies. Workshops and panel discussions featuring this documentary (and other similar forms of media) may be relatively low cost, easy to implement, and enjoyable interventions. Thus, the current findings can help inform future organizational policies and workshops, implementing viewings of this documentary or similar films.
\end{abstract}




\section{Introduction}

Gender bias in hiring, publishing, and prestigious talk invitations remains a continuing problem in STEM (Science, Technology, Engineering, and Mathematics) ) $^{1,2,3,4,5}$. Limiting women's inclusions in these disciplines ultimately harms innovation and scientific discoveries ${ }^{6,7}$, creating a pressing need for empirically validated interventions to address gender biases and disparities $^{8}$. Moreover, it is critical that such interventions not only change beliefs and attitudes but also encourage support of gender-inclusive policies (e.g., parental leave, hiring initiatives $)^{9,10,11}$. Effective workshops for reducing sexism and improving climates typically have relied on in-person formats with trained facilitators, limiting their scalability ${ }^{12,13,14,15}$. Additionally, in-person trainings were often not feasible during the COVID-19 pandemic, as organizations moved online ${ }^{16}$. Given that employees may have felt distracted and fatigued from multiple daily virtual meetings ${ }^{17,18}$, online formats also may have reduced participation in diversity trainings ${ }^{19}$, during a time when the pandemic further exasperated gender disparities in research and publishing ${ }^{20,21}$. In fact, one survey found that workplace anti-discrimination trainings dropped by $19 \%$ during the first year of the pandemic ${ }^{22}$.

Media (e.g., films and television) has a unique potential to reach large audiences, and when carefully developed, can promote messages that inspire lasting change while entertaining viewers $^{23,24,25}$. Thus, immersive and engaging videos may enhance online diversity interventions and ensure such trainings are widespread and scalable. Indeed, during the first year of the pandemic, when diversity workshops were negatively impacted, a documentary called "Picture a Scientist" reached a large audience through over 1,300 online screenings across many countries. This documentary featured facts about gender bias in STEM and first-person, emotionally evocative stories from women who personally faced sexism and harassment in their STEM 
disciplines. We capitalized on this widespread real-world data collection opportunity with large and diverse samples. We explored whether screenings of the documentary also functioned as successful online diversity interventions to promote awareness of sexism in STEM and encourage behaviours and policies to address biases and disparities. In a unique collaboration between film creators and researchers, we aimed to test a new conceptualization of diversity interventions (i.e., high-quality media featuring gender bias-related themes). Specifically, in the first study, we explored whether measures of engagement with the documentary related to behaviours to address gender disparities and bias. In a second preregistered study with a quasiexperimental design, we examined whether watching the film encouraged intentions to promote positive climates and inclusive policies.

In many STEM fields, there are well-documented and persistent gender disparities ${ }^{27}$, and people tend to stereotype scientists as masculine or as having traits associated with men ${ }^{28,29,30}$. This lack of gender parity coupled with masculine stereotypes can lead to hiring and publishing biases favouring men ${ }^{1,2}$ and create hostile environments for women in $\mathrm{STEM}^{31,32,33}$. To help rectify this unfair treatment, researchers and diversity practitioners have developed "bias literacy" interventions, which present facts and research about stereotypes and discrimination in STEM, to enhance awareness of this pervasive sexism $^{8,34}$. In-person bias literacy workshops have successfully promoted awareness of gender biases and inequities among scientists, STEM faculty, and researchers ${ }^{35,36}$ and encouraged equitable treatment for women in STEM departments $^{12,13,14,15}$.

Many of these successful workshops have relied on in-person formats and carefully trained facilitators. Unfortunately, in-person workshops were not feasible during the pandemic, and there is some evidence that online traditional diversity workshops (i.e., those that focus on 
presenting facts about bias and discrimination and may inadvertently imply blame) have limited success ${ }^{19}$. More broadly, requiring in-person workshops and expert facilitators undermines the interventions' scalability. To ensure the efficacy of these workshops, they must be administered consistently, and organizations should not attempt to create modified versions that may be ineffective or even harmful (i.e., lead to backlash and more discriminatory behaviour) ${ }^{37,38,39}$. However, these trainings can be costly, and trained facilitators can only administer so many workshops, which ultimately limits their availability ${ }^{8,40}$. Thus, a critical question that became all the more pertinent during the pandemic is - how can organizations implement empirically validated bias literacy interventions that are cost-effective, efficacious, and engaging for their employees?

The use of entertaining films and documentaries may help address this vital question. Past research has demonstrated visual and audio media, which feature engaging stories about marginalized groups, can effectively reduce biases towards those groups ${ }^{41,42,43,44}$. Media is particularly successful at changing beliefs when viewers are highly engaged with the featured story $^{26}$. For instance, messages are more convincing when individuals are transported into the story (i.e., feel immersed and engrossed in the story) $)^{45,42,46}$ and experience emotions while engaging with the story (e.g., experience anger or sadness) $)^{41,47,48}$. Moreover, stories have a more substantial impact when people feel empathetic concern for the characters involved (e.g., experience sympathy $)^{49}$ and can take the perspective of these characters (i.e., experience the same feelings as the characters as story events unfold) ${ }^{50,42}$.

When viewers are intensely engaged with a film, it also can promote lasting changes in beliefs and behaviours by inspiring viewers to continue learning about the topics highlighted in the film ${ }^{51,52}$. Indeed, individuals who feel highly immersed or transported into a video are more 
likely to seek out additional information related to that video ${ }^{53}$. Moreover, a film that forces viewers to reflect on their personal biases may also motivate them to find resources to help address their bias ${ }^{54,55}$. Critically, acquiring new information about a topic ultimately shapes people's attitudes and beliefs ${ }^{56,57}$ and changes behaviours ${ }^{58,59,60}$. Thus, engaging with entertaining media has the potential to encourage viewers to continue acquiring new information and learning about bias and mistreatment.

Importantly for the current research, there is a strong foundation of experimental research testing the benefits of short, high-quality videos featuring both research about sexism and engaging stories highlighting examples of gender bias in STEM (called Video Interventions for Diversity in STEM or VIDS) ${ }^{61}$. Using rigorous experimental methods and a randomized control trial design, researchers found that VIDS successfully increased awareness of biases, reduced sexism, and enhanced behavioural intentions to address gender bias and inequity among academic scientists. These effects persisted for at least one week after the intervention ${ }^{62,63}$. The intervention videos were successful because viewers experienced emotions while watching the videos, felt transported into the videos' stories, could take the perspective of the characters in the videos, and felt knowledgeable about gender bias facts and research after watching the videos $^{63,61}$. Although these experiments provided causal evidence for the benefits of videos as an intervention to address gender bias in STEM, this research was limited in its ecological validity and generalizability. That is, academic scientists watched VIDS, knowing they were participating in research experiments. Addressing this limitation will be crucial for determining whether organizational workshops with videos are valuable.

Therefore, the primary aim of the current research was to examine the benefits of the documentary "Picture a Scientist" in more naturalistic settings among those engaging with the 
film regardless of the research study. Indeed, many of our participants were involved in company, university, and society screenings, similar to how these organizations would implement future workshops featuring "Picture a Scientist." In our first exploratory study, we were curious whether measures of film engagement (e.g., feeling immersed in the film, feeling emotional during the film, taking the perspective of the women in the film) would relate to more awareness of gender bias in STEM and behaviours to address sexism and disparities. In order to more directly explore the benefits of watching (versus not watching) "Picture a Scientist," we ran a second preregistered study with a quasi-experimental design. We recruited participants who had watched the film or were planning to watch the film (i.e., had signed up for a viewing or participated in an event associated with "Picture a Scientist"). Critically, for both studies, we recruited participants who had viewed or were intending to view the film, irrespective of the current research.

\section{Exploring the International Impact of "Picture a Scientist"}

As mentioned earlier, in-person diversity workshops were not safe or possible during the pandemic, and there is some survey evidence suggesting that anti-discrimination trainings declined during the first year of the pandemic ${ }^{22}$. Thus, an initial exploratory question was whether organizations were taking advantage of "Picture a Scientist," and this documentary reached a large audience during a period when traditional bias literacy trainings (e.g., in-person workshops with trained facilitators) may have been less prevalent. "Picture a Scientist" was released in April 2020. By May 2021, there were approximately 1,333 online screenings of "Picture a Scientist" across universities, companies, and professional societies, and at least 155,476 unique film viewings via these screenings. Of note, the majority of these viewings occurred before the broader release of the film on PBS and Netflix. Many organizations paired 
screenings with complimentary panels; however, we do not have data on the exact number of corresponding panels. "Picture a Scientist" also had an international impact, with screenings across 42 countries (see Fig. 1 for specific countries). The reach of "Picture a Scientist" continues to grow, as the film is currently streaming on PBS (as of April 2021) and Netflix (as of June 2021).

Taken together, the many screenings and unique viewings of "Picture a Scientist" across multiple countries provide clear evidence that this documentary was far-reaching during a time (i.e., April 2020-May 2021) when in-person diversity workshops were unsafe and not feasible. Moreover, viewers appeared to enjoy the documentary, and the film received a 7.7 out of 10 stars on IMDB and numerous positive reviews. In a unique partnership with the "Picture a Scientist" film team, we ran two studies in conjunction with these screenings to explore whether the many viewings of "Picture a Scientist" also functioned as online diversity interventions. Empirically testing the outcomes associated with "Picture a Scientist" can help inform future organizational policies, which may choose to mandate viewings of this documentary or similar films. 


\section{Picture a Scientist Impact April, 2020-May, 2021 1,333 screenings across universities, companies, and professional socities}

\section{Screenings across 42 countries}

Australia, Austria, Belgium, Brazil, Canada, Chile, Colombia, Columbia, Denmark, Ecuador, England, Estonia, Finland, France, Germany, Guatemala, Hong Kong, India, Ireland, Israel, Italy, Japan, Mexico, Netherlands, New Zealand, Norway, Philippines, Portugal, Russia, Scotland, Singapore, Republic of, Slovenia, South Africa, South Korea, Spain, Sweden, Switzerland, The Netherlands, United Arab Emirates, United Kingdom, United States, Uruguay

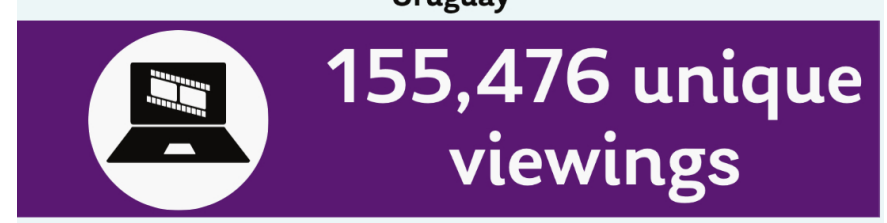
Now Streaming
PBS (April, 2021)
Netflix (June, 2021)

Fig. 1: The international Impact of "Picture a Scientist" from April 2020 to May 2021

\section{Results}

Study 1

This first exploratory study examined whether engagement with "Picture a Scientist" related to behavioural intentions and actual behaviours to address gender bias and disparities. All 2,756 participants in the current study had watched "Picture a Scientist" and completed the time 
1 survey after viewing the film. Approximately six weeks later, participants were invited to participate in the time 2 survey (1,362 [49.6\%] of participants completed this survey). In the time 1 survey, we employed multiple indices of film engagement, including measuring their sadness, anger, empathic concern, transportation (i.e., immersion), and perspective-taking while watching the film, and how knowledgeable they felt about gender bias research and facts after watching the film. In addition to the film engagement measures, participants also indicated their awareness of gender bias in the sciences and self-efficacy to combat gender bias after watching the documentary.

Participants also reported their various behavioural intentions after watching the film. All participants indicated their intentions to confront sexism or harassment, to seek out additional information about sexism and ways to combat bias, and to donate their time or money to organizations working to address disparities in STEM. We also measured specific types of intentions among subsets of participants in positions to enact these behaviours. In particular, participants who worked in a university or were graduate students $(n=1,705$; i.e., participants who might interact with students in the classroom) reported their intentions to support minoritized students. Participants who worked in a university or company $(n=1,823)$ indicated their intentions to help create welcoming climates for women in their organization. Finally, participants in a leadership position $(n=589)$ reported their intentions to enact inclusive policies and initiatives to create welcoming environments and promote diversity in their organization. Participants had the option of skipping any item or measure that made them uncomfortable. We also included a "Not Applicable" option for all behavioural intention items. We encouraged participants to choose that option when they were not in a position to enact that action (i.e., did not currently work with students, could not enact specific policies). When participants skipped a 
question or chose "Not Applicable," that item was treated as missing. If participants did not answer a subset of questions from a measure, we averaged the items they did complete to create the index. Participants who did not answer all questions from a given index were treated as missing for analyses with that outcome.

Participants again completed measures at the time 2 survey assessing their awareness of gender bias, self-efficacy to combat bias, and behavioural intention (using the same measures from time 1). Participants also disclosed whether they completed a variety of behaviours since watching the documentary. We assessed whether each behaviour was new (i.e., participants had not done the behaviour before watching the film) or old (i.e., participants had taken part in the behaviour before watching the film). Similar to behavioural intentions, we measured specific types of behaviours among subsets of participants who were in positions to enact these behaviours

Before looking at how film engagement related to behavioural intentions and reported behaviours, we were first interested in how many participants indicated doing behaviours to help address biases and disparities between time 1 and 2 (see Table 1 frequencies of these behaviours). We found that participants were the least likely to do a donate behaviour (i.e., donating time or money to organizations addressing bias). Approximately $9 \%$ of participants did a new donate behaviour (i.e., a behaviour they did not do before the film), and 32\% did any donate behaviour (i.e., a new behaviour or behaviour they also had done before watching the film). For all other behaviours (seeking information, supporting minoritized students, creating a positive climate, or enacting policies in a leadership role), $26 \%-35 \%$ did a new behaviour, and $69 \%-87 \%$ did any behaviour (i.e., a new or old behaviour). Thus, in the six weeks following the 
film, most of our sample took at least one action to help address biases and disparities. Finally, when participants witnessed sexism, $47 \%$ confronted or said something about the sexism.

Table 1. Frequencies of reported new and old behaviours at time 2

\begin{tabular}{c|ccc}
\hline Measures & & Did new behaviour & Did new or old behaviour \\
\hline Confront & $n$ & 180 & N/A \\
sexism (if see saw it) & $\%$ & $47.00 \%$ & N/A \\
& Total $n$ & 383 & N/A \\
\hline Did a seek information behaviour & $n$ & 417 & 927 \\
& $\%$ & $31.24 \%$ & $69.44 \%$ \\
& Total $n$ & 1335 & 1335 \\
\hline Did a donate behaviour & $n$ & 121 & 419 \\
\cline { 2 - 4 } & $\%$ & $9.15 \%$ & $31.67 \%$ \\
\cline { 2 - 4 } & Total $n$ & 1323 & 1323 \\
\hline Did a supporting minoritize student & $n$ & 178 & 574 \\
behaviour & $\%$ & $27.01 \%$ & 659 \\
\hline Did a positive climate & Total $n$ & 659 & 610 \\
behaviour & $n$ & 209 & $76.73 \%$ \\
& $\%$ & $26.29 \%$ & 795 \\
\hline Did a positive leader & Total $n$ & 795 & $82.57 \%$ \\
behaviour & $n$ & 85 & 241 \\
\hline & $\%$ & $35.27 \%$ & \\
\hline
\end{tabular}

We were also curious whether behavioural intentions measured at time 1 related to participants reporting actual behaviours at time 2 . We found that our behavioural intentions measures at time 1 positively and significantly correlated with participants indicating doing at least one related behaviour at time 2 . Thus, our measures of behavioural intentions corresponded to reported behaviours (see Supplementary Table 1 for these correlations).

We next explored whether different forms of engagement with "Picture a Scientist" related to behavioural intentions and reported behaviours. We ran partial correlations controlling for demographic variables to look at these relationships because supplementary analyses found 
that film engagement, awareness of bias, and behavioural intentions varied across different demographic groups (see Supplementary Tables 9-12 for results). As one example, women tended to feel more transported in the film and report higher donation intentions. Consequently, any relationship between transportation and donation intentions may be driven primarily or solely by variations across gender. To address this issue, we aimed to examine these correlations above and beyond any relationships with demographic variables, and thus, controlled for these potential third variables.

First, looking at partial correlations between measures assessed at time 1, we found that anger, empathy, knowledge, transportation, and perspective-taking positively related to most of our outcomes (see Table 2 for all partial correlations). Anger $(p=.018)$ did not significantly relate to self-efficacy (with our Bonferroni corrected $p$-value). Moreover, feeling sad while watching the film related to significantly lower feelings of self-efficacy $(p<.001)$ and did not relate to confrontation intentions $(p=.446)$ or leadership behaviours $(p=.907)$. 
Table 2. Partial correlations between film engagement and behavioural intentions (all at time 1) controlling for demographic variables

\begin{tabular}{|c|c|c|c|c|c|c|c|}
\hline Measures & & Anger & Sadness & Empathy & Knowledge & Transportation & Perspective-taking \\
\hline \multirow[t]{3}{*}{ Awareness of gender bias } & $r$ & .31 & .23 & .26 & .15 & .30 & .35 \\
\hline & $p$ & $<.001 *$ & $<.001 *$ & $<.001 *$ & $<.001 *$ & $<.001 *$ & $<.001 *$ \\
\hline & $n$ & 2730 & 2730 & 2730 & 2730 & 2730 & 2730 \\
\hline \multirow[t]{3}{*}{ Self-efficacy } & $r$ & .05 & -.21 & .20 & .35 & .11 & .10 \\
\hline & $p$ & .018 & $<.001 *$ & $<.001 *$ & $<.001 *$ & $<.001 *$ & $<.001 *$ \\
\hline & $n$ & 2730 & 2730 & 2730 & 2730 & 2730 & 2730 \\
\hline \multirow[t]{3}{*}{ Confront intentions } & $r$ & .21 & -.02 & .29 & .18 & .24 & .13 \\
\hline & $p$ & $<.001 *$ & .446 & $<.001 *$ & $<.001 *$ & $<.001 *$ & $<.001 *$ \\
\hline & $n$ & 2726 & 2726 & 2726 & 2726 & 2726 & 2726 \\
\hline \multirow[t]{3}{*}{ Seek information intentions } & $r$ & .23 & .11 & .31 & .27 & .29 & .22 \\
\hline & $p$ & $<.001 *$ & $<.001 *$ & $<.001 *$ & $<.001 *$ & $<.001 *$ & $<.001 *$ \\
\hline & $n$ & 2721 & 2721 & 2721 & 2721 & 2721 & 2721 \\
\hline \multirow[t]{3}{*}{ Donate intentions } & $r$ & .18 & .09 & .22 & .14 & .20 & .19 \\
\hline & $p$ & $<.001 *$ & $<.001$ & $<.001 *$ & $<.001 *$ & $<.001 *$ & $<.001 *$ \\
\hline & $n$ & 2720 & 2720 & 2720 & 2720 & 2720 & 2720 \\
\hline \multirow[t]{3}{*}{ Supporting minoritized students ${ }^{1}$} & $r$ & .19 & .10 & .23 & .13 & .19 & .17 \\
\hline & $p$ & $<.001 *$ & $<.001 *$ & $<.001 *$ & $<.001 *$ & $<.001 *$ & $<.001 *$ \\
\hline & $n$ & 1456 & 1456 & 1456 & 1456 & 1456 & 1456 \\
\hline \multirow[t]{3}{*}{ Positive Climate Behaviours $^{2}$} & $r$ & .19 & .09 & .22 & .16 & .21 & .16 \\
\hline & $p$ & $<.001 *$ & $<.001^{*}$ & $<.001 *$ & $<.001 *$ & $<.001 *$ & $<.001 *$ \\
\hline & $n$ & 1665 & 1665 & 1665 & 1665 & 1665 & 1665 \\
\hline \multirow[t]{3}{*}{ Leadership behaviours $^{3}$} & $r$ & .16 & -.01 & .16 & .13 & .19 & .11 \\
\hline & $p$ & $<.001 *$ & .907 & $<.001 *$ & $.002 *$ & $<.001 *$ & .012 \\
\hline & $n$ & 554 & 554 & 554 & 554 & 554 & 554 \\
\hline
\end{tabular}

Note: Bolded correlations $=$ significant at $p<.008$ Bonferroni corrected value. We controlled for whether participants were leaders, worked or majored in a STEM field, worked in a university, were students, gender (dummy coded with men as the reference group), and race (dummy coded with White participants as the reference group)

${ }^{1}$ Only completed among participants who worked in a university or students, and thus, we did not control whether participants worked in a university ${ }^{2}$ Only completed among participants who work in a university or company (i.e., no participants were students), and thus, we did not control for students versus non-students

${ }^{3}$ Only completed by leaders, and thus, we did not control for leader versus non-leader or student versus non-student 
For time 2 behavioural intentions, we explored how film engagement and awareness of gender bias in sciences (all measured at time 1) predicted changes in behavioural intentions from time 1 to time 2 . Thus, we ran partial correlations between film engagement and awareness of gender bias at time 1 with behavioural intentions at time 2 , controlling for time 1 intentions and demographic variables (see Table 3 for all correlations). For instance, we looked at the partial correlations between intentions to seek out information at time 2 and film engagement and awareness of bias while controlling for (or partialling-out) intentions to seek out information measured at time 1 and demographic variables. We found that empathy $(p=.004)$, knowledge $(p$ $<.001)$, perspective-taking $(p=.001)$, and awareness of gender bias $(p<.001)$, positively related to higher intentions to seek out new information at time 2 (controlling for time 1 intentions). Feeling sad also related to lower intentions to confront bias $(p=.003)$, whereas feeling knowledgeable related to higher intentions to confront bias at time $2(p=.001$; controlling for time 1). Anger $(p=.001)$, sadness $(p=.002)$, empathy $(p=.001)$, transportation $(p<.001)$, perspective-taking $(p=.001)$, and awareness of gender bias $(p<.001)$ all related to stronger intentions to support minoritized students at time 2 (controlling for time 1 intentions). Finally, transportation and perspective-taking related to changes in donation intentions $(p s<.004)$ and awareness of gender bias predicted changes in intentions to create a positive climate $(p=.001)$.

We also examined whether reactions to the film and awareness of bias (all measured at time 1) correlated with reported behaviours (i.e., doing at least one new or old behaviour $=1$ or not completing a new or old behaviour $=0$ ) at time 2 (controlling for demographic variables; see Table 4 for all correlations). Awareness of gender bias in the sciences and all film engagement measures, except for feeling knowledgeable, correlated with seeking information between time 1 
and 2 (all ps $<001$; see Table 4). Moreover, transportation, perspective-taking, and awareness of bias related to a higher likelihood of doing a donate behaviour (all $p s<.007$; see Table 4). 
Table 3. Partial correlations between film engagement (time 1) and behavioural intentions (time 2) controlling for demographic variables and time intentions

\begin{tabular}{|c|c|c|c|c|c|c|c|c|}
\hline Measures & & Anger & Sadness & Empathy & Knowledge & Transportation & $\begin{array}{c}\text { Perspective } \\
\text { taking }\end{array}$ & $\begin{array}{c}\text { Aware of } \\
\text { gender bias }\end{array}$ \\
\hline \multirow[t]{2}{*}{$\begin{array}{l}\text { Confront } \\
\text { intentions }\end{array}$} & $\begin{array}{l}r \\
p\end{array}$ & $\begin{array}{l}.01 \\
.719\end{array}$ & $\begin{array}{l}-.08 \\
.003 *\end{array}$ & $\begin{array}{l}.07 \\
.016\end{array}$ & $\begin{array}{c}.09 \\
.001 *\end{array}$ & $\begin{array}{l}.03 \\
.329\end{array}$ & $\begin{array}{l}.03 \\
.302\end{array}$ & $\begin{array}{l}.02 \\
.478\end{array}$ \\
\hline & $n$ & 1306 & 1306 & 1306 & 1306 & 1306 & 1306 & 1306 \\
\hline \multirow{3}{*}{$\begin{array}{l}\text { Seek information } \\
\text { intentions }\end{array}$} & $r$ & .05 & -.01 & .08 & .14 & .06 & .10 & .11 \\
\hline & $p$ & .097 & .801 & $.004^{*}$ & $<.001 *$ & .049 & $.001 *$ & $<.001 *$ \\
\hline & $n$ & 1300 & 1300 & 1300 & 1300 & 1300 & 1300 & 1300 \\
\hline \multirow{3}{*}{$\begin{array}{l}\text { Donate } \\
\text { intentions }\end{array}$} & $r$ & .05 & .00 & .06 & .07 & .08 & .10 & .07 \\
\hline & $p$ & .086 & .970 & .037 & .013 & $.003^{*}$ & $<.001 *$ & .018 \\
\hline & $n$ & 1300 & 1300 & 1300 & 1300 & 1300 & 1300 & 1300 \\
\hline \multirow{3}{*}{$\begin{array}{l}\text { Supporting minoritized } \\
\text { students }{ }^{1}\end{array}$} & $r$ & .13 & .12 & .18 & .08 & .18 & .13 & .18 \\
\hline & $p$ & $.001 *$ & $.002 *$ & $<.001 *$ & .059 & $<.001 *$ & $.001 *$ & $<.001 *$ \\
\hline & $n$ & 634 & 634 & 634 & 634 & 634 & 634 & 634 \\
\hline \multirow{3}{*}{$\begin{array}{c}\text { Positive Climate } \\
\text { Behaviours }^{2}\end{array}$} & $r$ & .05 & .04 & .05 & -.01 & .08 & .09 & .13 \\
\hline & $p$ & .201 & .248 & .217 & .853 & .040 & .021 & $.001 *$ \\
\hline & $n$ & 710 & 710 & 710 & 710 & 710 & 710 & 710 \\
\hline \multirow[t]{3}{*}{$\begin{array}{l}\text { Leadership } \\
\text { Behaviours }^{3}\end{array}$} & $r$ & .15 & -.01 & .12 & .12 & .06 & .11 & .16 \\
\hline & $p$ & .055 & .874 & .120 & .106 & .470 & .147 & .033 \\
\hline & $n$ & 172 & 172 & 172 & 172 & 172 & 172 & 172 \\
\hline
\end{tabular}

Note: Bolded correlations $=$ significant at $p<.007$ Bonferroni corrected value. We controlled for whether participants were leaders, worked or majored in a STEM field, worked in a university, were students, gender (dummy coded with men as the reference group), race (dummy coded with White participants as the reference group), and time 1 intentions.

${ }^{1}$ Only completed among participants who worked in a university or students, and thus, we did not control whether participants worked in a university ${ }^{2}$ Only completed among participants who work in a university or company (i.e., no participants were students), and thus, we did not control for students versus non-students.

${ }^{3}$ Only completed by leaders, and thus, we did not control for leader versus non-leader or student versus non-student 
Table 4. Correlations between engagement with the film at time 1 and reported behaviours at time 2 in Study 1

\begin{tabular}{|c|c|c|c|c|c|c|c|c|}
\hline Measures & & Anger & Sadness & Empathy & Knowledge & Transportation & $\begin{array}{c}\text { Perspective } \\
\text { taking }\end{array}$ & $\begin{array}{c}\text { Aware of } \\
\text { gender bias }\end{array}$ \\
\hline \multirow{3}{*}{$\begin{array}{c}\text { Confront } \\
\text { sexism (if see saw it) } \\
(1=\text { Yes, } 0=\text { No })\end{array}$} & $r$ & -.07 & -.07 & .00 & -.01 & .01 & -.11 & -.10 \\
\hline & $p$ & .156 & .164 & .948 & .892 & .830 & .034 & .050 \\
\hline & $n$ & 372 & 372 & 372 & 372 & 372 & 372 & 372 \\
\hline \multirow{3}{*}{$\begin{array}{c}\text { Did a new seek } \\
\text { information behaviour } \\
(1=\text { Yes, } 0=\text { No })\end{array}$} & $r$ & .12 & .12 & .16 & .05 & .18 & .14 & .11 \\
\hline & $p$ & $<.001^{*}$ & $<.001 *$ & $<.001 *$ & .054 & $<.001 *$ & $<.001^{*}$ & $<.001 *$ \\
\hline & $n$ & 1321 & 1321 & 1321 & 1321 & 1321 & 1321 & 1321 \\
\hline \multirow{3}{*}{$\begin{array}{l}\text { Did a new donate } \\
\text { behaviour } \\
(1=\text { Yes, } 0=\text { No })\end{array}$} & $r$ & .04 & .03 & .06 & -.02 & .09 & .11 & .08 \\
\hline & $p$ & .123 & .217 & .031 & .597 & $.001^{*}$ & $<.001^{*}$ & $.007^{*}$ \\
\hline & $n$ & 1309 & 1309 & 1309 & 1309 & 1309 & 1309 & 1309 \\
\hline \multirow{3}{*}{$\begin{array}{c}\text { Did a supporting } \\
\text { minoritize student } \\
\text { behaviour }^{1} \\
(1=\text { Yes, } 0=\text { No })\end{array}$} & $r$ & .08 & .06 & .06 & -.05 & .05 & .02 & .04 \\
\hline & $p$ & .044 & .108 & .165 & .174 & .168 & .540 & .267 \\
\hline & $n$ & 648 & 648 & 648 & 648 & 648 & 648 & 648 \\
\hline \multirow{3}{*}{$\begin{array}{c}\text { Did a new positive } \\
\text { climate } \\
\text { behaviours } \\
(1=\text { Yes, } 0=\mathrm{No}) \\
\end{array}$} & $r$ & .04 & .03 & .06 & -.03 & .05 & .08 & .07 \\
\hline & $p$ & .281 & .431 & .075 & .408 & .154 & .036 & .066 \\
\hline & $n$ & 782 & 782 & 782 & 782 & 782 & 782 & 782 \\
\hline \multirow{3}{*}{$\begin{array}{c}\text { Did a positive leader } \\
\text { behaviour } \\
(1=\text { Yes, } 0=\text { No })\end{array}$} & $r$ & .01 & -.04 & .03 & .12 & .10 & .05 & .11 \\
\hline & $p$ & .847 & .525 & .646 & .081 & .121 & .461 & .107 \\
\hline & $n$ & 231 & 231 & 231 & 231 & 231 & 231 & 231 \\
\hline
\end{tabular}

Note: Bolded correlations $=$ significant at $p<.007$ Bonferroni corrected value. We controlled for whether participants were leaders, worked or majored in a STEM field, worked in a university, were students, gender (dummy coded with men as the reference group), race (dummy coded with White participants as the reference group), and time 1 intentions.

${ }^{1}$ Only completed among participants who worked in a university or students, and thus, we did not control whether participants worked in a university

${ }^{2}$ Only completed among participants who work in a university or company (i.e., no participants were students), and thus, we did not control for students versus non-students.

${ }^{3}$ Only completed by leaders, and thus, we did not control for leader versus non-leader or student versus non-student 
An interesting finding from our correlations was that the measures of film engagement most consistently related to seeking out new information about bias (whether measured via behavioral intentions or reported behaviors). These analyses replicated past work ${ }^{53,54,55}$, which has found that film engagement and awareness of bias encouraged participants to learn more about issues surrounding unfair treatment and biases. Moreover, as mentioned in the introduction, engaging with new information can further influence attitudes and beliefs ${ }^{56,57}$ and behaviours ${ }^{58,59,60}$. Thus, in secondary analyses, we examined whether seeking out additional information after "Picture a Scientist" would lead to further positive actions and a stronger awareness of gender bias.

To test this possibility, we ran regression analyses predicting awareness of gender bias, self-efficacy, and behavioural intentions, from whether participants reported seeking out information between time 1 and 2. For these analyses, we controlled for time 1 assessments to examine how acquiring relevant information predicted changes in these outcomes across the six weeks. We also tested whether certain demographic groups were more or less likely to seek out information between time 1 and time 2 . We found that leaders were more likely to look up related information (no other demographic variables were significant, see Supplementary Table 2). Thus, we also controlled for whether participants identified as a leader in the subsequent analyses.

Seeking out information between time 1 and 2 positively predicted awareness of gender bias $(b=0.21, S E=0.04,95 \%$ CI $[0.18,0.29], t[1331]=4.93, p<.001$, intentions to donate $(b$ $=0.29, S E=0.06,95 \% \mathrm{CI}[0.17,0.41], t[1304]=4.70, p<.001$, intentions to support minoritized students, $(b=0.18, S E=0.05,95 \%$ CI $[0.08,0.29], t[640]=3.37, p<.001)$, and intentions to create a positive climate $(b=0.44, S E=0.08,95 \%$ CI $[0.13,0.44], t[1331]=3.62$, 
$p<.001)$ at time 2 , controlling for time 1 measures and whether participants were leaders. Thus, attaining relevant new information predicted changes in awareness of bias and positive behavioural intentions. Seeking out information between time 1 and 2 did not relate to selfefficacy, confrontation intentions, or leadership behaviours (see Supplementary Table 3 for detailed regression results).

As mentioned above, in additional analyses, we also explored whether demographic groups had different reactions to the film and varied in their behavioural intentions. All of the findings with demographic variables are available in Supplementary Materials and Supplementary Tables 9-12.

Taken together, Study 1 provided initial evidence suggesting there are benefits associated with viewing "Picture a Scientist." For instance, we found promising descriptive data suggesting that most of our sample took part in at least one action to address gender bias and disparities in the six weeks following the film. Approximately a third of our sample did a new behaviour they had not completed before the film. Additionally, measures of film engagement correlated with stronger behavioural intentions (at time 1) to combat biases and disparities. Interestingly, our indices of film engagement most consistently related to seeking out new information. In secondary analyses, we found that interacting with this new information, in turn, predicted increases in awareness of gender bias, donation intentions, intentions to support minoritized students, and intentions to create positive organizational climates. Thus, Study 1 suggests "Picture a Scientist" may lead to cascading and persisting positive effects among those highly engaged with the film. Specifically, stronger film engagement encourages seeking out additional relevant information, which in turn promotes continued awareness of these issues and intentions to combat biases. 


\section{Study 2}

In Study 1, all participants completed our survey after viewing the documentary. As a result, we could not examine whether there were any benefits associated with watching versus not watching "Picture a Scientist," nor directly test whether the film acted as an online intervention. To address this limitation, we ran a second study with a quasi-experimental design. Specifically, we recruited 1255 participants who had watched the film $(833,66.4 \%)$ or were planning to watch the film (i.e., had signed up for a viewing or participated in an event associated with the documentary; 422, 33.6\%). We also sent a follow-up survey to participants three weeks after the initial survey and looked at changes in outcomes among participants who viewed the film between the first and second time points. In the time 1 and 2 surveys, we included the same film engagement, awareness of gender bias in the sciences, self-efficacy to combat bias, and behavioural intentions measures from Study 1.

We preregistered our research questions and data collection plans (available here: https://osf.io/csjzx/?view_only=e62700073eb04d6f9eee5cfc5bc54f6b). Our primary preregistered research questions were - a) At time 1, would participants who had already seen the film report higher awareness of gender bias in the sciences and higher intentions to enact behaviours to address gender bias and disparities? b) Would participants who watched the film between time 1 and 2 show increased awareness of bias and positive behavioural intentions? c) Would measures of film engagement relate to stronger behavioural intentions?

To answer our first primary research question, we ran a series of between-subjects twosided $t$-tests, with whether or not participants had watched the film prior to the time 1 survey as our predictor. Compared to those who had not watched the film, participants who had watched the film were more aware of gender bias in STEM, (mean difference $=0.47, S E=0.05,95 \% \mathrm{CI}$ 
$[0.37,0.57], d=0.53, t[1253]=9.60 . p<.001)$, and indicated higher intentions to seek out information, $($ mean difference $=0.38, S E=0.06,95 \% \mathrm{CI}[0.25,0.50], d=0.34, t[1249]=5.88$, $p<.001$ ), to donate to organizations addressing gender bias and disparities, (mean difference $=$ $0.31, S E=0.08,95 \%$ CI $[0.25,0.50], d=0.22, t[1248]=3.88, p<.001)$, and to create a welcoming climates in their organizations, (mean difference $=0.43, S E=0.08,95 \%$ CI $[0.26$, $0.60], d=0.38, t[850]=5.41, p<.001)$. Among those in a leadership position, participants who had viewed the film reported higher intentions to enact policies that would help address bias relative to those had not watched the film (mean difference $=0.42, S E=0.12,95 \%$ CI $[0.19$, 0.66], $d=0.43, t[294]=3.57, p<.001)$. Participants who watched the film also indicated higher intentions to confront sexism and mentor and support students with minoritized identities; however, these effects were not significance using the Bonferroni corrected $p$-value (See Supplementary Table 4 for full effects). Finally, there was a tendency for participants who watched the film to feel lower self-efficacy to address gender bias, although this effect also did not reach significance (See Supplementary Table 4 for full effects).

We also tested whether different demographic groups were more or less likely to have watched the film. We found that a significantly higher percentage of women and people employed at universities had watched "Picture a Scientist." (There were no other differences across demographic groups, see Supplementary Table 5.) Thus, we ran follow-up regression analyses predicting our outcome measures from having watched the film (1) versus not (0), while controlling for gender (dummy coded, with men as the reference group) and university affiliation ( $1=$ employed at a university, $0=$ not employed at a university). We found similar results with these regression analyses, which are available in Supplementary Table 6. 
Participants also varied in how much time had passed since watching the "Picture a Scientist." Among participants who watched the film, 471 (37.2\%) watched it within the previous month, and 361 (27.1\%) watched the film a month or longer before the survey. In exploratory analyses (i.e., not preregistered), we ran a series of between-subjects ANOVAs with three groups (participants who had not watched the film vs. participants who watched the film within the past month vs. participants who watched the film over a month before the survey; see Supplementary Table 7 for full ANOVA results). Participants who viewed "Picture a Scientist" a month or more before the survey did not show lower scores on our outcome measures, and in fact, tended to have higher scores relative to those who had watched the documentary more recently. We did not test this possibility directly; however, participants who had watched the film a month or more before the survey may have had more time to continue learning about and finding resources related to the topics featured in the film. Thus, these exploratory (and nonpreregistered) analyses provided some initial evidence suggesting "Picture a Scientist" can have a lasting impact.

We were next interested in whether there were benefits associated with watching the film between time 1 and 2, particularly for participants who had not watched the documentary at time 1. We had 668 participants (53.2\%) complete the time 2 survey, and among these participants, 237 (35.5\% of time 2 respondents, $18.8 \%$ of total sample) watched the film between time 1 and 2. Focusing on participants who had watched the film between the two time points, we ran a mixed model ANOVA with time as the within-subjects factor and having watched the film at time 1 versus not as our between-subjects factor ( 96 had already watched the film at time 1 and 141 had not watched the film at time 1; see Supplementary Table 8 full ANOVA results). Of 
note, we specified that we only would conduct these analyses among participants who had watched the film between time 1 and 2 in our preregistration.

There were significant time (time 1 versus time 2) by having watched the film at time 1 (versus not watch) interactions for awareness gender bias in the sciences, $F(1,235)=10.83, \mathrm{p}=$ $.001, \eta_{p}{ }^{2}=0.044$, confrontation intentions, $F(1,235)=19.55, p<.001, \eta_{p}{ }^{2}=0.077$, and intentions to create a positive organizational climate $F(1,149)=8.65, p=.004, \eta_{p}{ }^{2}=0.055$. Among participants who had not watched the film at time 1, there was a significant increase from time 1 to time 2 on awareness of gender bias (mean difference $=0.36, S E=0.07,95 \% \mathrm{CI}$ $[0.22,0.50], d=0.36, p<.001$ ), intentions to confront sexism (mean difference $=0.22, S E=$ $0.05,95 \% \mathrm{CI}[0.11,0.32], d=0.35, p<.001)$, and intentions to foster a positive organizational climate (mean difference $=0.22, S E=0.09,95 \%$ CI $[0.04,0.39], d=0.23, p=.017$ ). We found a similar pattern of results for intentions to seek information and leadership behaviour intentions, although the effect of time did not reach significance for these outcomes. These lack of significant effects may have been due to the fact that we had a small sample watch the film between time 1 and 2. Unexpectedly, participants who had already watched the film at time 1 , showed a significant decrease in confrontation intentions from time 1 to time 2 (mean difference $=-0.14, S E=0.06,95 \% \mathrm{CI}[-0.27,0.02], d=0.26, p=.023)$; however, that was the only effect of time among these participants. Thus, we did not see any added benefit to watching the film between time 1 and 2, when participants had already seen the film at time 1 . In contrast, we did find positive effects on awareness of gender bias, confrontation intentions, and creating positive climate intentions, among participants, who had not previously seen the film at time 1.

Finally, we were curious whether our measures of film engagement would relate to behavioural intentions. We first examined correlations among participants who had watched the 
film at time 1. Specifically, using the same analyses from Study 1, we ran partial correlations to explore the relationship between film engagement and behavioural intentions, awareness of gender bias in the sciences, and self-efficacy while controlling for or partialling out demographic variables (see Table 5 for all correlations). We found that most film engagement measures positively correlated with behavioural intentions and awareness of bias (controlling for demographic variables, see Table 5). Anger, empathy, knowledge, and perspective-taking related to higher self-efficacy for addressing bias, whereas sadness was associated with lower selfefficacy (similar to Study 1).

We next examined whether engagement with the film and awareness of bias related to changes in behavioural intentions from time 1 to time 2 . Among participants who had watched the film at time 1, we used the time 1 film engagement measures. For participants, who had not watched the film at time 1 but watched the documentary between time 1 and 2, we utilized the time 2 film engagement measures. We ran partial correlations between film engagement (at time 1 and time 2 depending on when participants watched the film) and awareness of gender bias (at time 1 for all participants) with behavioural intentions at time 2 , controlling for time 1 intentions and demographic variables (see Table 6 for all correlations). Of note, we found a similar pattern of results as Study 1 in that measures of film engagement most consistently related to changes in intentions to seek out new information. Anger, empathy, knowledge, transportation, and perspective-taking all related to changes in intentions to seek out information (all $p s<.008$; see Table 6). Higher awareness of bias positively related to changes in seeking out information; however, this correlation did not research significance with about Bonferroni corrected $p$-value. We also found that empathy $(p=.003)$ predicted greater changes in donation intentions and 
anger related to greater changes in intentions to support minoritized students $(p=.007$; see Table $6)$. 
Table 5. Partial correlations between film engagement and behavioural intentions (all at time 1) controlling for demographic variables in Study 2

\begin{tabular}{|c|c|c|c|c|c|c|c|}
\hline Measures & & Anger & Sadness & Empathy & Knowledge & Transportation & Perspective-taking \\
\hline \multirow{3}{*}{ Bias Aware } & $r$ & .29 & .21 & .26 & .02 & .29 & .32 \\
\hline & $p$ & $<.001 *$ & $<.001 *$ & $<.001 *$ & .483 & $<.001 *$ & $<.001 *$ \\
\hline & $n$ & 822 & 822 & 822 & 822 & 822 & 822 \\
\hline \multirow[t]{3}{*}{ Self-efficacy } & $r$ & $.09 *$ & $-.14 *$ & $.15 *$ & $.11 *$ & .02 & $.10 *$ \\
\hline & $p$ & .008 & $<.001$ & $<.001$ & .001 & .504 & .006 \\
\hline & $n$ & 821 & 821 & 821 & 821 & 821 & 821 \\
\hline \multirow[t]{3}{*}{ Confront intentions } & $r$ & .24 & .06 & .33 & .10 & .22 & .12 \\
\hline & $p$ & $<.001 *$ & .115 & $<.001 *$ & $.004^{*}$ & $<.001 *$ & $.001 *$ \\
\hline & $n$ & 822 & 822 & 822 & 822 & 822 & 822 \\
\hline \multirow[t]{3}{*}{ Seek information intentions } & $r$ & .24 & .12 & .30 & .15 & .23 & .16 \\
\hline & $p$ & $<.001 *$ & $<.001 *$ & $<.001 *$ & $<.001 *$ & $<.001 *$ & $<.001 *$ \\
\hline & $n$ & 820 & 820 & 820 & 820 & 820 & 820 \\
\hline \multirow[t]{3}{*}{ Donate intentions } & $r$ & .19 & .11 & .24 & .06 & .17 & .14 \\
\hline & $p$ & $<.001 *$ & $.002 *$ & $<.001 *$ & .069 & $<.001 *$ & $<.001 *$ \\
\hline & $n$ & 819 & 819 & 819 & 819 & 819 & 819 \\
\hline \multirow[t]{3}{*}{ Support minoritized students ${ }^{1}$} & $r$ & .27 & .19 & .27 & .01 & .25 & .16 \\
\hline & $p$ & $<.001 *$ & $<.001 *$ & $<.001 *$ & .783 & $<.001 *$ & $<.001 *$ \\
\hline & $n$ & 446 & 446 & 446 & 446 & 446 & 446 \\
\hline \multirow[t]{3}{*}{ Positive climate behaviours ${ }^{2}$} & $r$ & .22 & .10 & .24 & .05 & .23 & .18 \\
\hline & $p$ & $<.001^{*}$ & .016 & $<.001 *$ & .204 & $<.001 *$ & $<.001 *$ \\
\hline & $n$ & 561 & 561 & 561 & 561 & 561 & 561 \\
\hline \multirow[t]{3}{*}{ Leadership behaviours $^{3}$} & $r$ & .42 & .23 & .39 & .23 & .37 & .19 \\
\hline & $p$ & $<.001^{*}$ & $.002 *$ & $<.001 *$ & $.001 *$ & $<.001 *$ & .011 \\
\hline & $n$ & 180 & 180 & 180 & 180 & 180 & 180 \\
\hline
\end{tabular}

Note: Bolded correlations $=$ significant at $p \leq .008$ Bonferroni corrected value. We controlled for whether participants were leaders, worked or majored in a STEM field, worked in a university, were students, gender (dummy coded with men as the reference group), and race (dummy coded with White participants as the reference group)

${ }^{1}$ Only completed participants who worked in a university or students, and thus, we did not control whether participants worked in a university

${ }^{2}$ Only completed by participants who work in a university or company(i.e., no participants were students), and thus, we did not control for students versus nonstudents.

${ }^{3}$ Only completed by leaders, and thus, we did not control for leader versus non-leader or student versus non-student 
Table 6. Partial correlations between film engagement and behavioural intentions (time 2) controlling for demographic variables and time 1 intentions in Study 2

\begin{tabular}{|c|c|c|c|c|c|c|c|c|}
\hline Measures & & Anger & Sadness & Empathy & Knowledge & Transportation & $\begin{array}{l}\text { Perspective } \\
\text { taking }\end{array}$ & $\begin{array}{c}\text { Aware of } \\
\text { gender bias }\end{array}$ \\
\hline \multirow{3}{*}{$\begin{array}{l}\text { Confront } \\
\text { intentions }\end{array}$} & $r$ & .05 & .01 & .06 & .09 & .06 & .03 & -.05 \\
\hline & $p$ & .213 & .726 & .122 & .030 & .121 & .445 & .253 \\
\hline & $n$ & 620 & 620 & 620 & 620 & 620 & 620 & 620 \\
\hline \multirow{3}{*}{$\begin{array}{l}\text { Seek information } \\
\text { intentions }\end{array}$} & $r$ & .11 & .05 & .18 & .14 & .13 & .14 & .10 \\
\hline & $p$ & $.007^{*}$ & .242 & $<.001 *$ & $.001 *$ & $.001 *$ & $.001 *$ & .011 \\
\hline & $n$ & 619 & 619 & 619 & 619 & 619 & 619 & 619 \\
\hline \multirow{3}{*}{$\begin{array}{c}\text { Donate } \\
\text { intentions }\end{array}$} & $r$ & .06 & .06 & .12 & .05 & .06 & .07 & .07 \\
\hline & $p$ & .118 & .162 & $.002 *$ & .248 & .139 & .090 & .085 \\
\hline & $n$ & 619 & 619 & 619 & 619 & 619 & 619 & 619 \\
\hline \multirow{3}{*}{$\begin{array}{l}\text { Supporting minoritized } \\
\text { students }\end{array}$} & $r$ & .16 & .03 & .04 & .01 & .01 & .14 & .09 \\
\hline & $p$ & $.007^{*}$ & .612 & .508 & .846 & .884 & .022 & .111 \\
\hline & $n$ & 283 & 283 & 283 & 283 & 283 & 283 & 283 \\
\hline \multirow{3}{*}{$\begin{array}{l}\text { Positive Climate } \\
\text { Behaviours }\end{array}$} & $r$ & .10 & .12 & .09 & .04 & .05 & .01 & .02 \\
\hline & $p$ & .047 & .018 & .063 & .400 & .336 & .776 & .681 \\
\hline & $n$ & 392 & 392 & 392 & 392 & 392 & 392 & 392 \\
\hline \multirow{3}{*}{$\begin{array}{l}\text { Leadership } \\
\text { behaviours }\end{array}$} & $r$ & -.02 & .11 & .14 & -.03 & .08 & .04 & -.17 \\
\hline & $p$ & .862 & .226 & .133 & .731 & .378 & .671 & .071 \\
\hline & $n$ & 113 & 113 & 113 & 113 & 113 & 113 & 113 \\
\hline
\end{tabular}

Note: Bolded correlations $=$ significant at $p<.007$ Bonferroni corrected value. We controlled for whether participants were leaders, worked or majored in a STEM field, worked in a university, were students, gender (dummy coded with men as the reference group), race (dummy coded with White participants as the reference group), and time 1 intentions.

${ }^{1}$ Only completed participants who worked in a university or students, and thus, we did not control whether participants worked in a university

${ }^{2}$ Only completed by participants who work in a university or company(i.e., no participants were students), and thus, we did not control for students versus nonstudents.

${ }^{3}$ Only completed by leaders, and thus, we did not control for leader versus non-leader or student versus non-student. We also took out the men versus selected other contrast because we did not have any leaders who selected other for these analyses. 
In addition to our primary research questions, we also had various secondary research questions. We present the results answering these questions in Supplementary Materials. First, we were curious whether differences would emerge among demographic groups. Similar to Study 1, we examined whether demographic groups differed in their engagement film and presented these findings in Supplementary Tables 13-14. Importantly, we also explored whether demographic variables moderated the effect of watching versus not watching the film and found that most demographic variables did not moderate our results (see Supplementary Table 15-19). Of note, we found similar patterns of results across gender groups, suggesting the film was equally effective for men and women. The only consistent moderation effect was that watching the documentary (versus not watching the film) was more impactful among participants who were in a STEM field (i.e., job or major) compared to those not in a STEM (see Supplementary Table 17). These findings were most likely due to the content (i.e., sexism and harassment in STEM) of the film being most relevant for participants in STEM fields and STEM majors.

During this second study, there was a panel event associated with "Picture a Scientist" and the themes presented during the film. We found that $34.5 \%$ of our sample also had watched the panel at time 1 . Thus, another secondary research question was whether there were benefits associated with observing the panel. Participants who had not yet viewed "Picture a Scientist" but virtually joined the panel indicated higher awareness of gender bias, information seeking intentions, donation intentions, and leadership intentions to enact inclusive policies compared to those who did not engage with the panel (see Supplementary Tables 20-21). Thus, we found benefits associated with this related panel among participants who had not yet watched "Picture a Scientist." Finally, we explored whether watching the panel and demographic variables 
moderated any changes on outcome variables from time 1 to time 2 and did not find evidence of moderation (see Supplementary Tables 22 and 23).

\section{Discussion}

In-person workshops led by expert facilitators can limit the scalability of empirically validated bias literacy trainings ${ }^{8}$. This issue became more relevant during the pandemic, when inperson trainings were less feasible and safe, leading to a decline in workplace anti-discrimination workshops ${ }^{22}$. Entertaining films and videos may help address this problem and function as highly scalable and impactful interventions ${ }^{26,23}$. Indeed, between April of 2020 and May of 2021 (i.e., during the pandemic), the documentary "Picture a Scientist" had a far-reaching international influence, with many organizational screenings and unique film views.

Our two large-scale studies demonstrate that the many viewings of "Picture a Scientist" were also acting as effective online interventions and further suggest that engaging media may be a helpful tool in combatting bias. Study 1 provided descriptive data, demonstrating that after watching "Picture a Scientist," the majority of our sample took part in at least one behaviour to address gender bias and disparities. Moreover, the higher engagement participants reported with the film, the more likely they were to do behaviours related to combating bias and to seek out additional relevant information. In secondary analyses, we found that interacting with this new information, in turn, predicted increased awareness of gender bias and intentions to help address unfair treatment and disparities. Critically, our preregistered quasi-experimental Study 2 also found positive outcomes associated with watching (versus not watching) the documentary. Compared to those who had not yet seen the documentary (but intended to), participants who viewed the film indicated more awareness of gender bias and stronger intentions to seek out information, donate to causes addressing biases, create welcoming organizational climates, and 
enact inclusive policies. Moreover, participants, who initially had not viewed "Picture a Scientist" and then watched the film during the following three weeks (i.e., before the second survey), showed increased awareness of gender bias, confrontation intentions, and intentions to create welcoming organizational climates.

Using randomized control trial experiments, previous research has demonstrated that video interventions can cause increased recognition of gender bias and behavioural intentions to combat sexism and disparities ${ }^{61,62,63}$. Building off this past work, we aimed to look at the benefits of "Picture of a Scientist" in naturally occurring situations (i.e., already scheduled viewings/screenings occurring regardless of our research) and outside of the more rigid experimental context. However, by examining the benefits of the film in these naturalistic settings, we were limited in our control. For instance, many screenings of "Picture a Scientist" were paired with panels discussing the topics featured in the film. Thus, the benefits associated with watching the film in Study 2 most likely were an effect of the documentary and a result of attending a related panel or looking up additional readings on sexism. Although we expect that "Picture a Scientist" alone can inspire positive actions, our Study 1 findings suggest that the film may encourage persisting beliefs and behaviours by motivating viewers to continue engaging with the topics featured in the documentary (e.g., attending panels or reading articles). Nevertheless, future research might run more controlled experiments to isolate the unique positive outcomes of viewing the film and examine any additional benefits of participating in a panel or reading related articles. Of note, in Study 2, 34\% of our participants also attended a virtual panel event associated with "Picture a Scientist," and we found initial evidence that this panel was valuable for participants who had not yet watched the documentary. 
Future workshops incorporating the documentary might also benefit from including carefully developed panels, highlighting concrete strategies for addressing biases. Although there were many positive outcomes associated with watching "Picture a Scientist," self-efficacy to combat bias was slightly lower among participants who had watched the film in Study 2 . Experiencing sadness while watching the documentary was also related to lower self-efficacy across both studies. These findings align with past work, which has found raising awareness of unfair treatment without strategies to reduce the mistreatment can undermine self-efficacy ${ }^{62}$. Additionally, feeling sad when reflecting on injustices can harm motivation for action ${ }^{64}$. However, providing concrete tips and techniques during a follow-up panel may help address these issues, enhance self-efficacy, and further motivate viewers to take action ${ }^{62}$. Exploring the value of a complementary panel focused on tangible action steps will be an important question for future work.

Given that measures of film engagement related to more positive outcomes (i.e., awareness of bias, behavioural intentions), future work should also test manipulations to further foster film engagement. For instance, viewers might be encouraged to actively take the perspective of the women in the film ${ }^{50}$. Future studies also might explore whether organizational screenings of similar films (i.e., films that highlight stories and facts about bias) produce comparable effects as those found with "Picture a Scientist." Indeed, the current studies represented a unique and fruitful collaboration between talented film creators, who know how to curate engaging media, and researchers with the skills to test such films' effectiveness empirically. Future intervention work would benefit from similar collaborations across fields.

In the current two studies, we acknowledge that many of our measures examined issues related to gender (e.g., awareness of gender in the sciences) or intentions to support minoritized 
individuals generally. Although "Picture a Scientist" discussed topics pertinent to sexism and gender harassment in STEM, it also highlighted the distinctive biases encountered by Black women in STEM due to their dual marginalized identities ${ }^{65}$. Encouraging recognition of intersectional biases (i.e., the prejudices faced by individuals with multiple marginalized and intersecting identities) promotes additional positive outcomes beyond increasing awareness of a singular bias ${ }^{66}$. Thus, the current work is limited because we did not include measures assessing intersectional biases awareness in STEM. Future research examining the benefits of "Picture a Scientist" and diversity interventions broadly should recognize issues of intersectionality.

To help address the pervasive sexism in STEM, it is critical to employ interventions that alter personal attitudes and behaviours without eliciting annoyance or boredom ${ }^{39}$ and implement new inclusive organizational-level policies $9,10,11$. "Picture a Scientist's" presence on popular streaming platforms (e.g., Netflix, PBS) and high rating on IMDB highlights the film's broad appeal, suggesting that people may find interventions incorporating the documentary both enjoyable and informative. Notably, the present two studies suggest that "Picture a Scientist" is not only an educational form of entertainment but may also act as an intervention to influence beliefs and behaviours. Indeed, it is particularly promising that relative to leaders who did not watch "Picture a Scientist," those who viewed the documentary had stronger intentions to enact new diversity and inclusion policies, which are crucial for addressing disparities in $\mathrm{STEM}^{9,10}$. Thus, the current findings can help inform company and university policies by highlighting the benefits of organizational diversity workshops incorporating documentaries, such as "Picture a Scientist." Workshops around such films may be relatively low cost, easy to implement, and enjoyable interventions with the potential to influence behaviours and policies. 


\section{References}

1. Eaton, A. A., Saunders, J. F., Jacobson, R. K. \& West, K. How Gender and Race Stereotypes Impact the Advancement of Scholars in STEM: Professors' Biased Evaluations of Physics and Biology Post-Doctoral Candidates. Sex Roles 82, 127-141 (2020).

2. Moss-Racusin, C. A., Dovidio, J. F., Brescoll, V. L., Graham, M. J. \& Handelsman, J. Science faculty's subtle gender biases favor male students. Proc. Natl. Acad. Sci. 109, 1647416479 (2012).

3. Asr, F. T. et al. The Gender Gap Tracker: Using Natural Language Processing to measure gender bias in media. PLOS ONE 16, e0245533 (2021).

4. Confronting gender bias in Nature's journalism. Nature 594, 473-474 (2021).

5. Nittrouer, C. L. et al. Gender disparities in colloquium speakers at top universities. Proc. Natl. Acad. Sci. 115, 104-108 (2018).

6. Freeman, R. B. \& Huang, W. Collaborating with People Like Me: Ethnic Coauthorship within the United States. J. Labor Econ. 33, S289-S318 (2015).

7. Powell, K. BEING INCLUSIVE GIVES TEAMS A COMPETITIVE EDGE IN SCIENCE. IT ALSO HAPPENS TO BE THE RIGHT THING TO DO. 4.

8. Moss-Racusin, C. A. et al. Scientific Diversity Interventions. Science 343, 615-616 (2014).

9. Gewin, V. What does it take to make an institution more diverse? Nature 558, 149-151 (2018).

10. Moss-Racusin, C. A., Pietri, E. S., van der Toorn, J. \& Ashburn-Nardo, L. Boosting the Sustainable Representation of Women in STEM With Evidence-Based Policy Initiatives. Policy Insights Behav. Brain Sci. 8, 50-58 (2021).

11. Onyeador, I. N., Hudson, S. T. J. \& Lewis, N. A. Moving Beyond Implicit Bias Training: Policy Insights for Increasing Organizational Diversity. Policy Insights Behav. Brain Sci. 8, 1926 (2021).

12. Devine, P. G. et al. A gender bias habit-breaking intervention led to increased hiring of female faculty in STEMM departments. J. Exp. Soc. Psychol. 73, 211-215 (2017).

13. Sekaquaptewa, D., Takahashi, K., Malley, J., Herzog, K. \& Bliss, S. An evidence-based faculty recruitment workshop influences departmental hiring practice perceptions among university faculty. Equal. Divers. Incl. Int. J. 38, 188-210 (2019).

14. Shea, C. M., Malone, M. F. F. T., Young, J. R. \& Graham, K. J. Interactive theater: an effective tool to reduce gender bias in faculty searches. Equal. Divers. Incl. Int. J. 38, 178-187 (2019).

15. Smith, J. L., Handley, I. M., Zale, A. V., Rushing, S. \& Potvin, M. A. Now Hiring! Empirically Testing a Three-Step Intervention to Increase Faculty Gender Diversity in STEM. BioScience 65, 1084-1087 (2015).

16. Molla, R. How working from home during coronavirus affects productivity and mental health - Vox. Vox.com https:/www.vox.com/2020/3/20/21187469/work-from-homecoronavirus-productivity-mental-health-nicholas-bloom (2020).

17. Fosslien, L. \& Duffy, M. W. How MEETINGS to Combat Zoom Fatigue. 6.

18. Morris, B. Why Does Zoom Exhaust You? Science Has an Answer - WSJ. The Wall Street Journal https:/www.wsj.com/articles/why-does-zoom-exhaust-you-science-has-ananswer-11590600269 (2020). 
19. Chang, E. H. et al. The mixed effects of online diversity training. Proc. Natl. Acad. Sci. 116, 7778-7783 (2019).

20. Gao, J., Yin, Y., Myers, K. R., Lakhani, K. R. \& Wang, D. Potentially long-lasting effects of the pandemic on scientists. Nat. Commun. 12, 6188 (2021).

21. Squazzoni, F. et al. Gender gap in journal submissions and peer review during the first wave of the COVID-19 pandemic. A study on 2329 Elsevier journals. PLOS ONE 16, e0257919 (2021).

22. Doherty, K. COVID-19 Was Bad for Discrimination Training. Association for Talent Development https://www.td.org/atd-blog/covid-19-was-bad-for-discrimination-training (2021).

23. Oschatz, C. \& Marker, C. Long-term Persuasive Effects in Narrative Communication Research: A Meta-Analysis. J. Commun. 70, 473-496 (2020).

24. Ratcliff, C. L. \& Sun, Y. Overcoming Resistance Through Narratives: Findings from a Meta-Analytic Review. Hum. Commun. Res. 46, 412-443 (2020).

25. Slater, M. D. \& Rouner, D. Entertainment?Education and Elaboration Likelihood: Understanding the Processing of Narrative Persuasion. Commun. Theory 12, 173-191 (2002). 26. Murrar, S. \& Brauer, M. Overcoming Resistance to Change: Using Narratives to Create More Positive Intergroup Attitudes. Curr. Dir. Psychol. Sci. 28, 164-169 (2019).

27. Women, Minorities, and Persons with Disabilities in Science and Engineering. National Science Foundation https://ncses.nsf.gov/pubs/nsf21321/report (2021).

28. Carli, L. L., Alawa, L., Lee, Y., Zhao, B. \& Kim, E. Stereotypes About Gender and Science: Women $\neq$ Scientists. Psychol. Women Q. 40, 244-260 (2016).

29. Cheryan, S., Ziegler, S. A., Montoya, A. K. \& Jiang, L. Why are some STEM fields more gender balanced than others? Psychol. Bull. 143, 1-35 (2017).

30. Nosek, B. A. \& Smyth, F. L. Implicit Social Cognitions Predict Sex Differences in Math Engagement and Achievement. Am. Educ. Res. J. 48, 1125-1156 (2011).

31. Leaper, C. \& Starr, C. R. Helping and Hindering Undergraduate Women's STEM Motivation: Experiences With STEM Encouragement, STEM-Related Gender Bias, and Sexual Harassment. Psychol. Women Q. 43, 165-183 (2019).

32. Steele, J., James, J. B. \& Barnett, R. C. Learning in a Man's World: Examining the Perceptions of Undergraduate Women in Male-Dominated Academic Areas. Psychol. Women $Q$. 26, 46-50 (2002).

33. Witze, A. Sexual harassment is rife in US science. 2.

34. Sevo, R. \& Chubin, D. E. Bias Literacy: A Review of concepts in research on discrimination. AAAS Cent. Sci. Eng. Capacity 31.

35. Carnes, M. et al. The Effect of an Intervention to Break the Gender Bias Habit for Faculty at One Institution: A Cluster Randomized, Controlled Trial. Acad. Med. 90, 221-230 (2015).

36. Moss-Racusin, C. A. et al. A "Scientific Diversity" Intervention to Reduce Gender Bias in a Sample of Life Scientists. CBE-Life Sci. Educ. 15, ar29 (2016).

37. Bezrukova, K., Spell, C. S., Perry, J. L. \& Jehn, K. A. A meta-analytical integration of over 40 years of research on diversity training evaluation. Psychol. Bull. 142, 1227-1274 (2016). 38. Dobbin, F. \& Kalev, A. Why Doesn't Diversity Training Work? The Challenge for Industry and Academia. Anthropol. Now 10, 48-55 (2018).

39. Legault, L., Gutsell, J. N. \& Inzlicht, M. Ironic Effects of Antiprejudice Messages: How Motivational Interventions Can Reduce (but Also Increase) Prejudice. Psychol. Sci. 22, 1472 1477 (2011). 
40. Lipman, J. How Diversity Training Infuriates Men and Fails Women. Time https://time.com/5118035/diversity-training-infuriates-men-fails-women/.

41. Dovidio, J. F. et al. Perspective and Prejudice: Antecedents and Mediating Mechanisms. Pers. Soc. Psychol. Bull. 30, 1537-1549 (2004).

42. Murrar, S. \& Brauer, M. Entertainment-education effectively reduces prejudice. Group Process. Intergroup Relat. 21, 1053-1077 (2018).

43. Paluck, E. L. Reducing intergroup prejudice and conflict using the media: A field experiment in Rwanda. J. Pers. Soc. Psychol. 96, 574-587 (2009).

44. Schiappa, E., Gregg, P. B. \& Hewes, D. E. The Parasocial Contact Hypothesis. Commun. Monogr. 72, 92-115 (2005).

45. Green, M. C. \& Brock, T. C. The role of transportation in the persuasiveness of public narratives. J. Pers. Soc. Psychol. 79, 701-721 (2000).

46. van Laer, T., de Ruyter, K., Visconti, L. M. \& Wetzels, M. The Extended TransportationImagery Model: A Meta-Analysis of the Antecedents and Consequences of Consumers'

Narrative Transportation. J. Consum. Res. 40, 797-817 (2014).

47. Nabi, R. L. \& Green, M. C. The Role of a Narrative's Emotional Flow in Promoting Persuasive Outcomes. Media Psychol. 18, 137-162 (2015).

48. Rickard, L. N., Yang, J. Z., Liu, S. \& Boze, T. Fish Tales: How Narrative Modality, Emotion, and Transportation Influence Support for Sustainable Aquaculture. Sci. Commun. 43, 252-275 (2021).

49. Batson, C. D., Chang, J., Orr, R. \& Rowland, J. Empathy, Attitudes, and Action: Can Feeling for a Member of a Stigmatized Group Motivate One to Help the Group? Pers. Soc. Psychol. Bull. 28, 1656-1666 (2002).

50. Johnson, D. R., Jasper, D. M., Griffin, S. \& Huffman, B. L. Reading Narrative Fiction Reduces Arab-Muslim Prejudice and Offers a Safe Haven From Intergroup Anxiety. Soc. Cogn. 31, 578-598 (2013).

51. Hart, P. S. \& Leiserowitz, A. A. Finding the Teachable Moment: An Analysis of Information-Seeking Behavior on Global Warming Related Websites during the Release of The Day After Tomorrow. Environ. Commun. 3, 355-366 (2009).

52. Slater, M. D. Reinforcing Spirals: The Mutual Influence of Media Selectivity and Media Effects and Their Impact on Individual Behavior and Social Identity. Commun. Theory 17, 281303 (2007).

53. Luong, K. T., Moyer-Gusé, E. \& McKnight, J. Let's Go to the Movies...for Science!: The Impact of Entertainment Narratives on Science Knowledge, Interest, and InformationSeeking Intention. J. Media Psychol. 32, 200-215 (2020).

54. Amodio, D. M., Devine, P. G. \& Harmon-Jones, E. A Dynamic Model of Guilt: Implications for Motivation and Self-Regulation in the Context of Prejudice. Psychol. Sci. 18, 524-530 (2007).

55. Monteith, M. J. Self-regulation of prejudiced responses: Implications for progress in prejudice-reduction efforts. J. Pers. Soc. Psychol. 65, 469-485 (1993).

56. Kupor, D., Jia, J. \& Tormala, Z. Change Appeals: How Referencing Change Boosts Curiosity and Promotes Persuasion. Pers. Soc. Psychol. Bull. 47, 691-704 (2021).

57. Sawicki, V. et al. Feeling Conflicted and Seeking Information: When Ambivalence Enhances and Diminishes Selective Exposure to Attitude-Consistent Information. Pers. Soc. Psychol. Bull. 39, 735-747 (2013). 
58. Niederdeppe, J. et al. Examining the Dimensions of Cancer-Related Information Seeking and Scanning Behavior. Health Commun. 22, 153-167 (2007).

59. Shim, M., Kelly, B. \& Hornik, R. Cancer Information Scanning and Seeking Behavior is Associated with Knowledge, Lifestyle Choices, and Screening. J. Health Commun. 11, 157-172 (2006).

60. Ramírez, A. S. et al. Information Seeking From Media and Family/Friends Increases the Likelihood of Engaging in Healthy Lifestyle Behaviors. J. Health Commun. 18, 527-542 (2013). 61. Pietri, E. S. et al. Using Video to Increase Gender Bias Literacy Toward Women in Science. Psychol. Women Q. 41, 175-196 (2017).

62. Hennes, E. P. et al. Increasing the perceived malleability of gender bias using a modified Video Intervention for Diversity in STEM (VIDS). Group Process. Intergroup Relat. 21, 788809 (2018).

63. Moss-Racusin, C. A. et al. Reducing STEM gender bias with VIDS (video interventions for diversity in STEM). J. Exp. Psychol. Appl. 24, 236-260 (2018).

64. Wang, K., Stroebe, K. \& Dovidio, J. F. Stigma consciousness and prejudice ambiguity: Can it be adaptive to perceive the world as biased? Personal. Individ. Differ. 53, 241-245 (2012).

65. Stidhum, T. Exclusive Clip from PBS NOVA's 'Picture a Scientist' Film. The Root https://www.theroot.com/pbs-novas-picture-a-scientist-exclusive-clip-being-a-b-1846672382 (2021).

66. Curtin, N., Stewart, A. J. \& Cole, E. R. Challenging the Status Quo: The Role of Intersectional Awareness in Activism for Social Change and Pro-Social Intergroup Attitudes. Psychol. Women Q. 39, 512-529 (2015). 


\section{Methods}

The Institutional Review Board at Indiana University approved the protocols for both Study 1 and Study 2. All participants consented to take part in the studies before beginning the surveys. Data files, codebooks, syntax files, and word documents of the Qualtrics surveys are available on the Study 1's Open Science Framework page: https://osf.io/45c8y/?view_only=a81c2c26acef470db84ac2e3f0fd2b4b and Study 2's Open Science Framework page: https://osf.io/tyuxj/?view_only=a264b9682efc42c3aa2dfa2828aec2b0

As part of the surveys sent out to participants in Study 1 and 2, there were items and indices related to separate research questions/studies (i.e., how the documentary impacts belonging). Analyses from these items will be part of a different manuscript. Critically, no measures or outcomes reported in the current paper will be included in any other manuscript or publication.

\section{Study 1}

\section{Participants}

"Picture a Scientist" screenings were hosted at universities and organizations across multiple countries, and individuals who signed up for these viewings were sent emails inviting them to participate in the current research study. Participants also were recruited through the "Picture a Scientist" social media pages (i.e., Twitter and Facebook). In total, 2779 participants completed the full time 1 survey. To ensure participants had watched film, we included easy film memory questions (see below for questions). We excluded 23 participants who did not pass this attention check, leaving a final total of 2756 participants. We did not have a target number of participants but rather had a pre-determined stopping date for the time 1 survey. We ran a power sensitivity analysis with this sample size using $\mathrm{G}^{*}$ Power $^{1}$ and looking at an analysis with 9 
control predictor variables and one primary predictor (i.e., the partial correlations we ran for time 1 variables controlling for demographic characteristics). This analyses revealed we were adequately powered to find a small effect $\left(f^{2}=0.007, R^{2}\right.$-change $\left.=0.007\right)$ at $p<.008$ and $95 \%$ power.

The racial composition of this final group of participants was: 2006 White (72.7\%), 58 (2.1\%) Black/African American, 195 (7.1\%) Latinx, 142 (5.1\%) East Asian, 113 (4.1\%) South Asian, 5 (0.2\%) Southwest Asian, 44 (1.6\%) Middle Eastern, 3 (0.1\%) Native Hawaiian/Pacific Islander, 3 (0.1\%) American Indian/Native American/Alaska Native/Indigenous, 128 (4.6\%) Multiracial, 49 (1.8\%) other, $12(0.4 \%)$ did not answer. We also had 2347 who identified as female (85.1\%), 374 who identified as male (13.6\%), 31 who identified as Other $(1.1 \%)$, and 6 who did not answer (0.2\%). There were 814 (29.5\%) participants who identified as students, and 1994 (70.5\%) were not students. Among participants who were not students, 1186 (43.0\%) worked in a university, and $758(27.5 \%)$ were not employed by a university. For participants who worked in a university or company, 589 (21.4\%) reported being in a leadership position, and $1233(44.7 \%)$ were not in a leadership role. Of participants who were students or worked in a university or company, $2393(86.8 \%)$ were in a STEM field or major, and $244(8.8 \%)$ were not in a STEM field. Finally, the age range for participants was $18-86(M=38.8, S D=13.79)$. (Additional demographic information about participants is available in Supplementary Table 24.)

\section{Procedure and Measures (time 1)}

All participants in the current study watched "Picture a Scientist." This one-hour and 43minute documentary film follows the stories of three female scientists facing inequitable treatment and harassment in their respective STEM fields. Scattered throughout the film are interviews with prominent researchers studying bias and discrimination in STEM. Thus, viewers 
watch emotionally evocative stories while also learning about the research related to this mistreatment. Participants either watched the film via their professional societies/organizations (762, 27.6\%), through their university or college (1501, 54.4\%), through their company (457, $16.6 \%)$ or did not indicate how they viewed the film $(38,1.4 \%)$.

The email invitation and the information provided at the beginning of the study described this study as being interested in participants' "reactions to the film, as well as [participants'] plans for future and specific actions inspired by the film." We noted that "[t]he results from this survey will help us identify the positive impact of this film and explore how reactions to films may influence beneficial changes in behaviour." All participants completed the study measures on a personal device, using the Qualtrics Survey platform. Participants began the survey by answering a subset of demographic questions, which influenced which questions Qualtrics would display throughout the survey. These initial demographic questions included whether or not participants were a student, worked in a university or organization, and were in a leadership position. (Participants also answered more general demographic questions at the end of the time 1 survey, including questions related to their gender, race/ethnicity, and age.)

Participants next completed the measures assessing their film engagement (i.e., anger, sadness, empathy, knowledge, transportation, and perspective-taking) and indicated their awareness of gender bias in the sciences and self-efficacy to combat gender bias after watching the documentary. The survey then asked participants to reflect on their future actions after watching the documentary, and participants completed the behavioural intention measures.

In Supplementary Table 25, we present detailed measure information from Study 1. We modified past measures assessing anger, sadness, and empathy from previous research looking at the influence of emotional reactions on attitudes and behaviour ${ }^{2,3,4}$. We also altered previous 
indices of transportation and perspective-taking from studies testing the impact of engaging stories and media ${ }^{5,6}$. Moreover, researchers have employed similar emotions, transportation, and perspective-taking measures in VIDS (Video Intervention for Diversity in STEM) experiments ${ }^{6,8}$. Finally, we took the knowledge measure from earlier VIDS work ${ }^{8}$.

We used shortened versions of the awareness of gender bias in sciences and self-efficacy measures from past VIDS research ${ }^{9,7,8}$. Additionally, the behavioural intentions indices also were modified from previous VIDS work ${ }^{7}$. The film team for "Picture a Scientist" provided screening hosts with a list of potential actions steps for viewers after watching the film. This list highlighted organizations working to address gender disparities in STEM and bystander interventions trainings. Thus, some of our behavioural intention items were directly related to supporting these organizations and participating in/implementing the suggested trainings.

To ensure participants had watched and remembered the documentary, at the end of the survey, participants answered three easy multiple-choice memory check questions (e.g., "Of the three main people whose stories were featured in the film: a) all three were male, b) two were female, one was male, c) all three were female [correct answer]." Using similar criteria from previous research ${ }^{7,8}$, we excluded participants if they failed to answer 2 out of the 3 easy questions. Of note, we added these questions into the survey after we posted the survey on social media. Forty-three participants, who took part in online screenings and received the study email invitation, completed the survey before we added these questions. Because these participants were associated with specific screenings, we retained them in the sample.

Finally, we asked participants whether they were willing to participate in the follow-up survey. If participants agreed, we asked them to provide their preferred email addresses. We had 2181 participants $(79.1 \%)$ agree to complete this second and provided their email information. 
(If participants did not agree to take part in the second survey, we directed them to the study debriefing.) Among these 2181, 1,362 (62.4\% of those who agreed to complete the survey and $49.6 \%$ of the full sample) completed the time 2 survey. Participants who were contacted but chose not to complete the second survey did not vary systematically across time 1 measures (see Supplementary Table 26 for these analyses). We ran a second power sensitivity analysis with the time 2 sample for an analysis with 10 control predictor variables and 1 primary predictor (i.e., the partial correlations we conducted between time 2 behavioural intentions and film engagement controlling for demographic variables and time 1 intentions). We found that we were adequately powered to find a small effect $\left(f^{2}=0.01, R^{2}\right.$-change $\left.=0.01\right)$ at $p<.008$ and $95 \%$ power.

\section{Procedure and Measures (Time 2)}

We emailed participants, who opted-in to the follow-up survey, a link to the time 2 survey approximately six weeks after the time 1 survey. Participants completed the same film engagement measures and behavioural intention measures from time 1.

In addition to indicating behavioural intentions, participants also reported whether they did various behaviours since watching the documentary film. To examine whether participants confronted bias, we first asked participants whether they had witnessed an instance of sexism. Among participants who completed the time 2 survey, 867 said they did not see an example of bias. An additional 105 participants indicated learning about a situation involving sexism but were not physically present during the event (i.e., saw it on T.V., learn about bias after it occurred). Thus, 383 participants were physically present for an instance of mistreatment. We asked these participants, "Did you confront or say something to the perpetrator of bias?" ("Yes" or "No"). 
For all remaining behaviours reported in results, participants could choose from 6 options $1=$ Yes, I did this behaviour, 2 = Yes, I did this behaviour, but I also did this behaviour before the film, $3=$ No, I did not do this behaviour, $4=$ No, but I have done this behaviour before the film, $5=$ No, but I plan to do this behaviour in the future, $6=$ Not Applicable. We created two indices of past behaviours. Specifically, we measured whether participants did a new behaviour after watching the film or selected "Yes, I did this behaviour." We also assessed whether participants did any behaviour after the film (i.e., a new or old behaviour) or selected "Yes, I did this behaviour" or "Yes, I did this behaviour, but I also did this behaviour before the film." We created two dichotomous scores indexing whether participants completed any new behaviour (1 $=$ did at least one new behaviour, $0=\operatorname{did}$ not do a new behaviour) and whether they did any (i.e., new or old) behaviour ( $1=$ did at least one behaviour, $0=$ did not do a behaviour). See Supplementary Table 27 for additional details about the past behaviour measures.

\section{Study 2}

\section{Participants}

Similar to Study 1, we invited individuals who registered for viewings of the documentary to participate in the current study. We also advertised the study through the "Picture a Scientist" social media pages. New to Study 2, individuals who had signed up to watch, but had not yet viewed the film, were sent an email invitation to participate in the current research, and we encouraged them to complete the survey before they watched the film. Finally, we also advertised the survey during a panel event hosted by Scientific American, which discussed the topics featured in the documentary. We had 1257 participants complete the full time 1 survey. We excluded two participants for failing the easy memory attention check items, leaving a final sample of 1255 participants. Similar to Study 1, we did not have a target number 
of participants but instead had a pre-determined stopping date for the time 1 survey, which we specified in our preregistration. We ran a power sensitivity analysis with our final sample size using $\mathrm{G}^{*}$ Power $^{1}$. We found that we were adequately powered to find a small effect $(d=0.26)$ for a between-subjects $t$-test at $p<.006$ and $95 \%$ power.

The racial composition of this final group of participants was: 915 White (72.9\%), 33 (2.6\%) Black/African American, 102 (8.1\%) Latinx, 62 (4.9\%) East Asian, 51 (4.1\%) South Asian, 1 (0.1\%) Southwest Asian, 18 (1.4\%) Middle Eastern, 3 (0.2\%) Native Hawaiian/Pacific Islander, $1(0.1 \%)$ American Indian/Native American/Alaska Native/Indigenous, 45 (1.8\%) Multiracial, $23(1.8 \%)$ other, $1(0.1 \%)$ did not answer. We also had 1081 participants who identified as female (86.1\%), 156 who identified as male (12.4\%), 18 who identified as Other (1.4\%). There were $324(25.8 \%)$ participants who identified as students, and 931 (74.2\%) were not students. Among those who did not identify as students, 529 (42.2\%) worked in a university, and $402(32.0 \%)$ were not employed by a university. For participants working in a university or company, $302(24.1 \%)$ reported being in a leadership position, and $580(46.2 \%)$ were not in a leadership role. Among participants who were students or worked in a university or company, $1066(84.9 \%)$ were in a STEM field or major, and $140(11.2 \%)$ were not in a STEM field. The age range for participants was $18-86(M=38.8, S D=13.79)$. (Additional demographic information about participants is available in Supplementary Table 28.)

New to Study 2, we also collected data on participants' current country of residence. The majority of participants resided in the U.S.A. (901, 71.8\%); however, participants reported being from an additional 43 countries/U.S.A. territories. The complete list of countries is available in Supplementary Table 29.

Procedure and Measures (Time 1) 
Similar to Study 1, participants completed study measures on personal devices using the Qualtrics Survey platform. The survey also was described as having the goal of helping to "identify the positive impact of this film and explor[ing] how reactions to films may influence beneficial changes in behaviour." The survey began by asking participants whether they had watched "Picture a Scientist" (833 [66.4\%] had watched the film, 422 [33.6\%] had not yet seen the film). We also asked participants to indicate how they had watched or planned to view the documentary. We found that $298(23.7 \%)$ had/planned to watch through their professional societies/organizations, 677 (53.9\%) had/planned to watch via their universities/colleges, 247 (19.7\%) had/planned to watch through their companies $(247,19.7 \%)$, and $33(2.6 \%)$ did not indicate how they had/planned to watch the film. Among those who had watched the film, we asked how long ago they had viewed the documentary and found that 471 (56.5\%) had watched "Picture a Scientist" within the past month ago, and 361 (43.3\%) had viewed the film over a month ago (1 person did not answer this question). Because we recruited participants via the Scientific American Panel, we also asked participants whether they had attended this panel (433 [34.5\%] had watched the panel, $822[65.5 \%]$ had not watched the panel). Using the same procedure as Study 1, participants then completed a series of demographic questions to determine which behavioural intentions items they would see later in the study.

Participants who indicated watching the film completed the same measures from Study 1 assessing film engagement. Moreover, using the same assessments from Study 1, all participants completed indices examining their general awareness of gender bias in the sciences, their feelings of self-efficacy to combated gender, and their behavioural intentions. We present detailed measure information in Supplementary Table 30. 
At the end of the survey, participants who already view "Picture a Scientist" completed the easy memory attention check questions from Study 1, and we again excluded participants who failed to answer at least two questions correctly. The survey ended by asking participants whether they were willing to participate in the follow-up survey, and if they agreed, they provided their email addresses. Participants who were not interested in completing the second survey were shown the study debriefing. There were 1126 participants who chose to take part in the time 2 survey, and provided their email information. Among these 1126 participants, 671 (59.6\% who agreed to complete the survey and $53.5 \%$ of the full sample) completed the time 2 survey. (Participants who were emailed the second survey, but choose not to complete it, did not vary systematically across time 1 measures; see Supplementary Table 31 for these analyses).

\section{Procedure and Measures (Time 1)}

We emailed participants, who opted-in to the follow-up survey, a link to the time 2 survey approximately 2-3 weeks after the first survey. For our time 2 analyses, we were specifically interested in changes among participants who watched the film between time 1 and

time 2 . We had 240 (35.8\% of time 2 participants) watched the documentary between time 1 and 2. Of these participants, 237 (98.8\%) passed the memory attention questions for the film. Participants who indicated watching the documentary completed the same film engagement measures and memory questions from time 1 . In addition, all participants completed the same awareness of bias, self-efficacy, and behavioural intentions measures from time 1. 


\section{Method References}

1. Faul, F., Erdfelder, E., Lang, A.-G. \& Buchner, A. G*Power 3: A flexible statistical power analysis program for the social, behavioral, and biomedical sciences. Behavior Research Methods 39, 175-191 (2007).

2. Okimoto, T. G. \& Brescoll, V. L. The Price of Power: Power Seeking and Backlash Against Female Politicians. Pers Soc Psychol Bull 36, 923-936 (2010).

3. Wang, K., Stroebe, K. \& Dovidio, J. F. Stigma consciousness and prejudice ambiguity: Can it be adaptive to perceive the world as biased? Personality and Individual Differences 53, 241245 (2012).

4. Batson, C. D., Early, S. \& Salvarani, G. Perspective Taking: Imagining How Another Feels Versus Imaging How You Would Feel. Pers Soc Psychol Bull 23, 751-758 (1997).

5. Green, M. C. \& Brock, T. C. The role of transportation in the persuasiveness of public narratives. Journal of Personality and Social Psychology 79, 701-721 (2000).

6. Cohen, J. Defining Identification: A Theoretical Look at the Identification of Audiences With Media Characters. Mass Communication and Society 4, 245-264 (2001).

7. Moss-Racusin, C. A. et al. Reducing STEM gender bias with VIDS (video interventions for diversity in STEM). Journal of Experimental Psychology: Applied 24, 236-260 (2018).

8. Pietri, E. S. et al. Using Video to Increase Gender Bias Literacy Toward Women in Science. Psychology of Women Quarterly 41, 175-196 (2017).

9. Hennes, E. P. et al. Increasing the perceived malleability of gender bias using a modified Video Intervention for Diversity in STEM (VIDS). Group Processes \& Intergroup Relations 21, 788-809 (2018). 


\section{Supplementary Results}

\section{Detailed Correlations, Chi-Square tests with Demographic Variables, and Regression Analyses from Study 1}

Supplementary Table 1. The relationship between reporting doing a behaviour (new or old) between time 1 and time 2 and behavioural intentions measured at time 1

\begin{tabular}{|c|c|c|}
\hline Measures & & avioural intentions \\
\hline \multirow{3}{*}{$\begin{array}{c}\text { Confront } \\
\text { sexism (if see saw it) } \\
\left(\mathrm{Yes}=1, \mathrm{No}_{0}=0\right)\end{array}$} & $r$ & .18 \\
\hline & $p$ & $<.001^{*}$ \\
\hline & $n$ & 383 \\
\hline \multirow{3}{*}{$\begin{array}{l}\text { Did a seek information behaviour } \\
\left(\text { Yes }=1, \mathrm{No}_{0}\right)\end{array}$} & $r$ & .38 \\
\hline & $p$ & $<.001^{*}$ \\
\hline & $n$ & 1333 \\
\hline \multirow{3}{*}{$\begin{array}{l}\text { Did a donate behaviour } \\
\quad\left(\text { Yes }=1, \mathrm{No}_{0}=0\right)\end{array}$} & $r$ & .33 \\
\hline & $p$ & $<.001^{*}$ \\
\hline & $n$ & 1321 \\
\hline \multirow{3}{*}{$\begin{array}{c}\text { Did a supporting minoritize student } \\
\text { behaviour } \\
\left(\text { Yes }=1, \mathrm{No}_{0}=0\right)\end{array}$} & $r$ & .16 \\
\hline & $p$ & $<.001^{*}$ \\
\hline & $n$ & 593 \\
\hline \multirow{3}{*}{$\begin{array}{c}\text { Did a positive climate } \\
\text { behaviours } \\
\left(\text { Yes }=1, \mathrm{No}^{\prime}=0\right)\end{array}$} & $r$ & .25 \\
\hline & $p$ & $<.001^{*}$ \\
\hline & $n$ & 737 \\
\hline \multirow{3}{*}{$\begin{array}{c}\text { Did a positive leaders } \\
\text { Behaviours } \\
\left(\mathrm{Yes}=1, \mathrm{No}^{\prime}=0\right)\end{array}$} & $r$ & .22 \\
\hline & $p$ & $.003^{*}$ \\
\hline & $n$ & 190 \\
\hline
\end{tabular}

Supplementary Table 2. Chi-Square tests examining whether seeking out information between time 1 and 2 varied by demographic variables

\begin{tabular}{|c|c|c|c|c|c|}
\hline $\begin{array}{l}\text { Demographic } \\
\text { variable }\end{array}$ & Did not seek more info & $\begin{array}{l}\text { Seeking out info behaviour } \\
\text { (Yes, No) }\end{array}$ & $\chi^{2}$ & $d f, N$ & $p$ \\
\hline Gender & $\begin{array}{l}\text { Male }=51 ; \text { Female }=354 \\
\quad \text { Selected other }=2\end{array}$ & $\begin{array}{l}\text { Male }=114 ; \text { Female }=798 \\
\quad \text { Selected other }=15\end{array}$ & 2.86 & 2,1334 & .240 \\
\hline Race & $\begin{array}{c}\text { White }=298 ; \\
\text { Black/Latinx/Ingenious = 33; } \\
\text { Asian = 49; Multiracial/Other }= \\
24\end{array}$ & $\begin{array}{c}\text { White }=298 ; \\
\text { Black } / \text { Latinx } / \text { Ingenious }=33 ; \\
\begin{array}{c}\text { Asian }=49 ; \\
=24 \\
=24 \text { tiracial/Other }\end{array}\end{array}$ & 6.15 & 3,1329 & .105 \\
\hline $\begin{array}{l}\text { STEM Field } \\
\text { (Yes, No) }\end{array}$ & $\mathrm{No}=33 ; \mathrm{Yes}=356$ & $\mathrm{No}=67 ; \mathrm{Yes}=829$ & 0.38 & 1,896 & .536 \\
\hline $\begin{array}{l}\text { Leader } \\
\text { (Yes, No) }\end{array}$ & $\mathrm{No}=199 ; \mathrm{Yes}=50$ & $\mathrm{No}=400 ; \mathrm{Yes}=190$ & 12.60 & 1,839 & $<.001$ \\
\hline $\begin{array}{l}\text { Student } \\
\text { (Yes, No) }\end{array}$ & $\mathrm{No}=268 ; \mathrm{Yes}=140$ & $\mathrm{No}=622 ; \mathrm{Yes}=305$ & 0.24 & 1,927 & .614 \\
\hline $\begin{array}{l}\text { Work at a } \\
\text { university } \\
\text { (Yes, No) }\end{array}$ & $\mathrm{No}=118 ; \mathrm{Yes}=150$ & $\mathrm{No}=240 ; \mathrm{Yes}=382$ & 2.31 & 1,622 & .129 \\
\hline
\end{tabular}


Supplementary Table 3. Seeking new information predicting time 2 outcomes (controlling for time 1 assessments and demographic variables)

\begin{tabular}{|c|c|c|c|c|c|c|c|c|}
\hline \multirow[t]{2}{*}{ Measures } & \multirow{2}{*}{$\begin{array}{c}R^{2-} \\
\text { changed }\end{array}$} & \multirow[t]{2}{*}{$b$} & \multicolumn{2}{|c|}{$95 \% \mathrm{CI}$} & \multirow[t]{2}{*}{$S E$} & \multirow[t]{2}{*}{$t$} & \multirow[t]{2}{*}{$d f_{s}$} & \multirow[t]{2}{*}{$p$} \\
\hline & & & UB & LB & & & & \\
\hline $\begin{array}{c}\text { Awareness of gender } \\
\text { bias }\end{array}$ & 0.014 & 0.21 & 0.18 & 0.29 & 0.04 & 4.93 & 1331 & $<.001 *$ \\
\hline Self-efficacy & 0.002 & 0.11 & -0.01 & 0.22 & 0.06 & 1.88 & 1331 & .061 \\
\hline Confront Intentions & $<0.001$ & -0.01 & -0.09 & 0.08 & 0.04 & -0.11 & 1310 & 912 \\
\hline Donate Intentions & 0.012 & 0.29 & 0.17 & 0.41 & 0.06 & 4.70 & 1304 & $<.001 *$ \\
\hline $\begin{array}{c}\text { Supporting } \\
\text { minoritized student } \\
\text { behaviours }\end{array}$ & 0.013 & 0.18 & 0.08 & 0.29 & 0.05 & 3.37 & 640 & $.001 *$ \\
\hline $\begin{array}{l}\text { Positive Climate } \\
\text { Behaviours }\end{array}$ & 0.013 & 0.28 & 0.13 & 0.44 & 0.08 & 3.62 & 716 & $<.001 *$ \\
\hline $\begin{array}{l}\text { Leadership } \\
\text { Behaviours }{ }^{1}\end{array}$ & 0.009 & 0.23 & -0.09 & 0.54 & 0.16 & 1.41 & 180 & .160 \\
\hline
\end{tabular}

Note. Bolded outcomes $=$ significant at $p \leq .007$ Bonferroni corrected value. We control for whether participants identified as a leader because being a leader significantly related to reporting seeking additional information.

${ }^{1}$ Only completed by leaders, and thus, we did not control for leader versus non-leader 
Detailed Chi-Square tests with Demographic Variables, T-test, and ANOVA Results from Study 2

Supplementary Table 4. Between-subjects t-test between participants had watched and not watched the film before time 1

\begin{tabular}{|c|c|c|c|c|c|c|c|c|c|c|c|}
\hline \multirow[t]{2}{*}{ Measure } & \multicolumn{2}{|c|}{$\begin{array}{l}\text { Watch film } \\
(n=813)\end{array}$} & \multicolumn{2}{|c|}{$\begin{array}{c}\text { Did not watch film } \\
\quad(n=1943)\end{array}$} & \multirow[b]{2}{*}{$\begin{array}{l}\text { Mean difference } \\
\text { (standard error) }\end{array}$} & \multicolumn{2}{|c|}{$95 \% \mathrm{C} 1$} & \multirow[b]{2}{*}{$t$-value } & \multirow[b]{2}{*}{$d f$} & \multirow[b]{2}{*}{$p$-value } & \multirow[b]{2}{*}{ Cohen's $d$} \\
\hline & $\mathrm{M}$ & SD & $\mathrm{M}$ & SD & & UB & LB & & & & \\
\hline $\begin{array}{c}\text { Aware of gender } \\
\text { bias }\end{array}$ & 6.47 & 0.66 & 6.00 & 1.07 & $0.47(0.05)$ & 0.37 & 0.57 & 9.60 & 1253 & $<.001 *$ & 0.53 \\
\hline Self-efficacy & 4.87 & 1.27 & 5.05 & 1.27 & $-0.18(0.08)$ & -0.33 & -0.03 & 2.40 & 1252 & .016 & -0.14 \\
\hline $\begin{array}{l}\text { Confront } \\
\text { intentions }\end{array}$ & 6.02 & 0.79 & 5.91 & 0.89 & $0.11(0.05)$ & 0.01 & 0.20 & 2.20 & 1252 & .028 & 0.13 \\
\hline $\begin{array}{l}\text { Seek information } \\
\text { intentions }\end{array}$ & 5.61 & 1.02 & 5.24 & 1.18 & $0.38(0.06)$ & 0.25 & 0.50 & 5.88 & 1249 & $<.001 *$ & 0.34 \\
\hline Donate intentions & 4.71 & 1.27 & 4.41 & 1.42 & $0.31(0.08)$ & 0.25 & 0.50 & 3.88 & 1248 & $<.001 *$ & 0.22 \\
\hline $\begin{array}{l}\text { Supporting } \\
\text { minorized } \\
\text { students }^{1}\end{array}$ & 6.25 & 0.85 & 6.12 & 0.91 & $0.13(0.08)$ & -0.02 & 0.28 & 1.69 & 627 & .091 & 0.15 \\
\hline $\begin{array}{l}\text { Positive climate } \\
\text { behaviours }^{2}\end{array}$ & 6.01 & 1.01 & 5.57 & 1.27 & $0.43(0.08)$ & 0.26 & 0.60 & 5.41 & 850 & $<.001 *$ & 0.38 \\
\hline $\begin{array}{l}\text { Leadership } \\
\text { behaviours }^{3}\end{array}$ & 6.05 & 0.89 & 5.62 & 1.12 & $0.42(0.12)$ & 0.19 & 0.66 & 3.57 & 294 & $<.001 *$ & 0.43 \\
\hline
\end{tabular}

Note: Bolded outcome measures $=$ significant at $p \leq .006$ Bonferroni corrected value

${ }^{1}$ Only participants who worked with students completed this measure (Watched the film: 456; Not watched the film: 173)

${ }^{2}$ Only participants employed at University or company completed this measure (Watched the film: 571; Not watched the film: 281

${ }^{3}$ Only leaders completed this measure (Watched the film: 189; Not watch the film: 107) 
Supplementary Table 5. Chi-Square tests examining whether watching the film versus not varied by demographic variables

\begin{tabular}{|c|c|c|c|c|c|}
\hline $\begin{array}{l}\text { Demographic } \\
\text { variable }\end{array}$ & Did not watch the film & Watched the film & $\chi^{2}$ & $d f, N$ & $p$ \\
\hline Gender & $\begin{array}{l}\text { Male }=75 ; \text { Female }=342 \\
\quad \text { Selected other }=5\end{array}$ & $\begin{array}{l}\text { Male }=81 ; \text { Female }=739 \\
\quad \text { Selected other }=13\end{array}$ & 16.79 & 2,1255 & $<.001$ \\
\hline Race & $\begin{array}{c}\text { White }=309 ; \\
\text { Black/Latinx/Ingenious }=48 ; \\
\begin{array}{c}\text { Asian }=41 ; \text { Multiracial/Other } \\
=23\end{array}\end{array}$ & $\begin{array}{c}\text { White = 606; } \\
\text { Black/Latinx/Ingenious = 91; } \\
\text { Asian = 91; Multiracial/Other }= \\
45\end{array}$ & 0.45 & 3,1254 & .930 \\
\hline $\begin{array}{c}\text { Leader } \\
\text { (Yes, No) }\end{array}$ & $\mathrm{No}=179 ; \mathrm{Yes}=109$ & $\mathrm{No}=401 ; \mathrm{Yes}=193$ & 2.47 & 1,882 & .116 \\
\hline $\begin{array}{l}\text { STEM Field } \\
\text { (Yes, No) }\end{array}$ & $\mathrm{No}=55 ; \mathrm{Yes}=345$ & $\mathrm{No}=85 ; \mathrm{Yes}=721$ & 2.68 & 1,806 & .102 \\
\hline $\begin{array}{l}\text { Student } \\
\text { (Yes, No) }\end{array}$ & No $=310 ;$ Yes $=112$ & $\mathrm{No}=621 ; \mathrm{Yes}=212$ & 0.17 & 1,1255 & .677 \\
\hline $\begin{array}{l}\text { Work at a } \\
\text { university } \\
\text { (Yes, No) }\end{array}$ & $\mathrm{No}=169 ; \mathrm{Yes}=141$ & $\mathrm{No}=233 ; \mathrm{Yes}=388$ & 24.35 & 1,931 & $<.001$ \\
\hline
\end{tabular}

Supplementary Table 6. Effect of watching the film versus not watching the film controlling for gender and working at university

\begin{tabular}{ccccccccc}
\hline Outcome & $R^{2-}$ & $b$ & \multicolumn{2}{c}{$95 \% \mathrm{CI}$} & $S E$ & $t$ & $d f$ & $p$ \\
& changed & & $\mathrm{UB}$ & $\mathrm{UB}$ & & & & \\
\hline Bias Awareness & 0.051 & 0.41 & 0.32 & 0.51 & 0.05 & 8.49 & 1250 & $<.001^{*}$ \\
$\quad$ Self-efficacy & 0.002 & -0.11 & -0.26 & 0.04 & 0.08 & -1.43 & 1249 & .152 \\
$\begin{array}{c}\text { Confront Intentions } \\
\text { Donate Intentions }\end{array}$ & 0.005 & 0.12 & 0.03 & 0.22 & 0.05 & 2.46 & 1249 & .014 \\
$\begin{array}{c}\text { Seeking information } \\
\text { intentions }\end{array}$ & 0.025 & 0.29 & 0.14 & 0.45 & 0.08 & 3.67 & 1246 & $<.001^{*}$ \\
$\begin{array}{c}\text { Supporting minoritized } \\
\quad \text { student }\end{array}$ & 0.003 & 0.11 & -0.04 & 0.27 & 0.08 & 1.47 & 624 & .142 \\
$\begin{array}{c}\text { Positive Climate } \\
\text { Behaviours }\end{array}$ & 0.027 & 0.40 & 0.24 & 0.56 & 0.08 & 4.85 & 847 & $<.001^{*}$ \\
Leadership Behaviours & 0.019 & 0.30 & 0.06 & 0.53 & 0.12 & 2.48 & 291 & .014 \\
\hline
\end{tabular}

Note. Bolded outcome measures $=$ significant at $p \leq .006$ Bonferroni corrected value. For this analyses we controlled for gender, dummy coded (with men as the reference group) and whether participants worked in a university $(1=$ worked in a university, $0=$ did not work in a university). 
Supplementary Table 7. Between-subject ANOVA results looking the effects of watching the film and time since watching the film

\begin{tabular}{|c|c|c|c|c|c|c|c|c|c|c|}
\hline \multirow[t]{2}{*}{ Measures } & \multicolumn{2}{|c|}{$\begin{array}{c}\text { Did not watch film } \\
\quad n=422\end{array}$} & \multicolumn{2}{|c|}{$\begin{array}{c}\text { Watched film less } 1 \\
\text { month } \\
n=471\end{array}$} & \multicolumn{2}{|c|}{$\begin{array}{c}\text { Watch film over } 1 \\
\text { month } \\
n=361\end{array}$} & \multicolumn{4}{|c|}{ Film effect } \\
\hline & $\mathrm{M}$ & SD & $\mathrm{M}$ & SD & $\mathrm{M}$ & $\mathrm{SD}$ & $F$ & $d f_{S}$ & $p$ & $\eta_{p}^{2}$ \\
\hline Aware of gender bias & $6.00_{a}$ & 1.07 & $6.48 \mathrm{~b}$ & 0.64 & $6.46 \mathrm{~b}$ & 0.67 & 46.70 & 2,1251 & $<.001$ & .069 \\
\hline Self-efficacy & 5.05 & 1.27 & 4.86 & 1.30 & 4.87 & 1.24 & 2.89 & 2,1250 & .056 & .005 \\
\hline Confront intentions & $5.91 \mathrm{a}$ & 0.89 & $5.99_{\mathrm{ab}}$ & 0.80 & $6.07 \mathrm{~b}$ & 0.76 & 3.33 & 2,1250 & .036 & .005 \\
\hline $\begin{array}{l}\text { Seek information } \\
\text { intentions }\end{array}$ & $5.24 \mathrm{a}$ & 1.16 & $5.54 \mathrm{~b}$ & 1.05 & $5.71_{b}$ & 0.96 & 20.11 & 2,1247 & $<.001$ & .031 \\
\hline Donate intentions & $4.41_{\mathrm{a}}$ & 1.42 & $4.63 \mathrm{~b}$ & 1.32 & $4.82 \mathrm{~b}$ & 1.21 & 9.66 & 2,1246 & $<.001$ & .015 \\
\hline $\begin{array}{l}\text { Supporting minoritized } \\
\text { students }{ }^{1}\end{array}$ & $6.12 \mathrm{a}$ & 0.91 & $6.22 \mathrm{a}$ & 0.94 & $6.29 \mathrm{a}$ & 0.74 & 1.72 & 2,625 & .179 & .005 \\
\hline $\begin{array}{c}\text { Positive climate } \\
\text { behaviours }^{2}\end{array}$ & $5.57 \mathrm{a}$ & 1.27 & $5.98 \mathrm{~b}$ & 1.00 & $6.04 \mathrm{~b}$ & 1.02 & 14.87 & 2,849 & $<.001$ & .034 \\
\hline $\begin{array}{l}\text { Leadership } \\
\text { behaviours }^{3}\end{array}$ & $5.62 \mathrm{a}$ & 1.12 & $5.93 \mathrm{ab}$ & 0.93 & $6.20 \mathrm{~b}$ & 0.81 & 8.11 & 2,293 & $<.001$ & .052 \\
\hline
\end{tabular}

Note. Bolded measures indicated a significant effect of film. Within each row, means with shared subscripts are not significantly different using a Bonferroni correction for multiple contrasts.

${ }^{1}$ Only participants who worked with students completed this measure (Did not watch film: 173; Less than 1 month: 252; Over 1 month: 203)

${ }^{2}$ Only participants employed at a University or company completed this measure (Did not watch film: 281; Less than 1 month: 332; Over 1 month: 239)

${ }^{3}$ Only leaders completed this measure (Did not watch film: 107; Less than 1 month: 108; Over 1 month: 81) 
Supplementary Table 8. Mixed-model ANOVA results for participants who watched the film between time 1 and 2

\begin{tabular}{|c|c|c|c|c|c|c|c|c|c|c|c|c|}
\hline \multirow{3}{*}{ Measures } & \multicolumn{6}{|c|}{$\begin{array}{l}\text { Watched film at time } 1 \\
\qquad(n=96)\end{array}$} & \multicolumn{6}{|c|}{$\begin{array}{l}\text { Did not watch film at time } 1 \\
\qquad(n=141)\end{array}$} \\
\hline & \multicolumn{2}{|c|}{ Time 1} & \multicolumn{2}{|c|}{ Time 2} & \multicolumn{2}{|c|}{ Time 1 vs. Time 2} & \multicolumn{2}{|c|}{ Time 1} & \multicolumn{2}{|c|}{ Time 1} & \multicolumn{2}{|c|}{ Time 1 vs. Time 2} \\
\hline & $\mathrm{M}$ & SD & $\mathrm{M}$ & SD & $d$ & $p$ & $\mathrm{M}$ & SD & $\mathrm{M}$ & SD & $d$ & $p$ \\
\hline Aware of gender bias & 6.47 & 0.68 & 6.46 & 0.59 & 0.02 & .881 & 5.96 & 1.12 & 6.32 & 0.95 & 0.36 & $<.001$ \\
\hline Self-efficacy & 4.78 & 1.36 & 4.98 & 1.25 & 0.19 & .092 & 4.88 & 1.24 & 4.98 & 1.24 & 0.08 & .330 \\
\hline Confront intentions & 6.10 & 0.83 & 5.95 & 0.84 & 0.26 & .023 & 5.93 & 0.89 & 6.15 & 0.71 & 0.35 & $<.001$ \\
\hline $\begin{array}{l}\text { Seek information } \\
\text { intentions }\end{array}$ & 5.68 & 1.04 & 5.55 & 1.04 & 0.21 & .102 & 5.09 & 1.27 & 5.17 & 1.28 & 0.09 & .222 \\
\hline Donate intentions & 4.90 & 1.30 & 4.85 & 1.22 & 0.07 & .660 & 4.26 & 1.50 & 4.23 & 1.48 & 0.03 & .649 \\
\hline $\begin{array}{l}\text { Supporting minoritized } \\
\text { students }{ }^{1}\end{array}$ & 6.35 & 0.72 & 6.46 & 0.66 & 0.14 & .303 & 6.21 & 0.79 & 6.28 & 1.05 & 0.07 & .502 \\
\hline $\begin{array}{l}\text { Positive climate } \\
\text { behaviours }^{2}\end{array}$ & 6.23 & 0.79 & 6.04 & 0.89 & 0.27 & .074 & 5.40 & 1.30 & 5.62 & 1.30 & 0.23 & .017 \\
\hline Leadership behaviours ${ }^{3}$ & 6.18 & 0.75 & 5.91 & 0.99 & 0.35 & .247 & 5.33 & 1.20 & 5.58 & 0.99 & 0.82 & .209 \\
\hline \multicolumn{13}{|c|}{ ANOVA results } \\
\hline \multirow[t]{2}{*}{ Measures } & \multicolumn{4}{|c|}{ Time } & \multicolumn{4}{|c|}{ Did not watch film vs. watched film } & \multicolumn{4}{|c|}{ Time x Film } \\
\hline & $F$ & $d f_{S}$ & $p$ & $\eta p^{2}$ & $F$ & $d f_{S}$ & $p$ & $\eta_{p}^{2}$ & $F$ & $d f_{S}$ & $p$ & $\eta_{p}^{2}$ \\
\hline Aware of gender bias & 9.35 & 1,235 & .002 & .038 & 9.72 & 1,235 & .002 & .040 & 10.83 & 1,235 & .001 & .044 \\
\hline Self-efficacy & 3.70 & 1,235 & .056 & .016 & 0.09 & 1,235 & .759 & $<.001$ & 0.47 & 1,235 & .496 & .002 \\
\hline Confront intentions & 0.81 & 1,235 & .370 & .003 & 0.02 & 1,235 & .887 & $<.001$ & 19.55 & 1,235 & $<.001$ & .077 \\
\hline $\begin{array}{l}\text { Seek information } \\
\text { intentions }\end{array}$ & 0.23 & 1,234 & .629 & .001 & 10.59 & 1,234 & .001 & .043 & 4.18 & 1,234 & .042 & .018 \\
\hline Donate intentions & 0.40 & 1,234 & .529 & .002 & 13.04 & 1,234 & $<.001$ & .053 & 0.00 & 1,234 & .961 & $<.001$ \\
\hline $\begin{array}{l}\text { Supporting minoritized } \\
\text { students }{ }^{1}\end{array}$ & 1.44 & 1,94 & .233 & .015 & 1.23 & 1,94 & .270 & .013 & 0.05 & 1,94 & .828 & .001 \\
\hline $\begin{array}{l}\text { Positive climate } \\
\text { behaviours }^{2}\end{array}$ & 0.04 & 1,149 & .833 & $<.001$ & 13.07 & 1,149 & $<.001$ & .081 & 8.65 & 1,149 & .004 & .055 \\
\hline Leadership behaviours ${ }^{3}$ & 0.01 & 1,37 & .933 & $<.001$ & 4.00 & 1,37 & .053 & .098 & 2.97 & 1,37 & .093 & .074 \\
\hline
\end{tabular}

Note. Bolded Outcome measures = significant interactions

${ }^{1}$ Only participants who worked with students completed this measure (Watched the film at time 1: 45; Not watched the film at time 1: 51)

${ }^{2}$ Only participants employed at University or company completed this measure (Watched the film at time 1: 64; Not watched the film at time 1: 87)

${ }^{3}$ Only leaders completed this measure (Watched the film at time 1: 16; Not watched the film at time 1:23) 


\section{Examining how reactions to the film, awareness of bias, self-efficacy, and behavioural intentions differed by demographic variables in Study 1}

We first explored whether reactions to the film, awareness of gender bias in the sciences and self-efficacy to address gender bias varied by demographic variables (see Supplementary Tables 8 and 9). Of note, for leaders versus non-leaders, we focused on participants who reported working in a university or company and compared those who indicated they were in a leadership position to those who reported not being in a leadership role. For STEM versus non-STEM profession or major, we focused on participants who reported working in a university, company, or being a student and compared those who indicated working/majoring in a STEM field to those who reported not working/majoring in a STEM field.

Compared to non-leaders, participants who indicated being in a leadership role reported higher anger, transportation, perspective-taking, and self-efficacy. Participants in a STEM field indicated higher feelings of sadness and lower empathy than participants not in a STEM field. Students reported lower empathy, transportation, and perspective-taking than non-students. However, compared to non-students, students were more likely to feel knowledgeable and indicated higher self-efficacy to address bias. Finally, participants who worked in a university felt less knowledgeable after watching the film than those who did not work in a university (see Supplementary Table 9).

We also examined whether reactions to the film, awareness of bias and self-efficacy varied by gender and race (see Supplementary Table 10). There was a significant effect of gender on all of the outcomes, except for empathy. Compared to men, women felt more angry, sad, and transported while watching the film. Moreover, women and participants who selected other for their gender identity indicated higher perspective-taking and awareness of gender bias than men. 
At the same time, men reported feeling more knowledgeable about gender bias research and facts after watching the film and indicated higher self-efficacy to address bias.

There was a main effect of race on feeling transported and knowledgeable, awareness of bias, and self-efficacy (see Supplementary Table 10). Asian participants indicated feeling more transported and more knowledgeable compared to White and multiracial participants and lower awareness of bias than the other three racial groups. Black/Latinx/Indigenous participants indicated higher feelings of self-efficacy than White and multiracial participants. Asian participants also reported higher self-efficacy than multiracial participants.

Supplementary Table 9. Correlations between film engagement, bias awareness, self-efficacy, and demographic variables in Study 1

\begin{tabular}{|c|c|c|c|c|c|}
\hline Measures & & $\begin{array}{l}\text { Leader position } \\
(1=\text { Yes; } 0=\text { No })\end{array}$ & $\begin{array}{c}\text { STEM profession } \\
\text { or major } \\
(1=\text { Yes; } 0=\mathrm{No})\end{array}$ & $\begin{array}{c}\text { Student } \\
(1=\text { Yes; } 0=\text { No })\end{array}$ & $\begin{array}{c}\text { Works in a } \\
\text { university } \\
(1=\text { Yes; } 0=\mathrm{No})\end{array}$ \\
\hline \multirow[t]{3}{*}{ Anger } & $r$ & .07 & -.03 & -.06 & -.03 \\
\hline & $p$ & .002 & .092 & .002 & .222 \\
\hline & $n$ & 1821 & 2635 & 2756 & 1943 \\
\hline \multirow[t]{3}{*}{ Depressed } & $r$ & -.02 & .06 & -.05 & .07 \\
\hline & $p$ & .419 & .002 & .017 & .001 \\
\hline & $n$ & 1821 & 2635 & 2756 & 1943 \\
\hline \multirow[t]{3}{*}{ Empathy } & $r$ & .05 & -.06 & -.08 & .01 \\
\hline & $p$ & .026 & .004 & .000 & .827 \\
\hline & $n$ & 1822 & 2636 & 2757 & 1944 \\
\hline \multirow[t]{3}{*}{ Transport } & $r$ & .10 & -.01 & -.06 & .01 \\
\hline & $p$ & .000 & .626 & .002 & .790 \\
\hline & $n$ & 1822 & 2637 & 2758 & 1944 \\
\hline \multirow[t]{3}{*}{ Knowledge } & $r$ & .02 & -.05 & .14 & -.09 \\
\hline & $p$ & .486 & .019 & .000 & .000 \\
\hline & $n$ & 1822 & 2637 & 2758 & 1944 \\
\hline \multirow[t]{3}{*}{ Perspective } & $r$ & .07 & .00 & -.08 & -.01 \\
\hline & $p$ & .005 & .831 & .000 & .588 \\
\hline & $n$ & 1822 & 2637 & 2758 & 1944 \\
\hline \multirow[t]{3}{*}{ Bias aware } & $r$ & .04 & .01 & .00 & .00 \\
\hline & $p$ & .066 & .603 & .975 & .967 \\
\hline & $n$ & 1822 & 2637 & 2758 & 1944 \\
\hline \multirow[t]{3}{*}{ Self-efficacy } & $r$ & .10 & .03 & .13 & $<.001$ \\
\hline & $p$ & .000 & .099 & $<.001$ & .965 \\
\hline & $n$ & 1822 & 2637 & 2758 & 1944 \\
\hline
\end{tabular}

Note. Bolded correlations $=$ significant at $p<.013$ Bonferroni corrected values 
Supplementary Table 10. Differences between film engagement, bias awareness, and self-efficacy by gender and by race in Study 1

\begin{tabular}{|c|c|c|c|c|c|c|c|c|c|c|c|c|c|}
\hline \multicolumn{14}{|c|}{ Looking at gender } \\
\hline \multirow[t]{2}{*}{ Measures } & \multicolumn{3}{|c|}{$\begin{array}{c}\text { Men } \\
n=374\end{array}$} & \multicolumn{3}{|c|}{$\begin{array}{l}\text { Women } \\
n=2347\end{array}$} & \multicolumn{2}{|c|}{$\begin{array}{c}\text { Selected Other } \\
n=31\end{array}$} & \multicolumn{5}{|c|}{ Gender effect } \\
\hline & $\mathrm{M}$ & & SD & \multicolumn{2}{|c|}{$\mathrm{M}$} & SD & $\mathrm{M}$ & $\mathrm{SD}$ & $F$ & \multicolumn{2}{|c|}{$d f_{s}$} & $p$ & $\eta_{p}^{2}$ \\
\hline Anger & 5.50 & & 1.24 & \multicolumn{2}{|c|}{$5.68 b$} & 1.21 & $5.95 \mathrm{ab}$ & 0.90 & 4.62 & \multicolumn{2}{|c|}{2,2747} & .010 & .003 \\
\hline Sad & 3.96 & & 1.24 & \multicolumn{2}{|c|}{$4.28 b$} & 1.34 & $4.49_{\mathrm{ab}}$ & 1.41 & 9.61 & \multicolumn{2}{|c|}{2,2747} & .000 & .007 \\
\hline Empathy & 6.00 & & 0.82 & \multicolumn{2}{|c|}{$6.07 \mathrm{a}$} & 0.86 & $6.02 \mathrm{a}$ & 0.89 & 1.14 & \multicolumn{2}{|c|}{2,2748} & 321 & .001 \\
\hline Transport & 5.84 & & 0.89 & \multicolumn{2}{|c|}{$6.01_{b}$} & 0.84 & $6.02_{\mathrm{ab}}$ & 0.84 & 6.97 & \multicolumn{2}{|c|}{2,2749} & .001 & .005 \\
\hline Knowledge & 5.98 & & 0.97 & \multicolumn{2}{|c|}{$5.81_{b}$} & 1.11 & $5.58 \mathrm{ab}$ & 1.47 & 4.55 & \multicolumn{2}{|c|}{2,2749} & .011 & .003 \\
\hline Perspective taking & 5.56 & & 0.98 & \multicolumn{2}{|c|}{$6.24 \mathrm{~b}$} & 0.89 & $6.29 \mathrm{~b}$ & 0.63 & 91.55 & \multicolumn{2}{|c|}{2,2749} & .000 & .062 \\
\hline Bias Aware & 6.32 & & 0.82 & \multicolumn{2}{|c|}{$6.55 b$} & 0.68 & $6.69 \mathrm{~b}$ & 0.52 & 18.12 & \multicolumn{2}{|c|}{2,2749} & .000 & .013 \\
\hline Self-efficacy & 5.32 & & 1.04 & \multicolumn{2}{|c|}{$4.72 b$} & 1.30 & $4.76 \mathrm{ab}$ & 1.74 & 35.43 & 2 & & .000 & .025 \\
\hline & & & & & & Lookin & at race & & & & & & \\
\hline Measure & $\begin{array}{l}\mathrm{W} \\
n=\end{array}$ & & & $\begin{array}{r}\text { Blac } \\
\text { Ind } \\
n \\
\end{array}$ & $\begin{array}{l}\operatorname{atinx} / \\
\text { hous } \\
59 \\
\end{array}$ & & $\begin{array}{l}\text { ian } \\
304 \\
\end{array}$ & $\begin{array}{c}\mathrm{Mu} \\
n \\
\end{array}$ & & & Rac & effect & \\
\hline & $\mathrm{M}$ & SD & & $\mathrm{M}$ & SD & $\mathrm{M}$ & SD & $\mathrm{M}$ & SD & $F$ & $d f_{S}$ & $p$ & $\eta_{p}{ }^{2}$ \\
\hline Anger & $5.67 \mathrm{a}$ & 1.18 & & $5.77 \mathrm{a}$ & 1.14 & $5.50 \mathrm{a}$ & 1.36 & $5.63 \mathrm{a}$ & 1.29 & 2.53 & 3,2740 & .056 & .003 \\
\hline Depressed & $4.24_{\mathrm{a}}$ & 1.31 & & $4.09 \mathrm{a}$ & 1.39 & $4.24 a$ & 1.35 & $4.34 \mathrm{a}$ & 1.44 & 1.44 & 3,2740 & .230 & .002 \\
\hline Empathy & $6.06 \mathrm{a}$ & 0.83 & & $6.11_{\mathrm{a}}$ & 0.86 & $6.12_{\mathrm{a}}$ & 0.86 & $5.96 \mathrm{a}$ & 1.03 & 1.54 & 3,2741 & .202 & .002 \\
\hline Transport & $6.02_{\mathrm{a}}$ & 0.81 & & $5.93 \mathrm{ab}$ & 0.95 & $5.80_{b}$ & 0.99 & $6.04 \mathrm{a}$ & 0.86 & 6.47 & 3,2742 & $<.001$ & .007 \\
\hline Knowledge & $5.80_{\mathrm{a}}$ & 1.08 & & $5.92_{\mathrm{ab}}$ & 1.17 & $6.02 \mathrm{~b}$ & 0.98 & $5.67 \mathrm{a}$ & 1.30 & 5.40 & 3,2742 & .001 & .006 \\
\hline Perspective taking & $6.12 \mathrm{a}$ & 0.95 & & $6.25 \mathrm{a}$ & 0.94 & $6.16 \mathrm{a}$ & 0.88 & $6.23 \mathrm{a}$ & 0.86 & 2.17 & 3,2742 & .090 & .002 \\
\hline Bias Aware & $6.54 a$ & 0.68 & & $6.53 \mathrm{a}$ & 0.77 & $6.35 b$ & 0.81 & $6.55 \mathrm{a}$ & 0.73 & 6.83 & 3,2742 & $<.001$ & .007 \\
\hline Self-efficacy & $4.77_{\mathrm{ac}}$ & 1.25 & & $5.11_{b}$ & 1.40 & $4.90_{\mathrm{ab}}$ & 1.31 & $4.55_{\mathrm{c}}$ & 1.50 & 8.41 & 3,2742 & $<.001$ & .009 \\
\hline
\end{tabular}

Note. Bolded measures indicated a significant effect of gender or race. Within each row, means with shared subscripts are not significantly different using a

Bonferroni correction for multiple contrasts. 
We next looked at whether positive behavioural intentions varied by demographic variables (see Supplementary Tables 11 and 12 full results). We found that compared to nonleaders, participants who were in leadership positions indicated higher confrontation intentions, higher likelihood of seeking out new information, higher intentions to donate time or money, and stronger intentions to create a welcoming climate in their organization. We also found that participants working/majoring in a STEM field reported higher intentions to seek out additional information, to donate, and to support minorized students than participants not in a STEM field. Finally, students indicated higher intentions to seek out additional information, donate, and support minoritized students than non-students. (Of note, among our student sample, only graduate students completed the measure assessing intentions to support minoritized students.) There was a main effect of gender on confrontation, donate, and supporting minoritized student intentions. Compared to men, women indicated stronger intentions to donate and support minoritized students but weaker intentions to confront bias. There were also main effects of race on all of the intentions measures, except for confrontation intentions. Black/Latinx/Indigenous and Asian participants indicated higher intentions to seek information and donate time/money than White and Multiracial/other participants. Black/Latinx/Indigenous also reported stronger intentions to support minoritized students and create welcoming climates for women than Multiracial/other participants. There were no significant contrasts between racial groups on leadership behaviours. 
Supplementary Table 11. Correlations between behavioural intentions and demographic variables in Study 1

\begin{tabular}{|c|c|c|c|c|c|}
\hline Measures & & $\begin{array}{l}\text { Leader position } \\
(1=\text { Yes; } 0=\text { No })\end{array}$ & $\begin{array}{c}\text { STEM profession } \\
\text { or major } \\
(1=\text { Yes; } 0=\mathrm{No})\end{array}$ & $\begin{array}{c}\text { Student } \\
(1=\text { Yes; } 0=\mathrm{No})\end{array}$ & $\begin{array}{c}\text { Works in a } \\
\text { university } \\
(1=\text { Yes; } 0=\text { No })\end{array}$ \\
\hline \multirow{3}{*}{ Confront intentions } & $r$ & .16 & -.02 & -.04 & .03 \\
\hline & $p$ & .000 & 267 & .051 & .195 \\
\hline & $n$ & 1820 & 2634 & 2754 & 1941 \\
\hline \multirow{3}{*}{$\begin{array}{l}\text { Seek information } \\
\text { intentions }\end{array}$} & $r$ & .12 & .07 & .06 & .04 \\
\hline & $p$ & .000 & .001 & .001 & .116 \\
\hline & $n$ & 1815 & 2629 & 2749 & 1936 \\
\hline \multirow[t]{3}{*}{ Donate intentions } & $r$ & .09 & .14 & .09 & -.05 \\
\hline & $p$ & .000 & .000 & .000 & .029 \\
\hline & $n$ & 1813 & 2627 & 2747 & 1934 \\
\hline \multirow{3}{*}{$\begin{array}{l}\text { Support minoritized } \\
\text { students behaviours }\end{array}$} & $r$ & .07 & .09 & .08 & $N / A$ \\
\hline & $p$ & .032 & .001 & .003 & \\
\hline & $n$ & 1066 & 1478 & 1478 & \\
\hline \multirow{3}{*}{$\begin{array}{l}\text { Positive Climate } \\
\text { behaviours }\end{array}$} & $r$ & .15 & .03 & $N / A$ & .06 \\
\hline & $p$ & .000 & .212 & & .009 \\
\hline & $n$ & 1686 & 1687 & & 1687 \\
\hline \multirow{3}{*}{$\begin{array}{l}\text { Leadership } \\
\text { behaviours }\end{array}$} & $r$ & $N / A$ & $<.001$ & $N / A$ & .08 \\
\hline & $p$ & & .957 & & .063 \\
\hline & $n$ & & 568 & & 568 \\
\hline
\end{tabular}

Note. Bolded correlations $=$ significant at $p<.013$ Bonferroni corrected values 
Supplementary Table 12. Differences on behavioural indentions by gender and by race in Study 1

\begin{tabular}{|c|c|c|c|c|c|c|c|c|c|c|c|c|}
\hline \multicolumn{13}{|c|}{ Looking at gender } \\
\hline \multirow{2}{*}{ Measures } & \multicolumn{2}{|c|}{$\begin{array}{c}\text { Men } \\
n=372\end{array}$} & \multicolumn{3}{|c|}{$\begin{array}{c}\text { Women } \\
n=2345\end{array}$} & \multicolumn{2}{|c|}{$\begin{array}{l}\text { Selected Other } \\
\quad n=31\end{array}$} & \multicolumn{5}{|c|}{ Gender effect } \\
\hline & $\mathrm{M}$ & $\mathrm{SD}$ & \multicolumn{2}{|c|}{$\mathrm{M}$} & SD & $\mathrm{M}$ & SD & $F$ & $d f_{s}$ & \multicolumn{2}{|r|}{$p$} & $\eta_{p}^{2}$ \\
\hline Confront intentions & $6.35 \mathrm{a}$ & 0.63 & \multicolumn{2}{|c|}{$6.13 b$} & 0.81 & $6.32 \mathrm{ab}$ & 0.70 & 13.20 & 2,2745 & \multicolumn{2}{|r|}{.000} & .010 \\
\hline Seek information intentions & $5.19 \mathrm{a}$ & 1.11 & \multicolumn{2}{|c|}{$5.34 \mathrm{a}$} & 1.13 & $5.31_{\mathrm{a}}$ & 1.41 & 2.84 & 2,2740 & \multicolumn{2}{|r|}{.059} & .002 \\
\hline Donate intentions & $3.91_{\mathrm{a}}$ & 1.29 & \multicolumn{2}{|c|}{$4.62 b$} & 1.27 & $4.29 \mathrm{ab}$ & 1.30 & 49.91 & 2,2738 & \multicolumn{2}{|r|}{.000} & .035 \\
\hline $\begin{array}{c}\text { Support minoritized students } \\
\text { behaviours } 1\end{array}$ & $6.04 \mathrm{a}$ & 0.91 & \multicolumn{2}{|c|}{$6.28 \mathrm{~b}$} & 0.86 & $6.33_{\mathrm{ab}}$ & 1.59 & 6.94 & 2,1470 & \multicolumn{2}{|r|}{.001} & .009 \\
\hline Positive Climate behaviours ${ }^{2}$ & $5.86 \mathrm{a}$ & 1.08 & \multicolumn{2}{|c|}{$5.99 \mathrm{a}$} & 1.08 & $6.32 \mathrm{a}$ & 0.87 & 2.00 & 2,1679 & \multicolumn{2}{|r|}{.135} & .002 \\
\hline Leadership behaviours $^{3}$ & $5.75 \mathrm{a}$ & 1.12 & & & 0.99 & $6.06 \mathrm{a}$ & 0.84 & 1.02 & 2,565 & & .362 & .004 \\
\hline & & & & & ooking at & race & & & & & & \\
\hline Measure & $\begin{array}{r}\text { Wh } \\
n=2 \\
\end{array}$ & & $\begin{array}{r}\text { Black } \\
\text { Indi } \\
n\end{array}$ & $\begin{array}{l}\text { atinx/ } \\
\text { hous } \\
65 \\
\end{array}$ & & $\begin{array}{l}\text { sian } \\
=321 \\
\end{array}$ & $\begin{array}{r}\text { Multir } \\
\qquad n\end{array}$ & 1/other & & Rac & e effect & \\
\hline & $\mathrm{M}$ & $\mathrm{SD}$ & $\mathrm{M}$ & SD & $\mathrm{M}$ & $\mathrm{SD}$ & $\mathrm{M}$ & SD & $F$ & $d f_{S}$ & $p$ & $\eta_{p}^{2}$ \\
\hline Confront intentions & $6.18 \mathrm{a}$ & 0.75 & $6.19 \mathrm{a}$ & 0.89 & $6.09 \mathrm{a}$ & 0.88 & $6.06 \mathrm{a}$ & 0.93 & 2.20 & 2733 & .086 & .002 \\
\hline Seek information intentions & $5.26 \mathrm{a}$ & 0.75 & $5.61 \mathrm{~b}$ & 0.89 & $5.55 \mathrm{~b}$ & 0.88 & $5.05 \mathrm{a}$ & 0.93 & 14.90 & 2733 & .000 & .016 \\
\hline Donate intentions & $4.42 \mathrm{a}$ & 1.31 & $4.84 b$ & 1.29 & $4.89 \mathrm{~b}$ & 1.11 & $4.49 \mathrm{a}$ & 1.34 & 17.32 & 2732 & .000 & .019 \\
\hline $\begin{array}{c}\text { Support minoritized } \\
\text { students behaviours }\end{array}$ & $6.21_{\mathrm{ab}}$ & 0.86 & $6.40 \mathrm{a}$ & 0.85 & $6.39 \mathrm{a}$ & 0.90 & $6.07 \mathrm{~b}$ & 1.25 & 4.32 & 1466 & .005 & .009 \\
\hline Positive Climate behaviours $^{5}$ & $5.95_{\mathrm{ab}}$ & 1.08 & $6.15 \mathrm{a}$ & 1.01 & $6.07 \mathrm{ab}$ & 1.00 & $5.76_{b}$ & 1.27 & 3.12 & 1675 & .025 & .006 \\
\hline Leadership behaviours $^{6}$ & $5.85 \mathrm{a}$ & 1.00 & $6.16_{\mathrm{a}}$ & 0.94 & $6.24_{\mathrm{a}}$ & 0.78 & $5.79 \mathrm{a}$ & 1.27 & 2.78 & 559 & .041 & .015 \\
\hline
\end{tabular}

Note. Bolded measures indicated a significant effect of gender or race. Within each row, means with shared subscripts are not significantly different using a

Bonferroni correction for multiple contrasts.

${ }^{1}$ Only completed by participants who work with students $(\mathrm{Men}=218$, Women $=1241$, Selected other $=14)$;

${ }^{2}$ Only completed by participants who work in a university or company $($ Men $=241$, Women $=1430$, Selected other $=11)$

${ }^{3}$ Only completed by leaders $($ Men $=86$, Women $=476$, Selected other $=6)$

${ }^{4}$ Only completed by participants who work with students $($ White $=1096$, Black/Latinx/Indigenous $=130$, Asian $=158 ;$ Multiracial/Other $=86)$

${ }^{5}$ Only completed by participants who work in a university or company $($ White $=1291$, Black/Latinx/Indigenous $=149$, Asian $=144 ;$ Multiracial/Other $=95$

${ }^{6}$ Only completed by leaders $($ White $=458$, Black/Latinx/Indigenous $=44$, Asian $=32 ;$ Multiracial/Other $=29$ ) 
Examining how reactions to the film, awareness of bias, self-efficacy, and behavioural intentions differed by demographic variables in Study 2

Similar to Study 1, we first explored whether reactions to the film (measured at time 1) varied by demographic variables (see Supplementary Table 13 and 14). Similar to Study 1, students felt more knowledgeable than non-students after watching the film. Compared to nonstudents, students also indicated feeling less sad while watching the film (see Supplementary Table 13). We also found that women could more easily take the perspective of the women in the documentary than man (see Supplementary Table 14). We did not find any other significant relationships. We see similar patterns as in Study 1 (e.g., leaders indicate feeling more transported than non-leaders, students felt less anger than non-students); however, these effects did not reach significance at the Bonferroni corrected value.

Supplementary Table 13. Correlations between film engagement and demographic variables in Study 2

\begin{tabular}{|c|c|c|c|c|c|}
\hline Measures & & $\begin{array}{l}\text { Leader position } \\
(1=\text { Yes; } 0=\text { No })\end{array}$ & $\begin{array}{l}\text { STEM profession } \\
\text { or major } \\
(1=\text { Yes; } 0=\mathrm{No})\end{array}$ & $\begin{array}{c}\text { Student } \\
(1=\text { Yes } ; 0=\text { No })\end{array}$ & $\begin{array}{c}\text { Works in a } \\
\text { university } \\
(1=\text { Yes; } 0=\mathrm{No})\end{array}$ \\
\hline \multirow[t]{3}{*}{ Anger } & $r$ & .02 & -.04 & -.08 & -.01 \\
\hline & $p$ & .608 & .247 & .026 & .722 \\
\hline & $n$ & 594 & 806 & 833 & 621 \\
\hline \multirow[t]{3}{*}{ Sad } & $r$ & -.11 & .02 & -.12 & .09 \\
\hline & $p$ & .009 & .656 & .001 & .024 \\
\hline & $n$ & 594 & 806 & 833 & 621 \\
\hline \multirow[t]{3}{*}{ Empathy } & $r$ & .01 & -.06 & -.07 & -.04 \\
\hline & $p$ & .883 & .078 & .050 & .339 \\
\hline & $n$ & 594 & 806 & 833 & 621 \\
\hline \multirow[t]{3}{*}{ Transport } & $r$ & .09 & -.01 & -.08 & -.03 \\
\hline & $p$ & .034 & .791 & .029 & .406 \\
\hline & $n$ & 594 & 806 & 833 & 621 \\
\hline \multirow[t]{3}{*}{ Knowledge } & $r$ & -.05 & -.07 & .13 & -.05 \\
\hline & $p$ & .236 & .062 & $<.001$ & .206 \\
\hline & $n$ & 594 & 806 & 833 & 621 \\
\hline \multirow[t]{3}{*}{ Perspective } & $r$ & .03 & .06 & -.05 & .04 \\
\hline & $p$ & .427 & .107 & .186 & .274 \\
\hline & $n$ & 594 & 806 & 833 & 621 \\
\hline
\end{tabular}

Note: Bolded correlations $=$ significant at $p \leq .008$ Bonferroni corrected value 
Supplementary Table 14. Differences between film engagement by gender and by race in Study 2

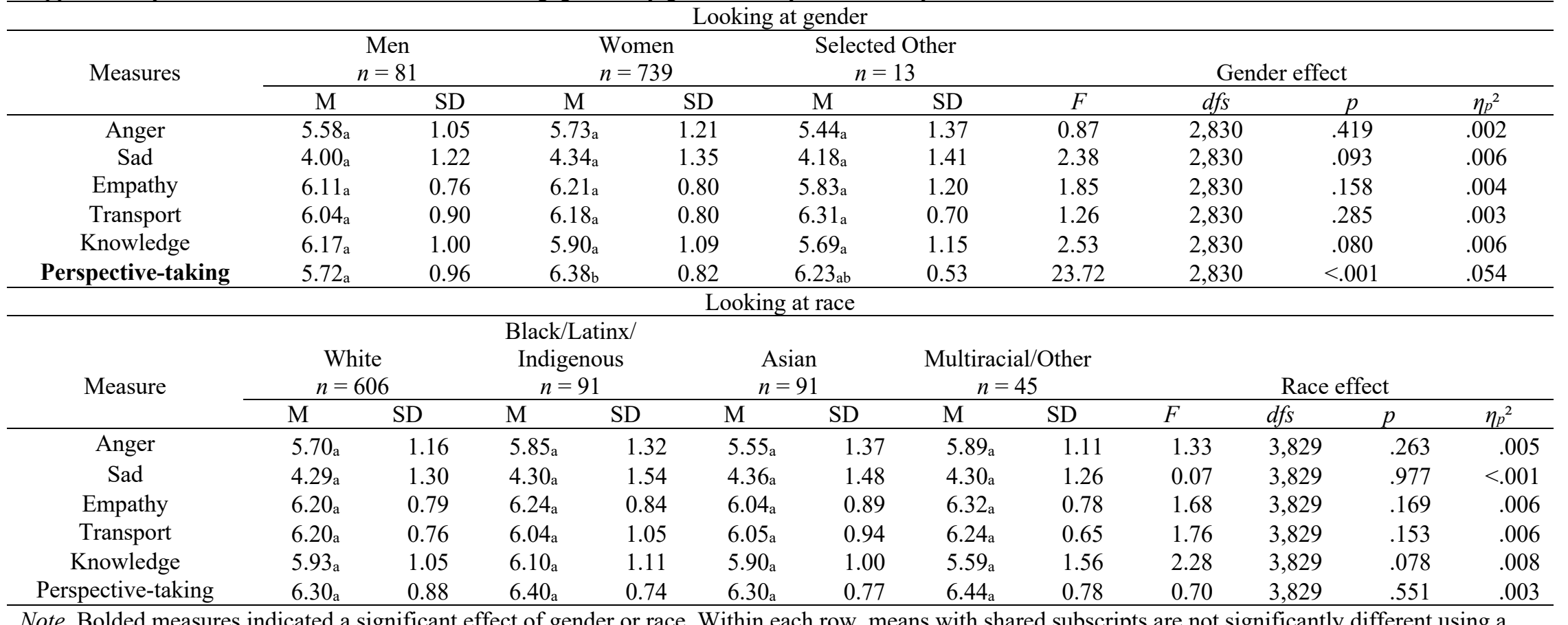

Note. Bolded measures indicated a significant effect of gender or race. Within each row, means with shared subscripts are not significantly different using a

Bonferroni correction for multiple contrasts. 
We also tested whether watching the film at time 1 interacted with demographic variables to predict awareness of gender bias in the sciences, self-efficacy to address bias, and behavioural intentions. We present these findings in Supplementary Tables 15-19.

There was a significant interaction with gender predicting awareness of gender bias in the sciences $(p<.001)$. Both female $(p<.001)$ and male $(p<.001)$ participants indicated higher awareness of gender bias when they had watched the film relative to not watching the film (see Supplementary Table 15). Although in the same direction, this difference was not significant among participants who selected other $(p=.403)$, possibly due to the low number of participants who chose other in our sample. There was also a significant interaction with race predicting awareness of gender bias $(p=.012$; see Supplementary Table 16). Compared to not watching the film, watching the film related to higher awareness of gender bias among White participants $(p<$ $.001)$, Black/Latinx/Ingenious participants $(p<.001)$, and Multiracial/other participants $(p<$ $.001)$. This effect was in the same direction for Asian participants but did not reach significant ( $p$ $=.090)$.

There were significant interactions with working/majoring in a STEM field versus not being in a STEM field predicting seeking information intentions $(p=.026)$ and supporting minoritized students intentions ( $p=.006$; see Supplementary Table 17). The interactions for selfefficacy $(p=.051)$ and donation intentions $(p=.053)$ did not reach significance but showed a similar pattern of results, and thus, we also probed these interactions. Among participants in a STEM field, those who watched the film had higher information-seeking intentions $(p<.001)$, donation intentions $(p<.001)$, and supporting minoritized students intentions $(p=.013)$. In contrast, among participants not in a STEM field, there was no effect of watching the film on intentions to seek information $(p=.846)$ or donate $(p=.508)$. Interestingly, participants not in a 
STEM field reported lower self-efficacy $(p=.008)$ and lower intentions to support minoritized students $(p=.048)$ when they had watched the film versus not watched the film. In contrast, watching the film did not affect STEM participants' self-efficacy $(p=.134)$. This pattern of results suggests that the film may have been particularly beneficial among participants who were in a STEM field. Indeed, the film's content (i.e., sexism and harassment in STEM) was most relevant to participants working in STEM fields and STEM majors.

Finally, there was a significant interaction with participants who were employed by a university versus not employed by a university (i.e., either worked at a company or were not currently employed) predicting intentions to seek out information ( $p=.005$; see Supplementary Table 19). Participants who were not part of a university intended to seek out more information after watching the film versus not watching the film $(p<.001)$. Although this effect was in the same direction, it was not significant among participants employed in a university $(p=.109)$. 
Supplementary Table 15. Differences between watching versus not watching the film by gender in Study 1

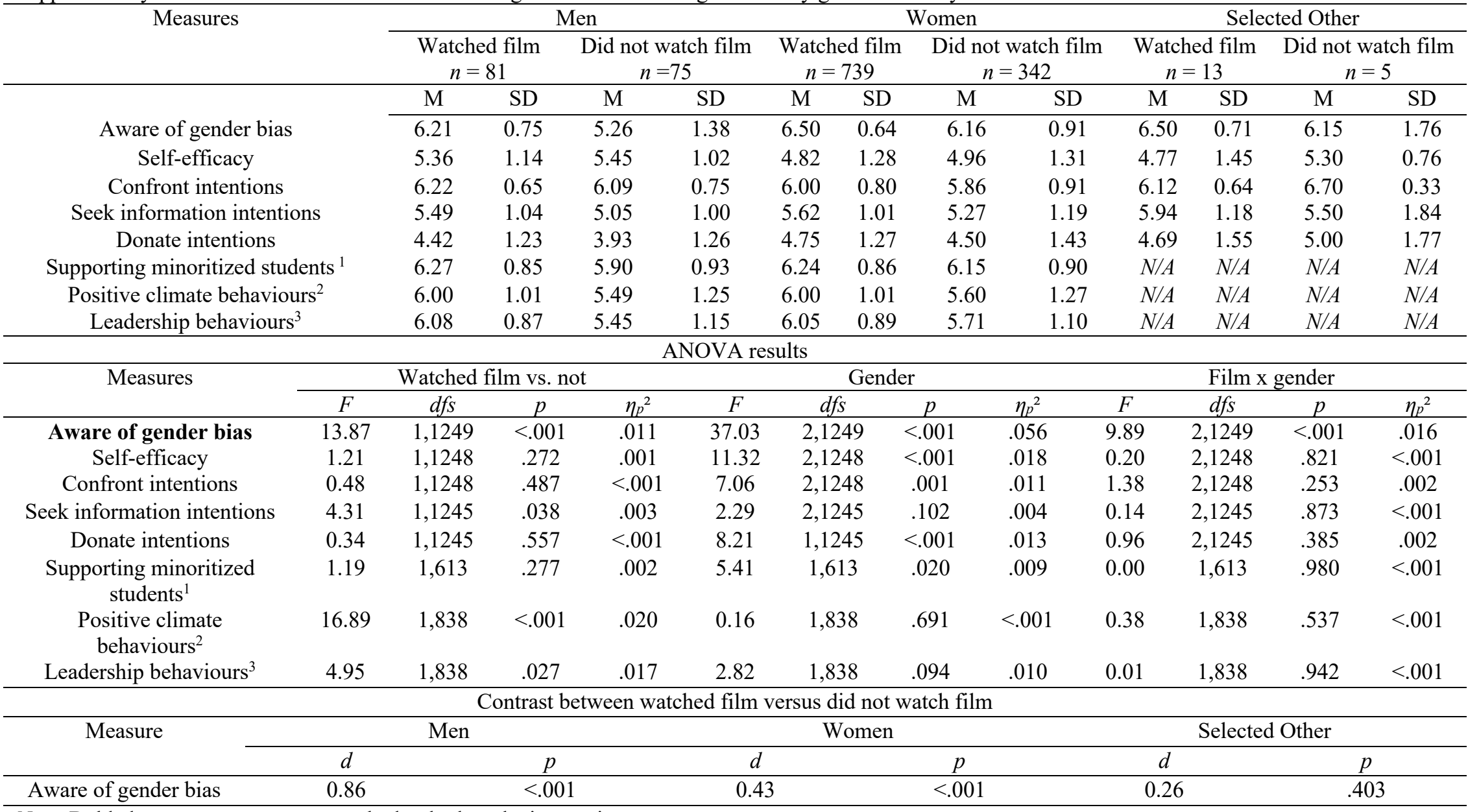

Note. Bolded measures $=$ measures probed to look at the interaction

${ }^{1}$ Only participants who worked with students completed this measure (Men: Watched the film: 47, Not watched the film: 30; Women: Watched the film: 400,

Not watched the film: 1400; we did not include participants who selected Other because cells were less than 5)

${ }^{2}$ Only participants employed at University or company completed this measure (Men: Watched the film: 58, Not watched the film: 52; Women: Watched the film: 505, Not watched the film: 227; we did not include participants who selected other because cells were less than 5)

${ }^{3}$ Only leaders completed this measure (Men: Watched the film: 19, Not watched the film: 28; Women: Watched the film: 169, Not watched the film: 78; we did not include participants who selected other because cells were less than 5) 
Supplementary Table 16. Differences between watching versus not watching the film by race in Study 2

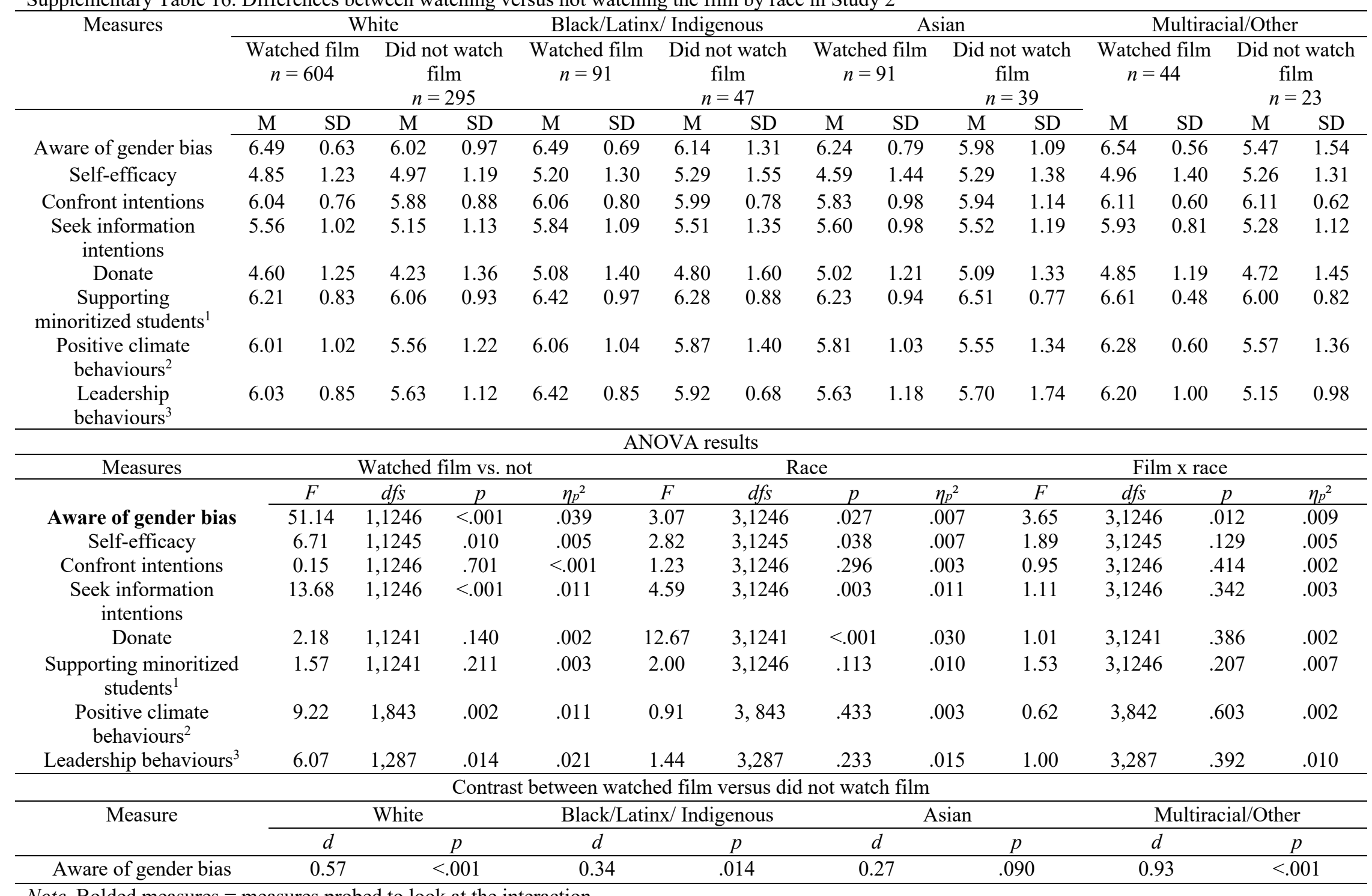

Note. Bolded measures $=$ measures probed to look at the interaction

${ }^{1}$ Only participants who worked with students completed this measure (White: Watched the film: 336, Not watched the film: 126; Black/Latinx/Indigenous:

Watched the film: 54, Not watched the film: 22; Asian: Watched the film: 45, Not watched the film: 13; Multiracial/Other: Watched the film: 21, Not

watched the film: 12) 
${ }^{2}$ Only participants employed at University or company completed this (White: Watched the film: 453, Not watched the film: 218; Black/Latinx/Indigenous: Watched the film: 46, Not watched the film: 23; Asian: Watched the film: 45, Not watched the film: 20; Multiracial/Other: Watched the film: 27, Not watched the film: 19)

${ }^{3}$ Only leaders completed this measure (White: Watched the film: 149, Not watched the film: 79; Black/Latinx/Indigenous: Watched the film: 17, Not watched the film: 12; Asian: Watched the film: 13, Not watched the film: 8; Multiracial/Other: Watched the film: 10, Not watched the film: 7)

Supplementary Table 16. Differences between watching versus not watching the film by leaders versus non-leaders in Study 2

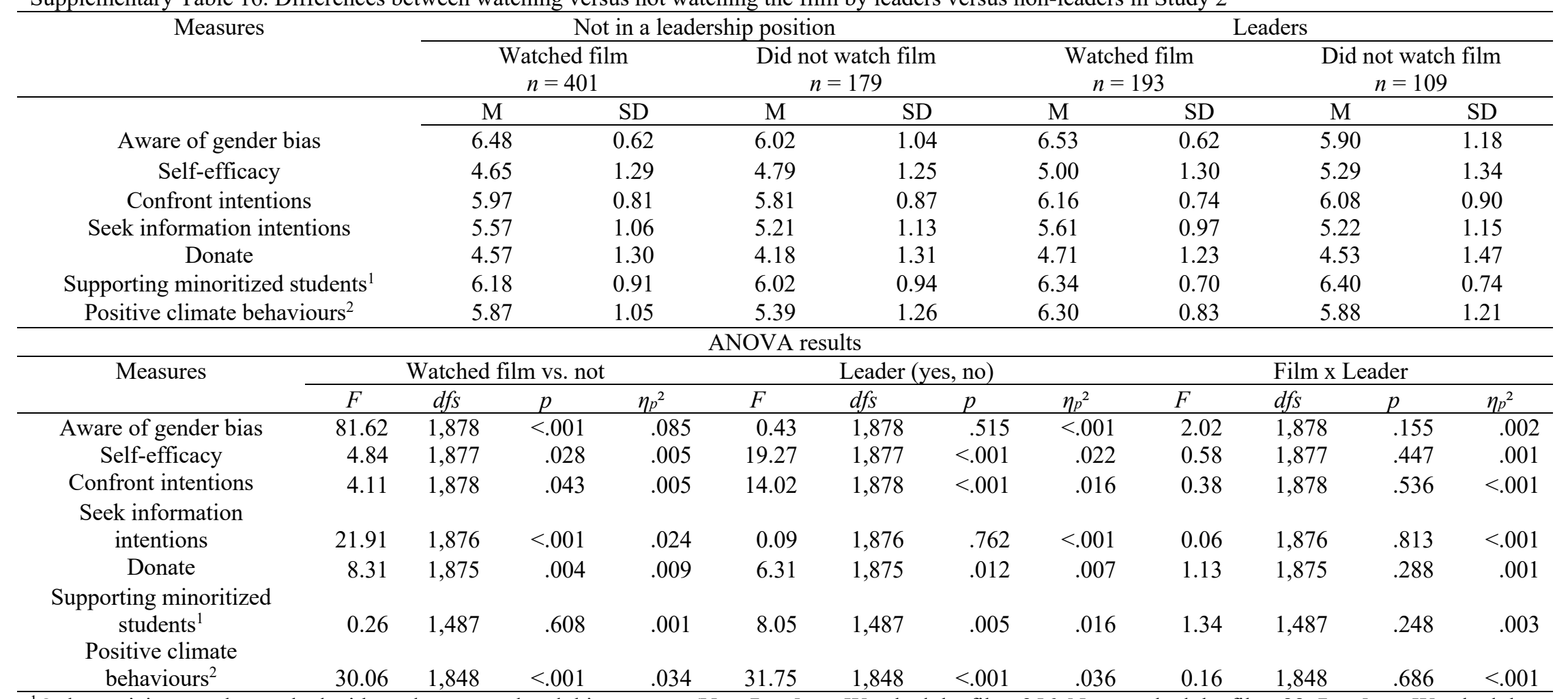

${ }^{1}$ Only participants who worked with students completed this measure (Non-Leaders: Watched the film: 256, Not watched the film: 88; Leaders: Watched the film: 105, Not watched the film: 42)

${ }^{2}$ Only participants employed at University or company completed this (Non-Leaders: Watched the film: 385, Not watched the film: 174; Leaders: Watched the film: 186, Not watched the film: 107) 
Supplementary Table 17. Differences between watching versus not watching the film by participants in STEM versus not in STEM fields/majors in Study 2

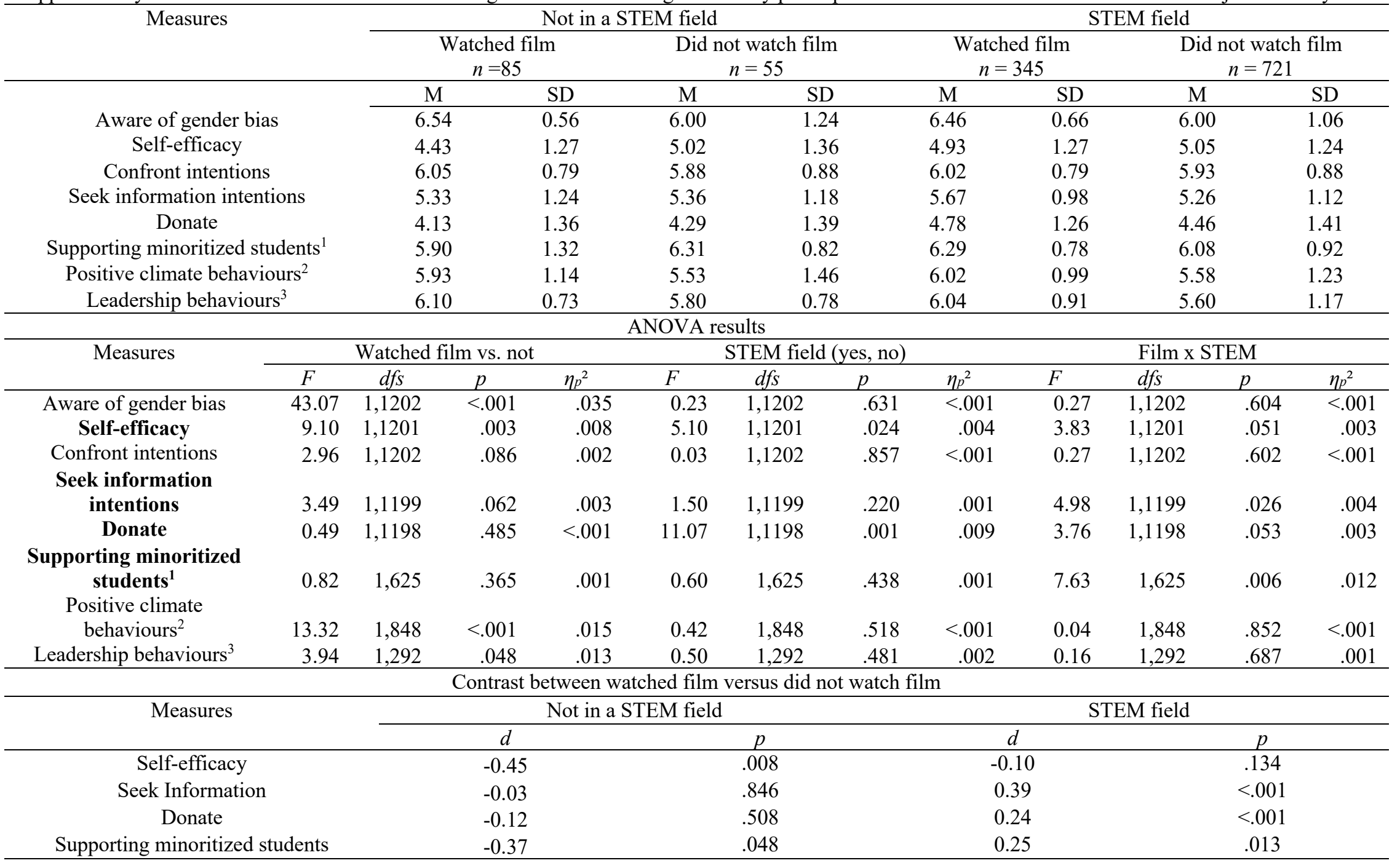

Note. Bolded measures $=$ measures probed to look at the interaction

${ }^{1}$ Only participants who worked with students completed this measure (Non-STEM: Watched the film: 46, Not watched the film: 28; STEM: Watched the film: 410, Not watched the film: 145) 
${ }^{2}$ Only participants employed at University or company completed this (Non-STEM: Watched the film: 76, Not watched the film: 42; STEM: Watched the film: 495, Not watched the film: 239)

${ }^{3}$ Only leaders completed this measure (Non-STEM: Watched the film: 18, Not watched the film: 14; STEM: Watched the film: 171, Not watched the film: 93)

Supplementary Table 18. Differences between watching versus not watching the film by students and non-students in Study 2

\begin{tabular}{|c|c|c|c|c|c|c|c|c|c|c|c|c|}
\hline \multirow{3}{*}{\multicolumn{2}{|c|}{ Measures }} & \multicolumn{6}{|c|}{ Not a student } & \multicolumn{5}{|c|}{ Students } \\
\hline & & \multicolumn{3}{|c|}{$\begin{array}{c}\text { Watched film } \\
n=621\end{array}$} & \multicolumn{3}{|c|}{$\begin{array}{c}\text { Did not watch film } \\
n=310\end{array}$} & \multicolumn{2}{|c|}{$\begin{array}{c}\text { Watched film } \\
n=422\end{array}$} & \multicolumn{3}{|c|}{$\begin{array}{c}\text { Did not watch film } \\
n=112\end{array}$} \\
\hline & & \multicolumn{2}{|c|}{$\mathrm{M}$} & SD & $\mathrm{M}$ & \multicolumn{2}{|c|}{ SD } & $\mathrm{M}$ & SD & & & SD \\
\hline \multicolumn{2}{|c|}{ Aware of gender bias } & \multicolumn{2}{|c|}{6.49} & 0.63 & 5.97 & \multicolumn{2}{|c|}{1.08} & 6.39 & 0.73 & \multicolumn{2}{|c|}{6.07} & 1.04 \\
\hline \multicolumn{2}{|c|}{ Self-efficacy } & \multicolumn{2}{|c|}{4.76} & 1.30 & 4.99 & \multicolumn{2}{|c|}{1.32} & 5.19 & 1.14 & \multicolumn{2}{|c|}{5.23} & 1.11 \\
\hline Confront intenti & & \multicolumn{2}{|c|}{6.03} & 0.79 & 5.90 & \multicolumn{2}{|c|}{0.90} & 5.99 & 0.77 & \multicolumn{2}{|c|}{5.95} & 0.85 \\
\hline Seek information int & ions & \multicolumn{2}{|c|}{5.56} & 1.03 & 5.16 & \multicolumn{2}{|c|}{1.18} & 5.76 & 0.97 & \multicolumn{2}{|c|}{5.43} & 1.10 \\
\hline Donate & & \multicolumn{2}{|c|}{4.62} & 1.26 & 4.28 & \multicolumn{2}{|c|}{1.40} & 5.00 & 1.27 & \multicolumn{2}{|c|}{4.75} & 1.43 \\
\hline Supporting minoritized & Ients $^{1}$ & \multicolumn{2}{|c|}{6.22} & 0.86 & 6.14 & \multicolumn{2}{|c|}{0.89} & 6.35 & 0.83 & \multicolumn{2}{|c|}{6.05} & 0.95 \\
\hline \multicolumn{13}{|c|}{ ANOVA results } \\
\hline \multirow[t]{2}{*}{ Measures } & \multicolumn{4}{|c|}{ Watched film vs. not } & & Studen & es, no) & & & Film & tudent & \\
\hline & $F$ & $d f_{S}$ & $p$ & $\eta_{p}^{2}$ & $F$ & $d f_{s}$ & $p$ & $\eta_{p}^{2}$ & $F$ & $d f_{S}$ & $p$ & $\eta_{p}^{2}$ \\
\hline Aware of gender bias & 57.07 & 1,1251 & $<.001$ & .044 & 0.00 & 1,1251 & .984 & $<.001$ & 3.43 & 1,1251 & .064 & .003 \\
\hline Self-efficacy & 2.40 & 1,1250 & .122 & .002 & 15.55 & 1,1250 & $<.001$ & .012 & 1.26 & 1,1250 & .262 & .001 \\
\hline Confront intentions & 2.36 & 1,1250 & .124 & .002 & 0.02 & 1,1250 & .896 & $<.001$ & 0.68 & 1,1250 & .409 & .001 \\
\hline Seek information & & & & & & & & & & & & \\
\hline intentions & 25.15 & 1,1247 & $<.001$ & .020 & 10.59 & 1,1247 & .001 & .008 & 0.21 & 1,1247 & .651 & $<.001$ \\
\hline Donate & 10.86 & 1,1246 & .001 & .009 & 22.49 & 1,1246 & $<.001$ & .018 & 0.18 & 1,1246 & .673 & $<.001$ \\
\hline $\begin{array}{l}\text { Supporting minoritized } \\
\text { students } 1\end{array}$ & 4.38 & 1,625 & .037 & .007 & 0.05 & 1,625 & .825 & $<.001$ & 1.41 & 1,625 & .235 & .002 \\
\hline
\end{tabular}

${ }^{1}$ Only participants who worked with students (i.e., graduate students) completed this measure (Non-Students: Watched the film: 361 , Not watched the film:

130; Students: Watched the film: 95, Not watched the film: 43) 
Supplementary Table 19. Differences between watching versus not watching the film by participants who worked in University versus did not work in a university in Study 2

\begin{tabular}{|c|c|c|c|c|c|c|c|c|c|c|c|c|}
\hline \multirow{2}{*}{\multicolumn{2}{|c|}{ Measures }} & \multicolumn{6}{|c|}{ Not in a University } & \multicolumn{5}{|c|}{ University } \\
\hline & & \multicolumn{3}{|c|}{$\begin{array}{c}\text { Watched film } \\
n=85\end{array}$} & \multicolumn{3}{|c|}{$\begin{array}{l}\text { Did not watch film } \\
\qquad n=55\end{array}$} & \multicolumn{2}{|c|}{$\begin{array}{c}\text { Watched film } \\
n=345\end{array}$} & \multicolumn{3}{|c|}{$\begin{array}{l}\text { Did not watch film } \\
\quad n=721\end{array}$} \\
\hline & & \multicolumn{2}{|c|}{$\mathrm{M}$} & SD & $\mathrm{M}$ & \multicolumn{2}{|c|}{ SD } & $\mathrm{M}$ & SD & & & $\mathrm{SD}$ \\
\hline \multicolumn{2}{|c|}{ Aware of gender bias } & \multicolumn{2}{|c|}{6.46} & 0.63 & 5.89 & \multicolumn{2}{|c|}{1.09} & 6.51 & 0.63 & \multicolumn{2}{|c|}{6.07} & 1.07 \\
\hline \multicolumn{2}{|l|}{ Self-efficacy } & \multicolumn{2}{|c|}{4.77} & 1.23 & 5.06 & \multicolumn{2}{|c|}{1.28} & 4.75 & 1.34 & \multicolumn{2}{|c|}{4.90} & 1.36 \\
\hline Confront intentic & & \multicolumn{2}{|c|}{6.02} & 0.81 & 5.88 & \multicolumn{2}{|c|}{1.00} & 6.04 & 0.78 & \multicolumn{2}{|c|}{5.92} & 0.77 \\
\hline Seek information int & ions & \multicolumn{2}{|c|}{5.59} & 0.99 & 4.99 & \multicolumn{2}{|c|}{1.20} & 5.54 & 1.06 & \multicolumn{2}{|c|}{5.37} & 1.12 \\
\hline Donate & & \multicolumn{2}{|c|}{4.66} & 1.21 & 4.21 & \multicolumn{2}{|c|}{1.41} & 4.59 & 1.29 & \multicolumn{2}{|c|}{4.37} & 1.38 \\
\hline Positive climate beha & $u^{1}$ & \multicolumn{2}{|c|}{5.94} & 1.05 & 5.38 & \multicolumn{2}{|c|}{1.32} & 6.04 & 0.98 & \multicolumn{2}{|c|}{5.78} & 1.17 \\
\hline Leadership behavi & & & & 0.94 & 5.34 & & & 6.17 & 0.84 & & & 0.78 \\
\hline & & & & & NOVA & ults & & & & & & \\
\hline Measures & & Watche & $11 \mathrm{~lm}$ vs. 1 & & & Univers & yes, no & & & Film $\mathrm{x}$ & versity & \\
\hline & $F$ & $d f_{S}$ & $p$ & $\eta_{p}^{2}$ & $F$ & $d f_{S}$ & $p$ & $\eta_{p}^{2}$ & $F$ & $d f_{S}$ & $p$ & $\eta_{p}^{2}$ \\
\hline Aware of gender bias & 80.44 & 1,927 & $<.001$ & .080 & 3.84 & 1,927 & .050 & .004 & 1.31 & 1,927 & .253 & .001 \\
\hline Self-efficacy & 5.65 & 1,926 & .018 & .006 & 0.97 & 1,926 & .325 & .001 & 0.50 & 1,926 & .481 & .001 \\
\hline Confront intentions & 4.84 & 1,926 & .028 & .005 & 0.18 & 1,926 & .675 & $<.001$ & 0.05 & 1,926 & .822 & $<.001$ \\
\hline Seek information & & & & & & & & & & & & \\
\hline intentions & 25.63 & 1,924 & $<.001$ & .027 & 5.10 & 1,924 & .024 & .005 & 7.99 & 1,924 & .005 & .009 \\
\hline Donate & 13.05 & 1,923 & $<.001$ & .014 & 0.24 & 1,923 & .624 & $<.001$ & 1.44 & 1,923 & .230 & .002 \\
\hline Positive climate & & & & & & & & & & & & \\
\hline Behaviours $^{1}$ & 26.19 & 1,848 & $<.001$ & .030 & 9.33 & 1,848 & .002 & .011 & 3.35 & 1,848 & .068 & .004 \\
\hline Leadership behaviours $^{2}$ & 7.88 & 1,292 & .005 & .026 & 18.15 & 1,292 & $<.001$ & .059 & 2.82 & 1,292 & .094 & .010 \\
\hline & & & Contra & oetween & ched filn & ersus di & ot watch & & & & & \\
\hline Measures & & & & Not & niversity & & & & & iversity & & \\
\hline & & & & & & $p$ & & & & & $p$ & \\
\hline Seek Informa & & & & & & $<.001$ & & & & & .109 & \\
\hline
\end{tabular}

Note. Bolded measures $=$ measures probed to look at the interaction

${ }^{1}$ Only participants employed at University or company completed this (Non- University: Watched the film: 198, Not watched the film: 64; University:

Watched the film: 373 , Not watched the film: 138)

${ }^{2}$ Only leaders completed this measure (Non- University: Watched the film: 79, Not watched the film: 143; University: Watched the film: 110, Not watched the film: 43) 


\section{Examining whether attending a virtual panel impacted awareness of gender bias, self-efficacy, and behavioural intentions in Study 2}

Approximately $34.5 \%$ of our sample in Study 2 also attended a virtual panel related to "Picture a Scientist." Thus, as a secondary research question, we were curious whether there were benefits associated with watching this online panel, in addition to viewing the film. To explore this possibility, we ran a between-subjects ANOVA with watched the film versus did not watch the film and watched the panel versus did not watch the panel as our predictors (see Supplementary Table 20 for full ANOVA results). In our preregistration, we planned to explore whether there was added value to watching the panel between the time 1 and 2 surveys because the panel occurred on March $24^{\text {th }}, 2021$, and the survey was only available until March $26^{\text {th }}$, 2021. Thus, we reasoned that the majority of participants would complete the time 1 survey before the panel. However, because the survey was advertised as part of the panel event, a large percentage of participants engaged with the panel before completing the first survey.

Consequently, we also examined whether there were benefits associated with the panel for time 1 survey outcomes.

These analyses revealed significant interactions between watching the panel and watching the film on awareness of gender bias $(p=.006)$, intentions to seek information $(p=$ $.002)$, donate intentions $(p=.036)$, and leadership behavioural intentions $(p=.004)$. Among participants who had not viewed the film, the panel alone was beneficial. Relative to those who had not engaged with the panel, participants who viewed the panel reported higher awareness of gender bias in $\operatorname{STEM}(p<.001)$, intentions to seek information $(p<.001)$, donate intentions $(p=$ $.046)$, and intentions to enact positive leadership behaviours $(p=.024)$. (See Supplementary Table 20.) We also probed the interactions from the alternative perspective. We found that among participants who did not watch the panel, those who watched the film were significantly 
higher on all of these outcomes compared to participants who had not watched the film (all ps $<$ .001 ; See Supplementary Table 21 for full results). Thus, watching the panel alone was helpful but did not provide any added benefits above and beyond watching the film. 
Supplementary Table 20. Between-subject ANOVA results looking the effects of watching the film and watching the panel in Study 2

\begin{tabular}{|c|c|c|c|c|c|c|c|c|c|c|c|c|}
\hline \multirow{3}{*}{ Measures } & \multicolumn{6}{|c|}{ Watched film } & \multicolumn{6}{|c|}{ Did not watch film } \\
\hline & \multicolumn{2}{|c|}{$\begin{array}{c}\text { Watched panel } \\
n=367\end{array}$} & \multicolumn{2}{|c|}{$\begin{array}{c}\text { Did not watch panel } \\
n=466\end{array}$} & \multicolumn{2}{|c|}{$\begin{array}{l}\text { Watched vs. did } \\
\text { not watch panel }\end{array}$} & \multicolumn{2}{|c|}{$\begin{array}{c}\text { Watched panel } \\
n=66\end{array}$} & \multicolumn{2}{|c|}{$\begin{array}{c}\text { Did not watch panel } \\
\quad n=356\end{array}$} & \multicolumn{2}{|c|}{$\begin{array}{l}\text { Watched vs. did } \\
\text { not watch panel }\end{array}$} \\
\hline & $\mathrm{M}$ & SD & $\mathrm{M}$ & SD & $d$ & $p$ & $\mathrm{M}$ & SD & $\mathrm{M}$ & SD & $d$ & $p$ \\
\hline Aware of gender bias & 6.49 & 0.63 & 6.45 & 0.68 & 0.06 & .500 & 6.32 & 0.98 & 5.94 & 1.08 & 0.37 & $<.001$ \\
\hline Self-efficacy & 4.88 & 1.23 & 4.86 & 1.31 & 0.02 & .779 & 4.99 & 1.41 & 5.06 & 1.24 & -0.05 & .690 \\
\hline Confront intentions & 6.01 & 0.80 & 6.03 & 0.78 & -0.03 & .813 & 5.97 & 0.87 & 5.90 & 0.89 & 0.08 & .522 \\
\hline $\begin{array}{l}\text { Seek information } \\
\text { intentions }\end{array}$ & 5.68 & 1.01 & 5.56 & 1.02 & 0.12 & .096 & 5.75 & 1.05 & 5.14 & 1.16 & 0.55 & $<.001$ \\
\hline Donate intentions & 4.68 & 1.28 & 4.74 & 1.27 & -0.05 & .534 & 4.71 & 1.43 & 4.35 & 1.41 & 0.25 & .042 \\
\hline $\begin{array}{l}\text { Supporting minoritized } \\
\text { students }{ }^{1}\end{array}$ & 6.27 & 0.89 & 6.24 & 0.83 & 0.03 & .687 & 6.44 & 0.63 & 6.04 & 0.95 & 0.50 & .018 \\
\hline $\begin{array}{l}\text { Positive climate } \\
\text { behaviours }^{2}\end{array}$ & 5.99 & 1.06 & 6.02 & 0.97 & -0.03 & .736 & 5.88 & 1.20 & 5.52 & 1.27 & 0.29 & .048 \\
\hline Leadership behaviours $^{3}$ & 5.88 & 1.06 & 6.17 & 0.73 & -0.32 & .045 & 6.17 & 1.15 & 5.54 & 1.10 & 0.56 & .024 \\
\hline \multicolumn{13}{|c|}{ ANOVA results } \\
\hline Measures & \multicolumn{4}{|c|}{ Watched film vs. not } & \multicolumn{4}{|c|}{ Watched panel vs. not } & \multicolumn{4}{|c|}{ Film x panel } \\
\hline & $F$ & $d f s$ & $p$ & $\eta_{p}^{2}$ & $F$ & $d f s$ & $p$ & $\eta_{p}^{2}$ & $F$ & $d f_{s}$ & $p$ & $\eta_{p}^{2}$ \\
\hline Aware of gender bias & 30.70 & 1,1251 & $<.001$ & .024 & 1,1251 & 1,1251 & .001 & .009 & 7.68 & 1,1251 & .006 & .006 \\
\hline Self-efficacy & 2.69 & 1,1250 & .101 & .002 & 0.05 & 1,1250 & .823 & $<.001$ & 0.23 & 1,1250 & .629 & $<.001$ \\
\hline Confront intentions & 1.78 & 1,1250 & .182 & .001 & 0.21 & 1,1250 & .646 & $<.001$ & 0.46 & 1,1250 & .498 & $<.001$ \\
\hline $\begin{array}{l}\text { Seek information } \\
\text { intentions }\end{array}$ & 4.66 & 1,1247 & .031 & .004 & 21.13 & 1,1247 & $<.001$ & .017 & 9.35 & 1,1247 & .002 & .007 \\
\hline Donate intentions & 3.23 & 1,1246 & .073 & .003 & 2.31 & 1,1246 & .129 & .002 & 4.40 & 1,1246 & .036 & .004 \\
\hline $\begin{array}{l}\text { Supporting minoritized } \\
\text { students }^{1}\end{array}$ & 0.01 & 1,625 & .911 & $<.001$ & 5.32 & 1,625 & .021 & .008 & 3.81 & 1,625 & .051 & .006 \\
\hline $\begin{array}{l}\text { Positive climate } \\
\text { behaviours }^{2}\end{array}$ & 9.36 & 1,848 & .002 & .011 & 2.58 & 1,848 & .109 & .003 & 3.66 & 1,848 & .056 & .004 \\
\hline $\begin{array}{l}\text { Leadership } \\
\text { behaviours }^{3}\end{array}$ & 1.12 & 1,292 & .291 & .004 & 1.20 & 1,292 & .274 & .004 & 8.63 & 1,292 & .004 & .029 \\
\hline
\end{tabular}

Note. Bolded Outcome measures = significant interactions

${ }^{1}$ Only participants who worked with students completed this measure (Watched film: Watched panel: 204; Not watch panel: 252; Not watched film: Watched panel: 33 Not watch panel: 140)

${ }^{2}$ Only participants employed at University or company completed this measure (Watched film: Watched panel: 257 ; Not watch panel: 314 ; Not watched

film: Watched panel: 44 Not watch panel: 237)

${ }^{3}$ Only leaders completed this measure (Watched film: Watched panel: 78; Not watch panel: 111; Not watched film: Watched panel: 14 Not watch panel: 93) 
Supplementary Table 21. The effect of watching versus not watching the film among those who did or did not watch the panel

\begin{tabular}{|c|c|c|c|c|c|c|c|c|c|c|c|c|}
\hline \multirow{3}{*}{ Measures } & \multicolumn{6}{|c|}{ Watched panel } & \multicolumn{6}{|c|}{ Did not watch panel } \\
\hline & \multicolumn{2}{|c|}{ Watched film } & \multicolumn{2}{|c|}{ Did not watch film } & \multicolumn{2}{|c|}{$\begin{array}{l}\text { Watched vs. did } \\
\text { not watch film }\end{array}$} & \multicolumn{2}{|c|}{ Watched film } & \multicolumn{2}{|c|}{ Did not watch film } & \multicolumn{2}{|c|}{$\begin{array}{l}\text { Watched vs. did } \\
\text { not watch film }\end{array}$} \\
\hline & $\mathrm{M}$ & SD & $\mathrm{M}$ & SD & $d$ & $p$ & $M$ & SD & $\mathrm{M}$ & SD & $d$ & $p$ \\
\hline Aware of gender bias & 6.49 & 0.63 & 6.32 & 0.98 & 0.21 & .118 & 6.45 & 0.68 & 5.94 & 1.08 & 0.57 & $<.001$ \\
\hline Self-efficacy & 4.88 & 1.23 & 4.99 & 1.41 & -0.08 & .514 & 4.86 & 1.31 & 5.06 & 1.24 & -0.16 & .023 \\
\hline Confront intentions & 6.01 & 0.80 & 5.97 & 0.87 & 0.05 & .710 & 6.03 & 0.78 & 5.90 & 0.89 & 0.16 & .031 \\
\hline $\begin{array}{l}\text { Seek information } \\
\text { intentions }\end{array}$ & 5.68 & 1.01 & 5.75 & 1.05 & -0.07 & .612 & 5.56 & 1.02 & 5.14 & 1.16 & 0.38 & $<.001$ \\
\hline Donate intentions & 4.68 & 1.28 & 4.71 & 1.43 & -0.02 & .866 & 4.74 & 1.27 & 4.35 & 1.41 & 0.29 & $<.001$ \\
\hline $\begin{array}{c}\text { Supporting minoritized } \\
\text { students }{ }^{1}\end{array}$ & 6.27 & 0.89 & 6.44 & 0.63 & -0.22 & .291 & 6.24 & 0.83 & 6.04 & 0.95 & 0.22 & .036 \\
\hline $\begin{array}{l}\text { Positive climate } \\
\text { behaviours }^{2}\end{array}$ & 5.99 & 1.06 & 5.88 & 1.20 & 0.10 & .518 & 6.02 & 0.97 & 5.52 & 1.27 & 0.44 & $<.001$ \\
\hline Leadership behaviours ${ }^{3}$ & 5.88 & 1.06 & 6.17 & 1.15 & -0.26 & .297 & 6.17 & 0.73 & 5.54 & 1.10 & 0.67 & $<.001$ \\
\hline
\end{tabular}

${ }^{1}$ Only participants who worked with students completed this measure (Watched film: Watched panel: 204; Not watch panel: 252; Not watched film: Watched panel: 33 Not watch panel: 140)

${ }^{2}$ Only participants employed at University or company completed this measure (Watched film: Watched panel: 257; Not watch panel: 314 ; Not watched

film: Watched panel: 44 Not watch panel: 237)

${ }^{3}$ Only leaders completed this measure (Watched film: Watched panel: 78; Not watch panel: 111; Not watched film: Watched panel: 14 Not watch panel: 93 ) 
Examining whether demographic variables or attending the virtual panel impacted changes in awareness of gender bias, self-efficacy, and behavioural intentions from time 1 to time 2 in Study 2

We initially explored whether there were significant interactions between having watched versus not watched the film at time 1 and time 1 versus time 2 outcomes among participants who watched the film between time 1 and time 2 . In secondary analyses, we also tested whether participating in the virtual panel and demographic variables moderated these results. That is, we examine whether there were significant three-way interactions between having watched the film at time 1 versus not, time 1 versus time 2 , by participating in the panel and demographic variables. We did not find any significant three-way interactions. (See Supplementary Tables 22 and 23 for full results).

Supplementary Table 22. Three-way interactions with having watched the film (versus not) at time 1 , time 1 and time 2, and participating in the panel (versus not), gender, and race in Study 2

\begin{tabular}{|c|c|c|c|c|}
\hline \multicolumn{5}{|c|}{ Three-way interactions with watched panel } \\
\hline Measures & $F$ & $d f_{S}$ & $p$ & $\eta_{p}^{2}$ \\
\hline Aware of gender bias & 0.57 & 1,233 & .451 & .002 \\
\hline Self-efficacy & 0.00 & 1,233 & .998 & .000 \\
\hline Confront intentions & 1.16 & 1,233 & .282 & .005 \\
\hline Seek information intentions & 1.33 & 1,232 & .249 & .006 \\
\hline Donate & 0.02 & 1,232 & .879 & .000 \\
\hline Supporting minoritized students & 0.05 & 1,92 & .829 & .001 \\
\hline Positive climate behaviours & 0.02 & 1,147 & .879 & .000 \\
\hline Leadership behaviours & 0.45 & 1,35 & .508 & .013 \\
\hline \multicolumn{5}{|c|}{ Three-way interactions with gender ${ }^{1}$} \\
\hline & $F$ & $d f_{S}$ & $p$ & $\eta_{p}^{2}$ \\
\hline Aware of gender bias & 0.17 & 1,229 & .680 & .001 \\
\hline Self-efficacy & 1.04 & 1,229 & .310 & .005 \\
\hline Confront intentions & 1.63 & 1,229 & .203 & .007 \\
\hline Seek information intentions & 1.96 & 1,228 & .163 & .009 \\
\hline Donate & 0.04 & 1,228 & .847 & .000 \\
\hline Supporting minoritized students & $\mathrm{N} / \mathrm{A}$ & $\mathrm{N} / \mathrm{A}$ & $\mathrm{N} / \mathrm{A}$ & $\mathrm{N} / \mathrm{A}$ \\
\hline Positive climate behaviours & 0.04 & 145 & .834 & $<.001$ \\
\hline Leadership behaviours & $N / A$ & $N / A$ & $N / A$ & $N / A$ \\
\hline \multicolumn{5}{|c|}{ Three-way interactions with race ${ }^{2}$} \\
\hline & $F$ & $d f_{S}$ & $p$ & $\eta_{p^{2}}^{2}$ \\
\hline Aware of gender bias & 2.01 & 2,219 & .136 & .018 \\
\hline Self-efficacy & 0.59 & 2,219 & .558 & .005 \\
\hline Confront intentions & 0.61 & 2,219 & .542 & .006 \\
\hline Seek information intentions & 2.55 & 2,218 & .080 & .023 \\
\hline Donate & 0.89 & 2,218 & .413 & .008 \\
\hline Supporting minoritized students & 0.01 & 1,79 & .938 & .000 \\
\hline Positive climate behaviours & 1.80 & 1,130 & .183 & .014 \\
\hline
\end{tabular}


Leadership behaviours

$N / A$

$N / A$

$N / A$

$N / A$

Note. Analyses were only conducted among participants who watched the film between time 1 and time $2 . N / A=$ there were cells with less than five participants and we could not conduct these analyses.

${ }^{1}$ For our analyses with gender, we had to exclude participants who identified as other because there were cells with less than 5 participants

${ }^{2}$ For our analyses with race, we had to exclude participants who identified as Multiracial/Other because there were cells with less than 5 participants. For supporting minoritized students and positive climate behaviours, with race, we also excluded Asian participants due to cells less than 5.

Supplementary Table 23. Three-way interactions with having watched the film (versus not) at time 1, time 1 and time 2, and leader versus non-leaders, STEM fields/majors versus non-STEM, students versus non-students, and working in a university versus not working a university in Study 2

\begin{tabular}{|c|c|c|c|c|}
\hline \multicolumn{5}{|c|}{ Three-way interactions leader versus non-leaders } \\
\hline Measures & $F$ & $d f_{s}$ & $p$ & $\eta p^{2}$ \\
\hline Aware of gender bias & 0.58 & 163 & .448 & .004 \\
\hline Self-efficacy & 0.07 & 163 & .794 & .000 \\
\hline Confront intentions & 0.25 & 163 & .617 & .002 \\
\hline Seek information intentions & 0.06 & 163 & .814 & .000 \\
\hline Donate & 0.77 & 162 & .383 & .005 \\
\hline Supporting minoritized students & 0.51 & 74 & 478 & .007 \\
\hline Positive climate behaviours & 0.48 & 147 & .492 & .003 \\
\hline \multicolumn{5}{|c|}{ Three-way interactions STEM fields/majors versus non-STEM } \\
\hline Measures & $F$ & $d f_{S}$ & $p$ & $\eta p^{2}$ \\
\hline Aware of gender bias & 2.02 & 219 & .157 & .009 \\
\hline Self-efficacy & 0.33 & 219 & .569 & .001 \\
\hline Confront intentions & 0.32 & 219 & .575 & 001 \\
\hline Seek information intentions & 0.10 & 218 & .752 & .000 \\
\hline Donate & 0.16 & 218 & .686 & .001 \\
\hline Supporting minoritized students & N/A & N/A & N/A & N/A \\
\hline Positive climate behaviours & 0.35 & 147 & .555 & .002 \\
\hline Leadership behaviours & N/A & N/A & N/A & N/A \\
\hline \multicolumn{5}{|c|}{ Three-way interactions students versus non-students } \\
\hline Measures & $F$ & $d f_{S}$ & $p$ & $\eta p^{2}$ \\
\hline Aware of gender bias & 2.97 & 233 & .086 & .013 \\
\hline Self-efficacy & 0.39 & 233 & .535 & .002 \\
\hline Confront intentions & 0.76 & 233 & .385 & .003 \\
\hline Seek information intentions & 0.01 & 232 & .931 & .000 \\
\hline Donate & 0.16 & 232 & 691 & .001 \\
\hline Supporting minoritized students & 0.39 & 92 & .534 & .004 \\
\hline \multicolumn{5}{|c|}{ Three-way interactions participants who work in a university versus does not work in a university } \\
\hline Measures & $F$ & $d f_{S}$ & $p$ & $\eta_{p}^{2}$ \\
\hline Aware of gender bias & 0.64 & 177 & .425 & .004 \\
\hline Self-efficacy & 0.07 & 177 & 790 & .000 \\
\hline Confront intentions & 0.25 & 177 & .619 & .001 \\
\hline Seek information intentions & 0.31 & 176 & .580 & .002 \\
\hline Donate & 0.63 & 176 & .427 & .004 \\
\hline Positive climate behaviours & 1.90 & 147 & 170 & .013 \\
\hline Leadership behaviours & 0.71 & 35 & 406 & .020 \\
\hline
\end{tabular}

Note. Analyses were only conducted among participants who watched the film between time 1 and time 2. N/A = there were cells with less than five participants and we could not conduct these analyses. 


\section{Supplementary Methods}

\section{Additional Participant Information from Study 1}

Supplementary Table 24. Additional Demographic Information from Study 1 Participants

\begin{tabular}{|c|c|}
\hline Demographic & Composition \\
\hline $\begin{array}{l}\text { Students STEM field } \\
\text { (Yes, No) }\end{array}$ & 772 were in a STEM field $(28 \%), 42$ were in a Non-STEM field $(1.5 \%)$ \\
\hline $\begin{array}{l}\text { Student STEM field } \\
\text { (area) }\end{array}$ & $\begin{array}{l}215 \text { Biological Sciences }(7.8 \%), 98 \text { Biomedical Sciences }(3.6 \%), 59 \text { Chemistry } \\
(2.1 \%), 90 \text { Engineering }(3.3 \%), 27 \text { Computer Science/Technology }(1.0 \%), 20 \\
\text { Mathematics }(0.7 \%), 16 \text { Medicine }(0.6 \%), 19 \text { Social Sciences }(0.7 \%), 227 \text { Other } \\
(8.2 \%)\end{array}$ \\
\hline Student Level & $\begin{array}{l}519 \text { Graduate Students in a terminal PhD program }(18.8 \%), 79 \text { Graduate Students in } \\
\text { a terminal Master's program }(2.9 \%), 15 \text { Professional Students }(0.5 \%) \text {, and } 201 \\
\text { Undergraduate Students }(7.3 \%)\end{array}$ \\
\hline $\begin{array}{l}\text { University employees - } \\
\text { Leaders (Yes, No) }\end{array}$ & $\begin{array}{l}\text { Of participants who identified themselves as university employees, } 319 \text { reported } \\
\text { having a leadership role }(11.6 \%) \text { and } 867 \text { reported not having a leadership role } \\
(31.4 \%)\end{array}$ \\
\hline $\begin{array}{l}\text { University employees } \\
\text { STEM field (Yes, No) }\end{array}$ & $\begin{array}{l}\text { Of participants who identified themselves as university employees, } 1062 \text { worked in } \\
\text { a STEM field }(38.5 \%) \text { and } 124 \text { worked in a field other than STEM }(4.5 \%)\end{array}$ \\
\hline $\begin{array}{l}\text { University employees } \\
\text { STEM field (area) }\end{array}$ & $\begin{array}{l}286 \text { Biological Sciences }(10.4 \%), 173 \text { Biomedical Sciences }(6.3 \%), 78 \text { Chemistry } \\
(2.8 \%), 77 \text { Engineering }(2.8 \%), 31 \text { Computer Science/Technology }(1.1 \%), 38 \\
\text { Mathematics }(1.1 \%), 49 \text { Medicine }(1.8 \%), 40 \text { Social Sciences }(1.5 \%), 290 \text { Other } \\
(10.5 \%)\end{array}$ \\
\hline $\begin{array}{l}\text { Participants not employed } \\
\text { at Universities }\end{array}$ & $\begin{array}{l}\text { Among those not employed in a university, } 637 \text { participants reported currently } \\
\text { working for a company/organization }(23.1 \%), 44 \text { identified as self-employed }(1.6 \%) \text {, } \\
\text { and } 76 \text { identified as currently unemployed }(2.8 \%)\end{array}$ \\
\hline $\begin{array}{l}\text { Company employees } \\
\text { Leaders (Yes, No) }\end{array}$ & $\begin{array}{l}\text { Of participants who were currently employed at a company/organization, } 270 \\
\text { reported having a leadership role }(9.8 \%) \text { and } 366 \text { reported not having a leadership } \\
\text { role }(13.3 \%)\end{array}$ \\
\hline $\begin{array}{l}\text { Company employees, } \\
\text { organization type }\end{array}$ & $\begin{array}{l}260(9.4 \%) \text { participants were employed at a for-profit organization and } 370(13.4 \%) \\
\text { were employed at a non-profit organization }\end{array}$ \\
\hline $\begin{array}{l}\text { Company employees } \\
\text { STEM field (Yes, No) }\end{array}$ & $\begin{array}{l}\text { Of participants who were currently employed at a company organization, } 559 \\
\text { participants were in a STEM field }(20.3 \%) \text {, and } 78 \text { were not in a STEM field }(2.8 \%)\end{array}$ \\
\hline $\begin{array}{l}\text { Company employees } \\
\text { STEM field (area) }\end{array}$ & $\begin{array}{l}\text { 146 Biological Sciences }(5.3 \%), 69 \text { Biomedical Sciences }(2.5 \%), 34 \text { Chemistry } \\
(2.1 \%), 52 \text { Engineering }(1.9 \%), 45 \text { Computer Science/Technology }(1.6 \%), 9 \\
\text { Mathematics }(0.3 \%), 28 \text { Medicine }(1.0 \%), 10 \text { Social Sciences }(0.4 \%), 166 \text { Other } \\
(6.0 \%)\end{array}$ \\
\hline
\end{tabular}




\section{Detailed Measure Information and Data Missing Analyses From Study 1}

Supplementary Table 25. Detailed Measure Information From Study 1

\begin{tabular}{|c|c|c|c|c|c|}
\hline \multicolumn{6}{|c|}{ Film engagement (only measured at time 1) } \\
\hline Measures & Example Item & Scale end points & Item \# & $M(S D)$ & Reliability \\
\hline Anger & Please rate the degree you felt: Anger & $1=$ Not at all to $5=A$ very high degree & 3 & $5.66(1.21)$ & $\alpha=.79$ \\
\hline Sadness & Please rate the degree you felt: Sad & $1=$ Not at all to $5=A$ very high degree & 3 & $4.23(1.33)$ & $\alpha=.73$ \\
\hline Empathy & Please rate the degree you felt: Concern & $1=$ Not at all to $5=A$ very high degree & 4 & $6.06(0.86)$ & $\alpha=.74$ \\
\hline Knowledge & $\begin{array}{l}\text { This film increased my knowledge of the facts and evidence } \\
\text { about gender bias/harassment. }\end{array}$ & $1=$ strongly disagree to $7=$ strongly agree & 2 & $5.82(1.10)$ & $\alpha=.79$ \\
\hline Transportation & I was mentally involved in the film while I was watching it. & $1=$ strongly disagree to $7=$ strongly agree & 4 & $5.99(0.85)$ & $\alpha=.54$ \\
\hline Perspective taking & $\begin{array}{l}\text { While viewing the documentary, I could feel the emotions of t } \\
\text { women featured in the film. }\end{array}$ & $1=$ strongly disagree to $7=$ strongly agree & 2 & $6.14(0.93)$ & $\alpha=.55$ \\
\hline
\end{tabular}

\begin{tabular}{|c|c|c|c|c|c|c|c|}
\hline & icacy, and behaviou & al intentions (measured & ross b & time 1 & & & \\
\hline Measures & Example Item & Scale end points & Item \# & & ne 1 & & me 2 \\
\hline & & & & $M(S D)$ & Reliability & $M(S D)$ & Reliability \\
\hline Aware of gender bias & $\begin{array}{l}\text { After watching this film, I believe that women in } \\
\text { science fields often face discrimination based on their } \\
\text { gender. }\end{array}$ & $\begin{array}{l}1=\text { strongly disagree to } \\
7=\text { strongly agree }\end{array}$ & 4 & $\begin{array}{c}6.52 \\
(0.72)\end{array}$ & $\alpha=.84$ & $\begin{array}{c}6.24 \\
(0.86)\end{array}$ & $\alpha=.90$ \\
\hline Self-efficacy & $\begin{array}{l}\text { After watching this film, I feel confident in my ability } \\
\text { to combat gender bias in sciences. }\end{array}$ & $\begin{array}{c}1=\text { strongly disagree to } \\
7=\text { strongly agree }\end{array}$ & 2 & $\begin{array}{l}4.80 \\
(1.29)\end{array}$ & $\alpha=.75$ & $\begin{array}{l}5.09 \\
(1.11)\end{array}$ & $\alpha=.72$ \\
\hline Confront intentions & $\begin{array}{l}\text { When I see others being harassed, I plan to confront } \\
\text { the perpetrators and speak out. }\end{array}$ & $\begin{array}{c}1=\text { strongly disagree to } \\
7=\text { strongly agree }\end{array}$ & 4 & $\begin{array}{l}6.16 \\
(0.79)\end{array}$ & $\alpha=.83$ & $\begin{array}{l}6.02 \\
(0.82)\end{array}$ & $\alpha=.83$ \\
\hline Seek information intentions & $\begin{array}{c}\text { I am interested in learning more about gender } \\
\text { bias/harassment in STEM. }\end{array}$ & $\begin{array}{c}1=\text { strongly disagree to } \\
7=\text { strongly agree }\end{array}$ & 4 & $\begin{array}{l}5.31 \\
(1.14)\end{array}$ & $\alpha=.85$ & $\begin{array}{l}5.56 \\
(1.01)\end{array}$ & $\alpha=.85$ \\
\hline Donate intentions & $\begin{array}{l}\text { I plan to donate to organizations that support women } \\
\text { in STEM (e.g., like the Association for Women in } \\
\text { Science [https://www.awis.org/]). }\end{array}$ & $\begin{array}{c}1=\text { strongly disagree to } \\
7=\text { strongly agree }\end{array}$ & 2 & $\begin{array}{c}4.52 \\
(1.30)\end{array}$ & $\alpha=.67$ & $\begin{array}{l}4.80 \\
(1.25)\end{array}$ & $\alpha=.67$ \\
\hline $\begin{array}{l}\text { Supporting minoritized } \\
\text { students behaviours }^{1}\end{array}$ & $\begin{array}{l}\text { I intend to provide career development and research } \\
\text { support for female students. }\end{array}$ & $\begin{array}{l}1=\text { strongly disagree to } \\
7=\text { strongly agree }\end{array}$ & 5 & $\begin{array}{l}6.24 \\
(0.89)\end{array}$ & $\alpha=.86$ & $\begin{array}{l}6.32 \\
(0.77)\end{array}$ & $\alpha=.82$ \\
\hline $\begin{array}{l}\text { Positive Climate } \\
\text { Behaviours }^{1}\end{array}$ & $\begin{array}{c}\text { I plan to personally work to create welcoming } \\
\text { environments for women in my } \\
\text { organization/university. }\end{array}$ & $\begin{array}{l}1=\text { strongly disagree to } \\
7=\text { strongly agree }\end{array}$ & 4 & $\begin{array}{l}5.97 \\
(1.09)\end{array}$ & $\alpha=.88$ & $\begin{array}{l}5.86 \\
(1.09)\end{array}$ & $\alpha=.90$ \\
\hline Leadership behaviours ${ }^{1}$ & $\begin{array}{l}\text { I plan to create new programs/resources that } \\
\text { specifically help advance women and/or employees } \\
\text { with minoritized identities. }\end{array}$ & $\begin{array}{c}1=\text { strongly disagree to } \\
7=\text { strongly agree }\end{array}$ & 9 & $\begin{array}{l}5.89 \\
(1.01)\end{array}$ & $\alpha=.91$ & $\begin{array}{c}6.02 \\
(0.89)\end{array}$ & $\alpha=.95$ \\
\hline
\end{tabular}

Note. ${ }^{1}$ For each of these behaviours, participants could choose "Not Applicable" if it was a behaviour there were not in a position to enact. This answer was treated as missing. 
Supplementary Table 26. Among Participants who Agreed to Take Part in the Second Survey, Correlations Between Time 1 Measures and Completing (versus not) the Second Survey in Study 1

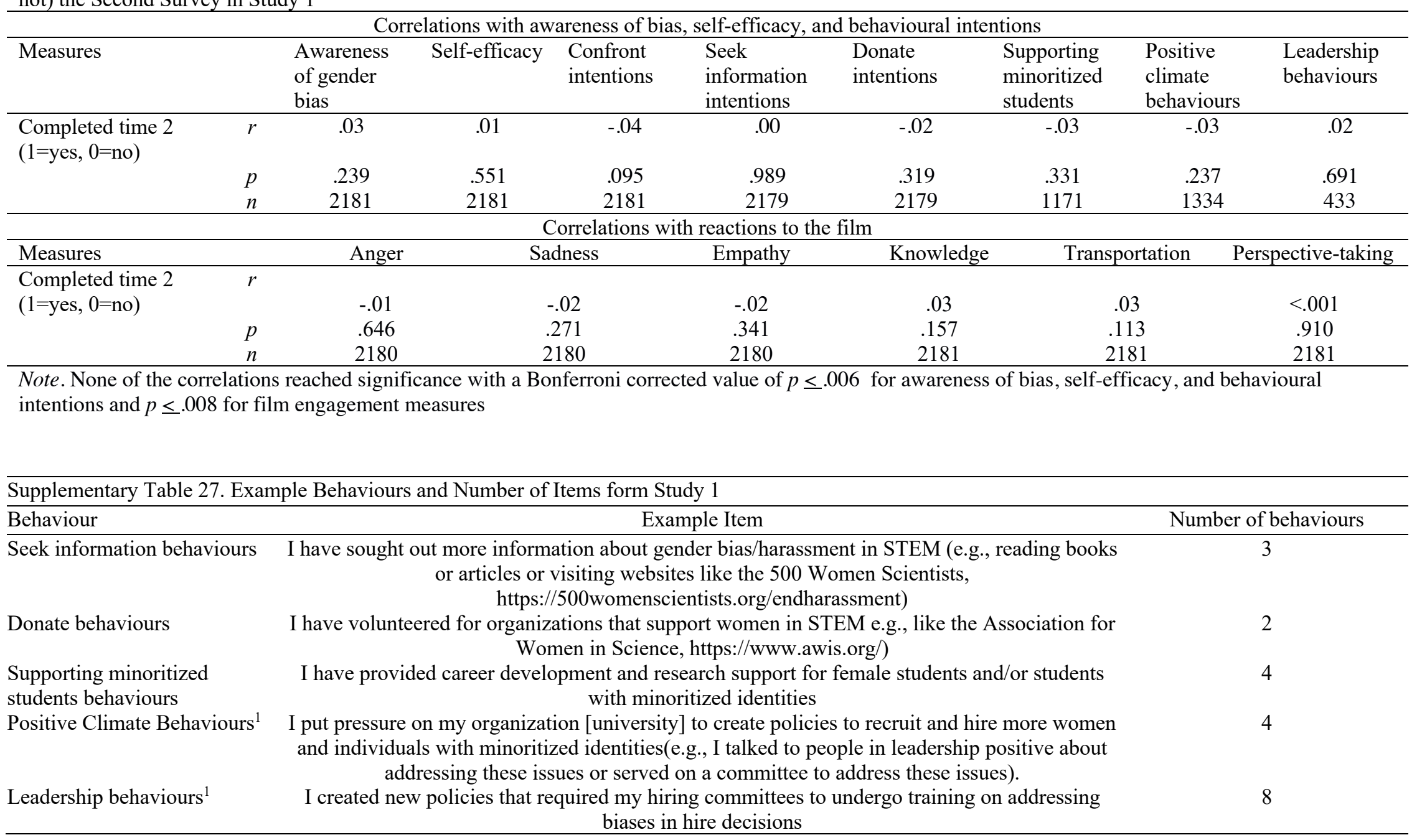




\section{Additional Participant Information from Study 2}

Supplementary Table 28. Additional Demographic Information from Study 2 Participants

\begin{tabular}{|c|c|}
\hline Demographic & Composition \\
\hline $\begin{array}{l}\text { Students STEM field } \\
\text { (Yes, No) }\end{array}$ & 307 were in a STEM field $24.5 \%), 17$ were in a Non-STEM field (1.4\%) \\
\hline Student Level & $\begin{array}{l}166 \text { Graduate Students in a terminal PhD program }(13.2 \%), 54 \text { Graduate Students in } \\
\text { a terminal Master's program }(4.3 \%), 13 \text { Professional Students }(1.0 \%) \text {, and } 91 \\
\text { Undergraduate Students }(28.1 \%)\end{array}$ \\
\hline $\begin{array}{l}\text { Student STEM field } \\
\text { (area) }\end{array}$ & $\begin{array}{l}100 \text { Biological Sciences }(8.0 \%), 46 \text { Biomedical Sciences }(3.7 \%), 22 \text { Chemistry } \\
(1.8 \%), 28 \text { Engineering }(2.2 \%), 10 \text { Computer Science/Technology }(0.8 \%), 4 \\
\text { Mathematics }(0.3 \%), 15 \text { Medicine }(1.2 \%), 11 \text { Social Sciences }(0.9 \%), 71 \text { Other } \\
(5.6 \%)\end{array}$ \\
\hline $\begin{array}{l}\text { University employees - } \\
\text { Leaders (Yes, No) }\end{array}$ & $\begin{array}{l}\text { Of participants who identified themselves as university employees, } 154 \text { reported } \\
\text { having a leadership role }(12.3 \%) \text { and } 375 \text { reported not having a leadership role } \\
(29.9 \%)\end{array}$ \\
\hline $\begin{array}{l}\text { University employees } \\
\text { STEM field (Yes, No) }\end{array}$ & $\begin{array}{l}\text { Of participants who identified themselves as university employees, } 451 \text { worked in a } \\
\text { STEM field }(35.9 \%) \text { and } 78 \text { worked in a field other than STEM }(6.2 \%)\end{array}$ \\
\hline $\begin{array}{l}\text { University employees } \\
\text { STEM field (area) }\end{array}$ & $\begin{array}{l}126 \text { Biological Sciences }(10.0 \%), 66 \text { Biomedical Sciences }(5.3 \%), 42 \text { Chemistry } \\
(3.3 \%), 37 \text { Engineering }(2.9 \%), 9 \text { Computer Science/Technology }(0.7 \%), 13 \\
\text { Mathematics }(1.0 \%), 24 \text { Medicine }(1.9 \%), 24 \text { Social Sciences }(1.9 \%), 110 \text { Other } \\
(8.8 \%)\end{array}$ \\
\hline $\begin{array}{l}\text { Participants not employed } \\
\text { at Universities }\end{array}$ & $\begin{array}{l}\text { Among those not employed in a university, } 353 \text { participants reported currently } \\
\text { working for a company/organization }(28.1 \%), 32 \text { identified as self-employed }(2.5 \%) \text {, } \\
\text { and } 16 \text { identified as currently unemployed }(1.3 \%)\end{array}$ \\
\hline $\begin{array}{l}\text { Company employees } \\
\text { Leaders (Yes, No) }\end{array}$ & $\begin{array}{l}\text { Of participants who were currently employed at a company/organization, } 148 \\
\text { reported having a leadership role }(11.8 \%) \text { and } 205 \text { reported not having a leadership } \\
\text { role }(58.8 \%)\end{array}$ \\
\hline $\begin{array}{l}\text { Company employees, } \\
\text { organization type }\end{array}$ & $\begin{array}{l}\text { Of participants who were currently employed at a company/organization, } 145 \\
(11.6 \%) \text { participants were employed at a for-profit organization, } 206(16.4 \%) \text { were } \\
\text { employed at a non-profit organization, and } 2 \text { did not answer }(0.2 \%)\end{array}$ \\
\hline $\begin{array}{l}\text { Company employees } \\
\text { STEM field (Yes, No) }\end{array}$ & $\begin{array}{l}\text { Of participants who were currently employed at a company organization, } 308 \\
\text { participants were in a STEM field }(24.5 \%) \text {, and } 45 \text { were not in a STEM field }(3.6 \%)\end{array}$ \\
\hline $\begin{array}{l}\text { Company employees } \\
\text { STEM field (area) }\end{array}$ & $\begin{array}{l}86 \text { Biological Sciences }(6.9 \%), 33 \text { Biomedical Sciences }(2.6 \%), 21 \text { Chemistry } \\
(1.7 \%), 26 \text { Engineering }(2.1 \%), 15 \text { Computer Science/Technology }(1.2 \%), 1 \\
\text { Mathematics }(0.1 \%), 19 \text { Medicine }(8.1 \%), 05 \text { Social Sciences }(0.5 \%), 101 \text { Other } \\
(8.1 \%)\end{array}$ \\
\hline
\end{tabular}

Supplementary Table 29. Full List of Countries in Study 2

\begin{tabular}{ccc}
\hline Country & Total & Percent \\
\hline Did not Answer & 3 & $0.2 \%$ \\
Argentina & 2 & $0.2 \%$ \\
Australia & 6 & $0.5 \%$ \\
Austria & 1 & $0.1 \%$ \\
Belgium & 3 & $0.2 \%$ \\
Brazil & 5 & $0.4 \%$ \\
Canada & 123 & $9.8 \%$ \\
Colombia & 3 & $0.2 \%$
\end{tabular}


Supplementary 33

\begin{tabular}{|c|c|c|}
\hline Denmark & 2 & $0.2 \%$ \\
\hline Egypt & 1 & $0.1 \%$ \\
\hline England & 3 & $0.2 \%$ \\
\hline Finland & 5 & $0.4 \%$ \\
\hline France & 6 & $0.5 \%$ \\
\hline Germany & 36 & $2.9 \%$ \\
\hline Guatemala & 1 & $0.1 \%$ \\
\hline India & 2 & $0.2 \%$ \\
\hline Iran & 1 & $0.1 \%$ \\
\hline Ireland & 4 & $0.3 \%$ \\
\hline Isa & 1 & $0.1 \%$ \\
\hline Israel & 5 & $0.4 \%$ \\
\hline Italy & 1 & $0.1 \%$ \\
\hline Jamaica & 1 & $0.1 \%$ \\
\hline Lorain & 1 & $0.1 \%$ \\
\hline Malawi & 1 & $0.1 \%$ \\
\hline Mexico & 21 & $1.7 \%$ \\
\hline Nepal & 3 & $0.2 \%$ \\
\hline Netherlands & 5 & $0.4 \%$ \\
\hline New Zealand & 2 & $0.2 \%$ \\
\hline Norway & 2 & $0.2 \%$ \\
\hline Peru & 1 & $0.1 \%$ \\
\hline Portugal & 5 & $0.4 \%$ \\
\hline Puerto Rico & 1 & $0.1 \%$ \\
\hline Saudi Arabia & 2 & $0.2 \%$ \\
\hline Scotland & 1 & $0.1 \%$ \\
\hline Serbia & 2 & $0.2 \%$ \\
\hline Spain & 5 & $0.4 \%$ \\
\hline Sweden & 14 & $1.1 \%$ \\
\hline Switzerland & 11 & $0.9 \%$ \\
\hline The Netherlands & 1 & $0.1 \%$ \\
\hline Turkey & 2 & $0.2 \%$ \\
\hline United Arab Emirates & 1 & $0.1 \%$ \\
\hline United Kingdom & 54 & $4.3 \%$ \\
\hline United States of America & 901 & $71.8 \%$ \\
\hline Uruguay & 2 & $0.2 \%$ \\
\hline Washtenaw & 1 & $0.1 \%$ \\
\hline
\end{tabular}




\section{Detailed Measure Information and Data Missing Analyses From Study 2}

Supplementary Table 30. Detailed Measure Information From Study 2

\begin{tabular}{|c|c|c|c|c|c|c|}
\hline \multicolumn{7}{|c|}{ Film engagement measures } \\
\hline \multirow[t]{2}{*}{ Measure } & \multicolumn{3}{|c|}{ Time 1} & \multicolumn{3}{|c|}{ Time 2} \\
\hline & $\mathrm{M}(\mathrm{SD})$ & \multicolumn{2}{|c|}{ Reliability } & $\mathrm{M}(\mathrm{SD})$ & \multicolumn{2}{|c|}{ Reliability } \\
\hline Anger & $5.71(1.20)$ & \multicolumn{2}{|c|}{$\alpha=.78$} & $5.64(1.23)$ & \multicolumn{2}{|c|}{$\alpha=.80$} \\
\hline Sadness & $4.30(1.35)$ & \multicolumn{2}{|c|}{$\alpha=.74$} & $4.27(1.35)$ & \multicolumn{2}{|c|}{$\alpha=.76$} \\
\hline Empathy & $6.19(0.80)$ & \multicolumn{2}{|c|}{$\alpha=.70$} & $6.07(0.86)$ & \multicolumn{2}{|c|}{$\alpha=.77$} \\
\hline Knowledge & $5.93(1.09)$ & \multicolumn{2}{|c|}{$\alpha=.88$} & $5.99(1.07)$ & \multicolumn{2}{|c|}{$\alpha=.90$} \\
\hline Transportation & $6.17(0.81)$ & \multicolumn{2}{|c|}{$\alpha=.52$} & $6.05(0.84)$ & \multicolumn{2}{|c|}{$\alpha=.61$} \\
\hline Perspective taking & $6.32(0.85)$ & \multicolumn{2}{|c|}{$\alpha=.54$} & $6.16(1.02)$ & \multicolumn{2}{|c|}{$\alpha=.62$} \\
\hline \multicolumn{7}{|c|}{ Awareness of gender bias, self-efficacy, and behavioural intentions (measured across both time points) } \\
\hline \multirow[t]{2}{*}{ Measure } & \multicolumn{2}{|c|}{ Time 1} & \multicolumn{2}{|c|}{$\begin{array}{c}\text { Time } 2 \text { (only participants } \\
\text { who watched the film } \\
\text { between Time } 1 \text { and 2) }\end{array}$} & \multicolumn{2}{|c|}{ Time 2 (all participants } \\
\hline & $\mathrm{M}(\mathrm{SD})$ & Reliability & $\mathrm{M}(\mathrm{SD})$ & Reliability & $\mathrm{M}(\mathrm{SD})$ & Reliability \\
\hline Aware of gender bias & $6.31(0.85)$ & $\alpha=.86$ & $6.38(0.82)$ & $\alpha=.89$ & $6.33(0.78)$ & $\alpha=.88$ \\
\hline Self-efficacy & 4.93(1.27) & $\alpha=.73$ & $4.98(1.24)$ & $\alpha=.80$ & 4.97(1.17) & $\alpha=.77$ \\
\hline Confront intentions & $5.99(0.82)$ & $\alpha=.81$ & $6.07(0.77)$ & $\alpha=.83$ & $5.98(0.76)$ & $\alpha=.81$ \\
\hline $\begin{array}{l}\text { Seek } \\
\text { information intentions }\end{array}$ & $5.49(1.08)$ & $\alpha=.86$ & $5.33(1.20)$ & $\alpha=.89$ & $5.52(1.07)$ & $\alpha=.87$ \\
\hline Donate intentions & $4.61(1.33)$ & $\alpha=.71$ & $4.48(1.41)$ & $\alpha=.83$ & $4.58(1.33)$ & $\alpha=.75$ \\
\hline $\begin{array}{l}\text { Supporting } \\
\text { minoritized students } \\
\text { behaviours }^{1}\end{array}$ & $6.22(0.87)$ & $\alpha=.87$ & $6.37(0.87)$ & $\alpha=.94$ & $6.28(0.86)$ & $\alpha=.91$ \\
\hline $\begin{array}{l}\text { Positive Climate } \\
\text { Behaviours }{ }^{1}\end{array}$ & $5.87(1.12)$ & $\alpha=.89$ & $5.79(1.16)$ & $\alpha=.91$ & $5.96(1.05)$ & $\alpha=.90$ \\
\hline $\begin{array}{l}\text { Leadership } \\
\text { behaviours }^{1}\end{array}$ & $5.89(1.00)$ & $\alpha=.94$ & $5.70(1.02)$ & $\alpha=.91$ & $5.82(0.97)$ & $\alpha=.93$ \\
\hline
\end{tabular}

Note. ${ }^{1}$ For each of these behaviours, participants could choose "Not Applicable" if it was a behaviour there were not in a position to enact. This answer was treated as missing. 
Supplementary Table 31. Among Participants who Agreed to Take Part in the Second Survey, Correlations Between Time 1 Measures and Completing (versus not) the Second Survey in Study 2

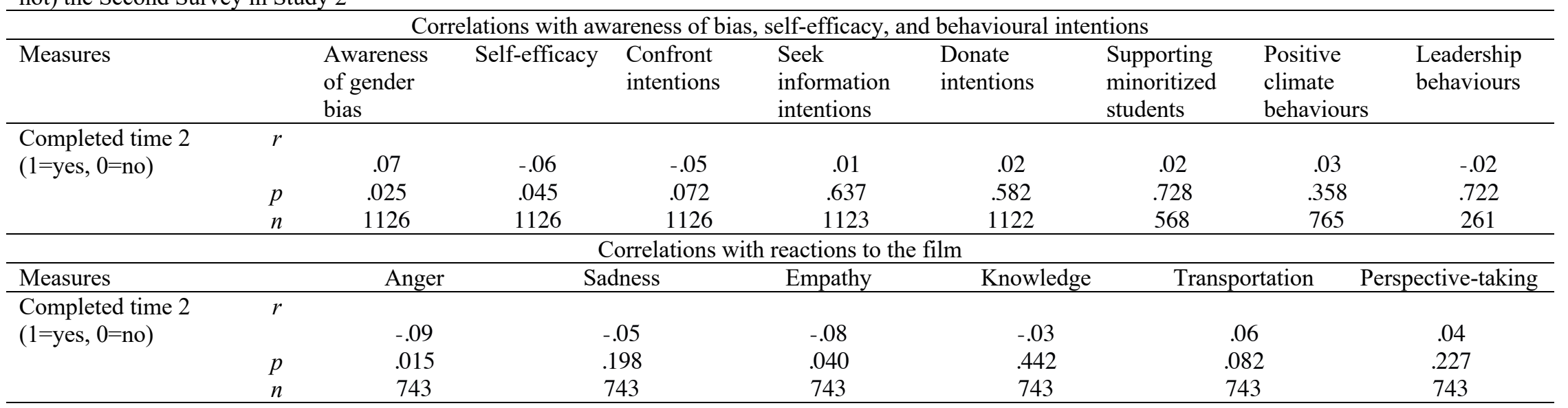

Note. None of the correlations reached significance with a Bonferroni corrected value of $p \leq .006$ for awareness of bias, self-efficacy, and behavioural intentions and $p \leq .008$ for film engagement measures 